Der Medizinischen Fakultät der Georg-August-Universität Göttingen eingereicht von Prof. Dr. med. U. Groß

\title{
Assoziation von Genvarianten aus der Chromosomenregion 5q31-33 mit der Inzidenz von Malaria und Anämie bei Kindern aus Ghana
}

\author{
INAUGURAL - DISSERTATION \\ zur Erlangung des Doktorgrades \\ der Medizinischen Fakultät \\ der Georg-August-Universität zu Göttingen \\ vorgelegt von \\ Christopher D. Intemann \\ aus \\ Hannover
}

Göttingen 2010 
Diese Dissertation wurde erstellt zwischen 2005 und 2010 an der Abteilung Grundlagenforschung des Bernhard-Nocht-Instituts für Tropenmedizin (BNI), Hamburg, Deutschland, sowie dem Kumasi Centre for Collaborative Research (KCCR), Kumasi, Ghana unter Anleitung von Prof. Dr. med. U. Groß und Prof. Dr. med. J. May.

Dekan: Prof. Dr. med. C. Frömmel

I. Berichterstatter: Prof. Dr. med. U. Groß

II. Berichterstatter/in: Prof. Dr. rer. nat. H. Bickeböller

III. Berichterstatter/in: Prof. Dr. med. M. Oppermann

Tag der mündlichen Prüfung: 22. November 2011 


\section{Inhaltsverzeichnis}

1 Einleitung $\quad 3$

1.1 Epidemiologie der Malaria . . . . . . . . . . . . . . . . . 3

1.2 Lebenszyklus und Pathogenese der Malaria . . . . . . . . . . . . . . . 3

1.3 Klinik und Diagnostik der akuten Malaria . . . . . . . . . . . . . . . 7

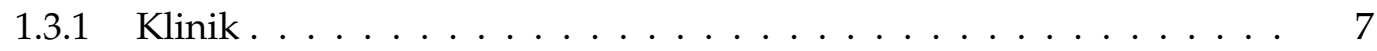

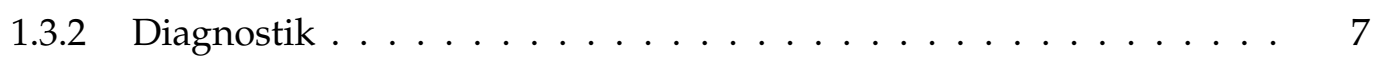

1.4 Therapie und Prophylaxe ........................ 7

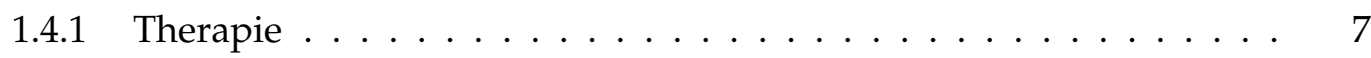

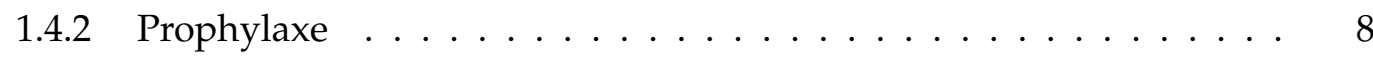

1.4.2.1 Intermittierende präventive Behandlung der Malaria bei Klein-

kindern .................. 8

1.5 Genetische Faktoren . . . . . . . . . . . . . . . . . . 9

1.5.1 Suche und Auswahl der Kandidatengene . . . . . . . . . . . . . . . 10

1.5.2 Interleukin 4 und Interleukin $13 \ldots \ldots 10$

1.5.3 Beta2-adrenerger Rezeptor ADRB2 . . . . . . . . . . . . . 11

1.6 Definition und Bestimmung der Phänotypen . . . . . . . . . . . . . 13

1.7 Fragestellung und Zielsetzung . . . . . . . . . . . . . . . . . 14

2 Material und Methoden $\quad 17$

2.1 Geräte und Materialien . . . . . . . . . . . . . . . 17

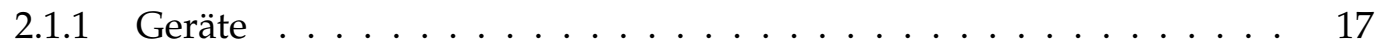

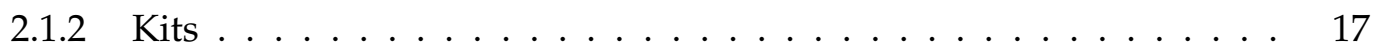

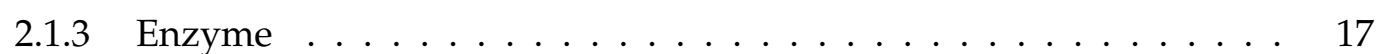

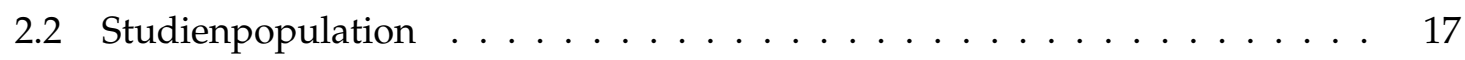

2.3 Aufbau der Studie . . . . . . . . . . . . . . . . . . . 18 
2.4 Genetische Analyse . . . . . . . . . . . . . . . . . . . . . 20

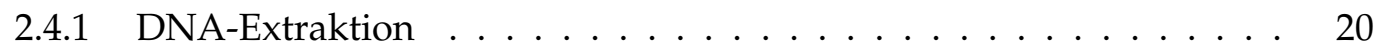

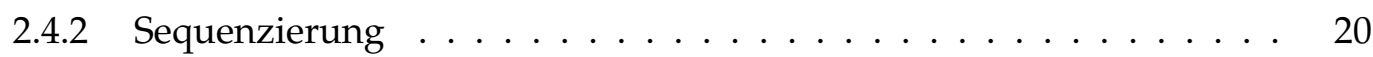

2.4.2.1 Optimierung der Assays der DNA-Amplifizierung . . . . . 20

2.4.2.2 Sephadex-Aufreinigung .............. 23

2.4.2.3 Big-Dye-Reaktion und Ablauf der Sequenzierung . . . . . . 25

2.5 Genotypisierung . . . . . . . . . . . . . . . . 25

2.5.1 Fluoreszenz-Resonanzenergietransfer (FRET) . . . . . . . . . . . . 25

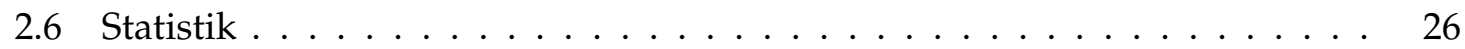

3 Ergebnisse $\quad 29$

3.1 Interleukin 4 und Interleukin $13 \ldots \ldots \ldots \ldots$

3.2 Beta2-adrenerger Rezeptor ADRB2 . . . . . . . . . . . . . . . 36

4 Diskussion $4 \mathbf{4 4}$

4.1 Interleukin 4 und Interleukin $13 \ldots \ldots \ldots \ldots$. . . . . . . . . . 48

4.2 Beta2-adrenerger Rezeptor ADRB2 _ . . . . . . . . . . . . . . 53

5 Zusammenfassung $\quad 57$

6 Anhang $\quad 59$

$\begin{array}{lll}7 & \text { Literaturverzeichnis } & 67\end{array}$

8 Abbildungsverzeichnis $\quad 79$

$\begin{array}{lll}9 & \text { Tabellenverzeichnis } & 80\end{array}$ 


\section{Einleitung}

\subsection{Epidemiologie der Malaria}

Obwohl in jüngster Zeit ein leichter Rückgang von Inzidenz und Mortalität zu verzeichnen ist, bleibt die Malaria auch weiterhin eine der häufigsten Infektionserkrankungen der Welt (Enserink 2008). So betrug die Anzahl an klinisch manifesten Erkrankungen im Jahre 2006 ca. 247 Millionen Fälle, ca. 881000 Infektionen verliefen tödlich (WHO 2010). Ca. 3.3 Milliarden Menschen, in etwa die Hälfte der Weltbevölkerung, sind durch eine Infektion gefährdet. Die meisten Erkrankungen und Todesfälle ereignen sich in Teilen Afrikas südlich der Sahara (Abbildung 1.1 und Abbildung 1.2). Plasmodium falciparum ist der Erreger mit der höchsten Virulenz und in diesen Gebieten weit verbreitet (Abbildung 1.3). Insbesondere in Subsahara-Afrika stellt die Malaria für Kinder im Alter von unter fünf Jahren mit ca. 18\% aller Todesfälle eine der wichtigsten Todesursachen dar (Rowe et al. 2006).

\subsection{Lebenszyklus und Pathogenese der Malaria}

Malaria wird durch eine Infektion mit Einzellern, den Plasmodien, hervorgerufen. Die Übertragung findet durch den Stich der weiblichen Anophelesmücke statt. In Abbildung 1.4 ist der Lebenszyklus der Malaria dargestellt. Es wird zwischen einer sexuellen Phase, der Sporogonie, und einer asexuellen Phase, der Schizogonie, unterschieden. Während sich die sexuelle Phase im Darm des Endwirtes, der Anophelesmücke, abspielt, findet die asexuelle Phase in der Leber und den Erythrozyten des Zwischenwirtes statt.

Nach Inokulation der Sporozoiten bewegen sich diese innerhalb von fünfzehn bis fünfundvierzig Minuten in die Leber. In den Hepatozyten findet in den nächsten fünf bis fünfzehn Tagen die erste intrazelluläre replikative Phase, die exoerythrozytäre Schizogonie, statt. Während dieser reifen in jeder einzelnen Zelle bis zu 30000 Merozoiten aus. Zum En- 
Abbildung 1.1 Geschätzte weltweite Inzidenz der Malaria auf 1000 Personen (aus WHO 2010, Seite 33)

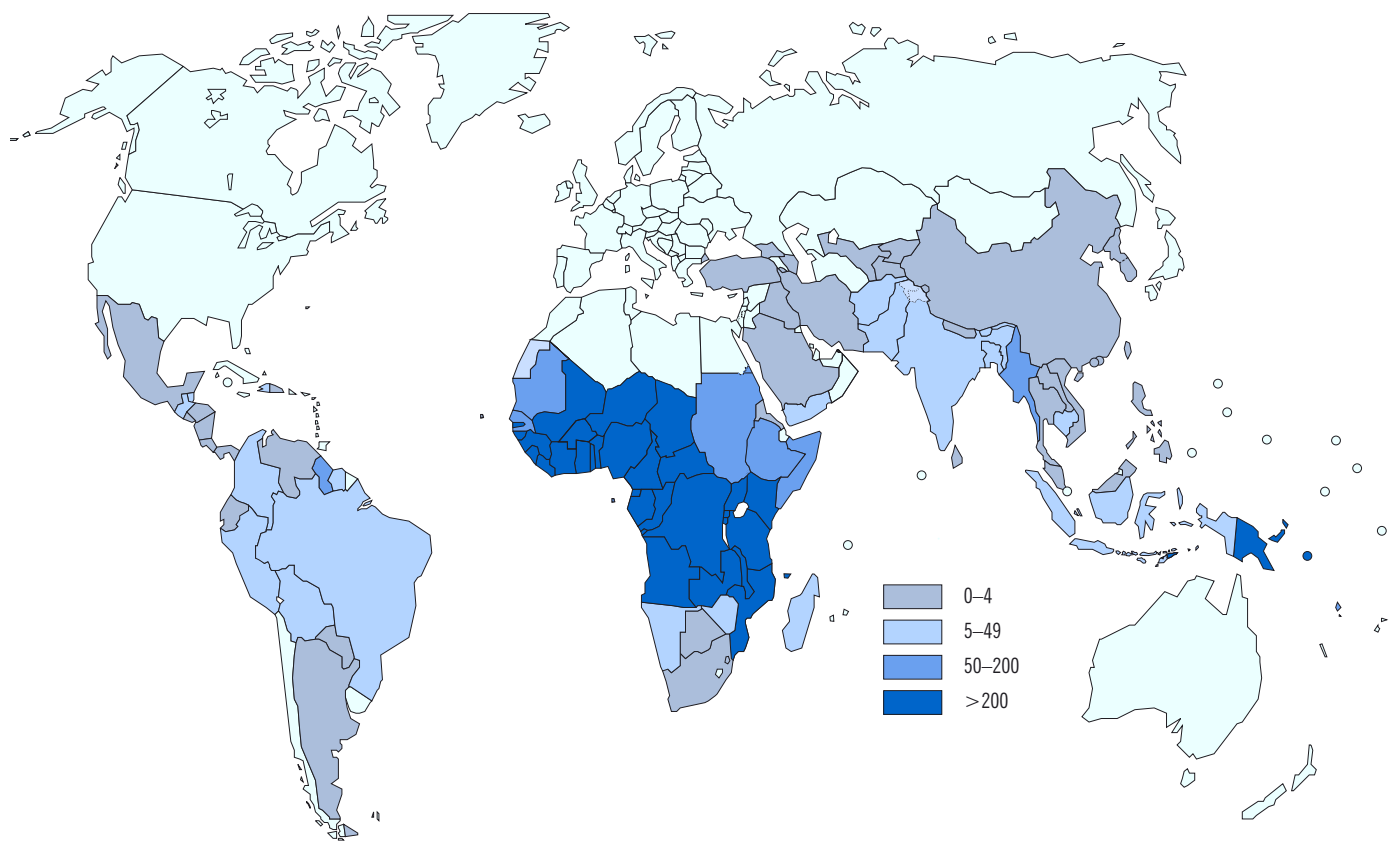

de dieser Phase lösen sich von Leberzellmembran umgebene Merosomen von der Leberzelle und gelangen in den Blutkreislauf (Heussler et al. 2002). Hier kommt es schließlich zu der Freisetzung der Merozoiten, welche darauf die Erythrozyten penetrieren. In den Erythrozyten reifen die Merozoiten erst zu Ringformen, dann weiter zu Trophozoiten, und schließlich zu Schizonten, welche bis zu 32 Merozoiten beinhalten können (erythrozytäre Schizogonie). Einige der freigesetzten Merozoiten können sich im Blut zu den geschlechtlichen Formen, den männlichen Mikrogametozyten und den weiblichen Makrogametozyten, weiterentwickeln. Sobald die Gametozyten von einer weiblichen Anophelesmücke aufgenommen werden, wird der Kreislauf geschlossen. Im Darm der Mücke verwandeln sich die Gametozyten zu Gameten und verschmelzen zu einer Oozyste. In der Oozyste entwickeln sich bis zu 1000 Sporozoiten, welche schließlich in die Speicheldrüsen der Mücke wandern und bei der nächsten Blutmahlzeit injiziert werden. 
Abbildung 1.2 Geschätzte weltweite Mortalität der Malaria auf 1000 Personen (aus WHO 2010, Seite 36)

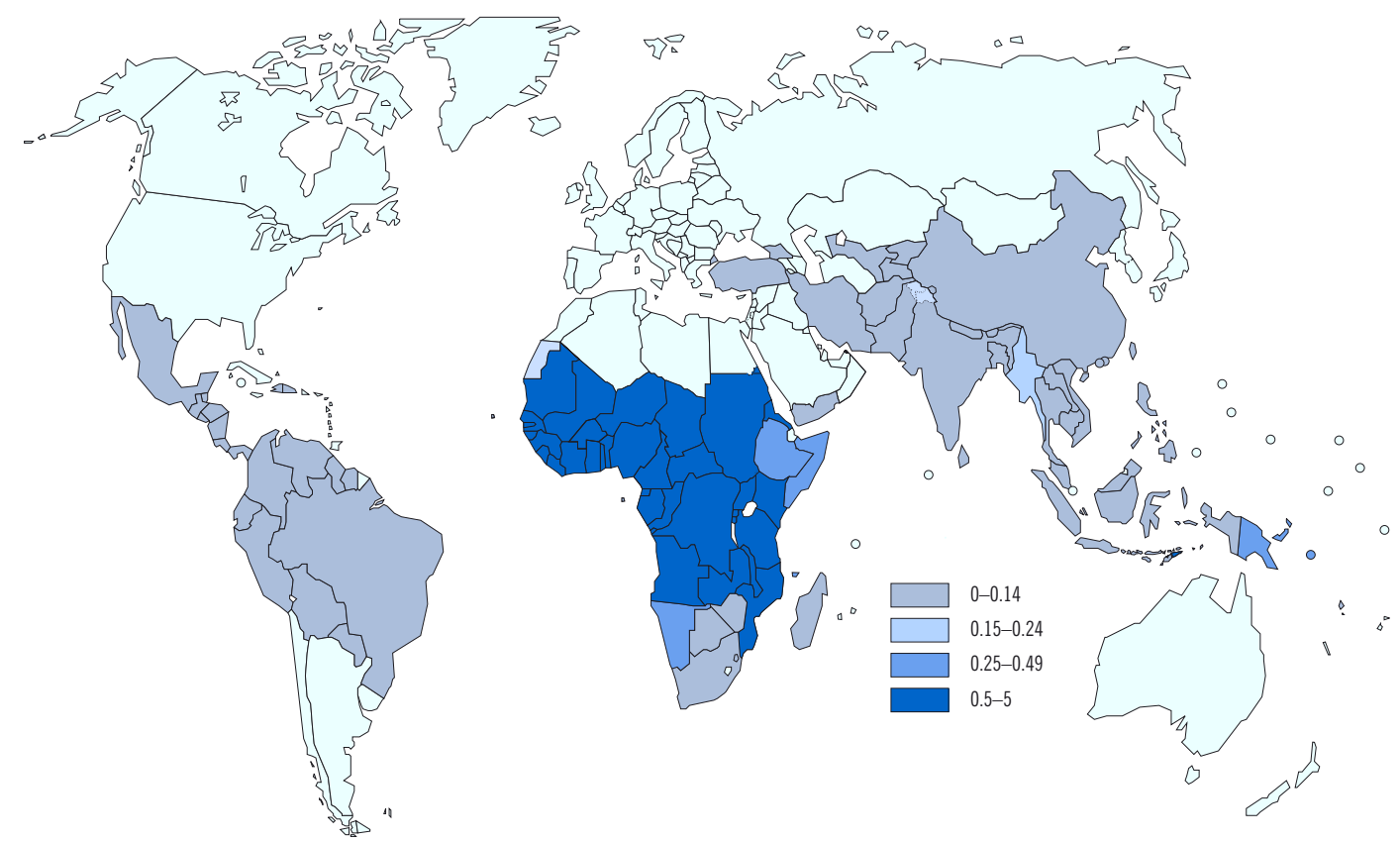

Die humane Malaria wird unterteilt in benigne und maligne Formen, abhängig von dem jeweiligen Erreger. Ein Teil der Pathologie der Malaria erklärt sich durch Zytokine, die während der Ruptur der Erythrozyten freigesetzt werden und für die Entstehung von Fieberschüben verantwortlich sind. Die durch P. falciparum verursachte Malaria tropica nimmt häufig einen schweren Verlauf und ist für den Großteil der durch Malaria verursachten Todesfälle verantwortlich. Ursächlich hierfür ist einerseits, insbesondere bei Kleinkindern und schwangeren Frauen, die Gefahr einer schweren Anämie, da, im Gegensatz zu anderen Formen der Malaria, sehr viele Erythrozyten befallen und zerstört werden können. Weiterhin spielen immunologische Prozesse und Hypersplenismus, sowie eine verminderte Erythropoese bei Niereninsuffizienz eine wichtige Rolle, häufig kommt es zusätzlich zu einer Thrombozytopenie.

Ein weiterer Grund für die schweren Verläufe ist die Tatsache, dass durch $P$. falciparum 
Abbildung 1.3 Geschätzter Prozentsatz der durch Plasmodium falciparum verursachten weltweiten Malaria-Fälle (aus WHO 2010, Seite 33)

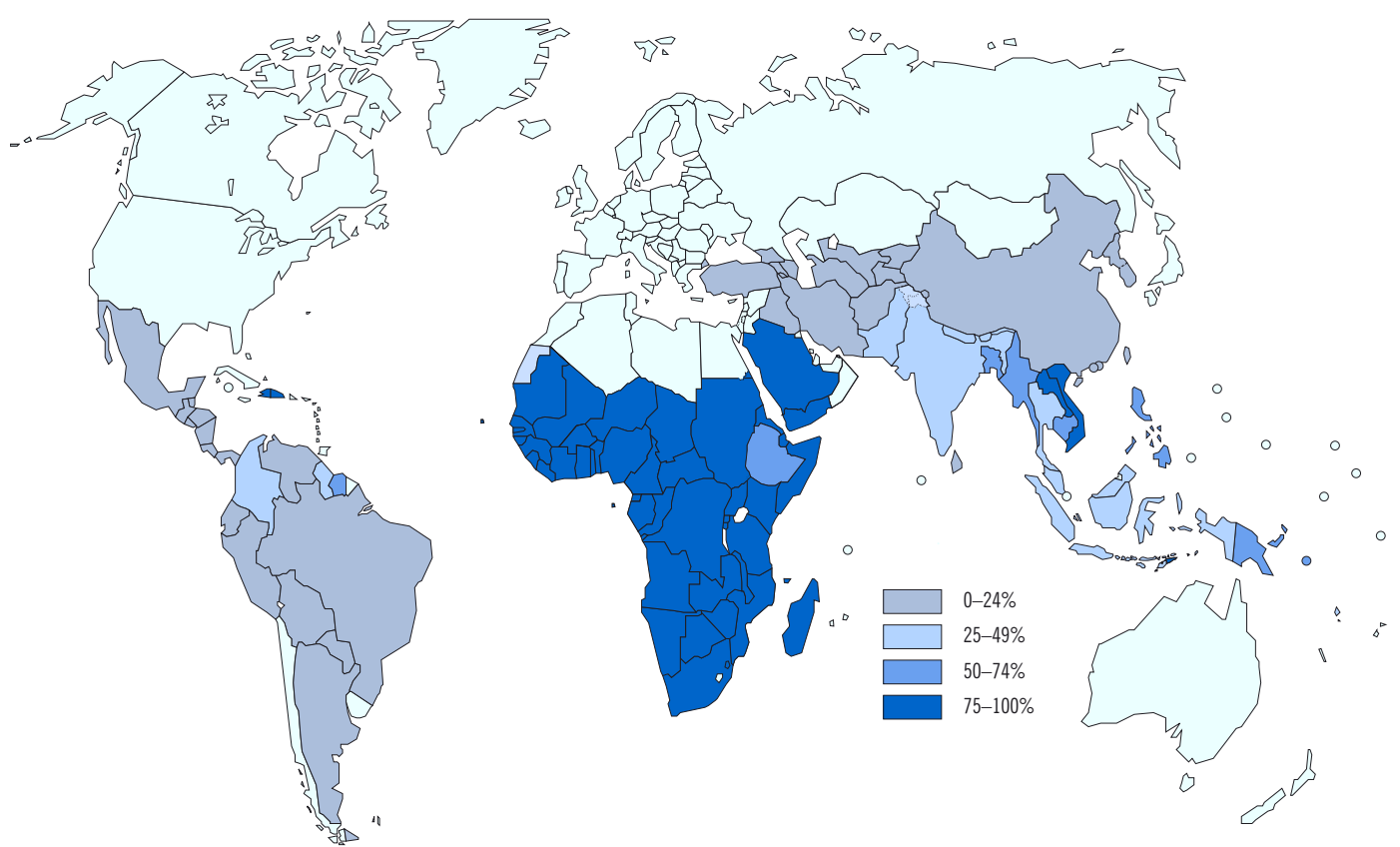

infizierte Erythrozyten in der Lage sind zu sequestrieren. Hierbei kommt es zu einer Adhärenz zuerst von infizierten, im weiteren Verlauf auch von nicht infizierten Erythrozyten an den Endothelien von Kapillaren und Venolen. Dieser Prozess wird als maßgeblich für die Entstehung einer zerebralen Malaria angesehen und trägt zusätzlich zu der Pathogenese des Hypersplenismus bei. Eine Sequestrierung im Rahmen von Erkrankungen, die durch $P$. vivax verursacht werden, wird nur in seltenen Fällen beobachtet (Kochar et al. 2005), bei Infektionen mit $P$. ovale und $P$. malariae tritt sie nicht auf.

Eine Besonderheit der durch P. vivax und P. ovale verursachten Malaria tertiana ist die Bildung von Schizonten, die in einer Ruheform, den Hypnozoiten, in den Leberparenchymzellen verbleiben und erst nach Monaten oder Jahren reifen und zu Rezidiven führen können. Auch bei der Malaria quartana, die durch Infektionen mit P. malariae verursacht wird, ist das Auftreten von Rezidiven noch lange Zeit nach der Primärinfektion möglich, 
da eine geringe Parasitämie unbemerkt fortbestehen kann. Im Gegensatz zu der Malaria tertiana kommt es jedoch nicht zu einer Hypnozoitenbildung.

\subsection{Klinik und Diagnostik der akuten Malaria}

\subsubsection{Klinik}

Klinisch äußert sich eine akute Malaria in erster Linie durch abrupt einsetzendes, hohes Fieber, teils mit Schüttelfrost, sowie Kopf-, Glieder-, und Rückenschmerzen. Zusätzlich können Symptome wie Emesis, Diarrhoe und Husten auftreten.

Im progredienten Stadium kann sich bei der Malaria tertiana bei dieser Form der Malaria eine Zwei-Tages-Rhythmik einstellen, bei der die Fieberanfälle durch einen fieberfreien Tag unterbrochen werden. Bei der Malaria quartana beträgt das fieberfreie Intervall zwei Tage.

\subsubsection{Diagnostik}

Die wichtigste diagnostische Maßnahme ist die Mikroskopie. Die Anfertigung des „Dicken Tropfens" ermöglicht die Diagnostik einer Parasitämie und stellt auch heute noch den Goldstandard dar. Durch Anreicherung und Lyse der Erythrozyten können pro Gesichtsfeld eine um Faktor zehn bis zwanzig höhere Anzahl an Erythrozyten als im Ausstrich kontrolliert werden. Die Anfärbung wird nach Giemsa durchgeführt.

Im Falle einer Parasitämie sollte zur Speziesdifferenzierung der Parasiten ein Ausstrich nicht lysierten Blutes in May-Grünwald-Giemsa-Färbung angefertigt werden.

\subsection{Therapie und Prophylaxe}

\subsubsection{Therapie}

Die Therapie der Malaria richtet sich zum einen nach der Plasmodien-Spezies, andererseits nach dem Verlauf der Erkrankung. Liegt eine komplizierte Malaria vor, ist eine intensivmedizinische Betreuung indiziert. Ein komplizierter Verlauf liegt bei Symptomen wie respiratorischer Insuffizienz, zerebraler Beteiligung (Somnolenz, Krampfanfall), Hypoglykämie, ausgeprägter Azidose oder dem Auftreten von Spontanblutungen vor. Ein 
weiteres wichtiges Kriterium ist die Region, in der die Infektion erworben wurde, da in vielen Gebieten bereits eine ausgeprägte Resistenz gegen Chloroquin, dem Standardtherapeutikum bei unkomplizierter Malaria, Malaria tertiana und Malaria quartana vorliegt. Bei bekannten Resistenzen sollten alternative Therapeutika wie Mefloquin eingesetzt werden. Im Falle eines komplizieren Verlaufs ist die Applikation von Chinin indiziert. Die aktuellen Leitlinien erlauben als Alternativtherapie den Einsatz des in China produzierten Artesunats. Allerdings ist dieses Medikament in Deutschland bisher nicht zugelassen und entspricht derzeit noch nicht den Standards nach guter medizinischer Praxis (engl. good medical practice, GMP [General Medical Council 2010]).

Neben der spezifischen Therapie der Infektion ist eine symptomatische Therapie angezeigt.

\subsubsection{Prophylaxe}

Bei Aufenthalt in Risikogebieten ist die Expositionsprophylaxe eine wichtige Maßnahme zum Schutz vor Malaria. Insbesondere bei Einbruch der Dunkelheit sollte Repellent aufgetragen und langärmelige Kleidung angelegt werden. Als weiterer Schutz sind Moskitonetze sowie Insektengitter an Türen und Fenstern indiziert. Zum Schutz der lokalen Bevölkerung wird seit einigen Jahren die Anwendung von Dichlordiphenyltrichlorethan (DDT) in Gebäuden empfohlen. So können Moskitos, die sich zwischen den Blutmahlzeiten an den Hauswänden absetzen, erreicht werden, während jedoch eine nur sehr geringe Belastung der Umwelt durch DDT zu erwarten ist. Weitere Maßnahmen betreffen die Trockenlegung von stehenden Gewässern, welche häufig als Moskitobrutstätten dienen.

Insbesondere für vorübergehende Aufenthalte in Risikogebieten ist die Chemoprophylaxe von elementarer Bedeutung. Je nach zu bereisendem Gebiet ist ein Stand-By, das Bereithalten von Arzneimitteln oder die kontinuierliche Applikation indiziert. Neben Chloroquin wird Mefloquin insbesondere in Gebieten mit einer bekannten Resistenz gegen Chloroquin empfohlen.

\subsubsection{Intermittierende präventive Behandlung der Malaria bei Kleinkindern}

Die „intermittierende präventive Behandlung der Malaria bei Kleinkindern” (engl. intermittent preventive treatment in infants, IPTi) stellt ein seit einigen Jahren etabliertes Konzept 
dar, mit dem in Malaria-Risikogebieten bisweilen sehr gute Ergebnisse zur Senkung der Mortalität bei Kleinkindern erzielt wurden (Schellenberg et al. 2001). Bei diesem Verfahren wird ein langwirksames Antimalariamedikament in periodischen Abständen in subtherapeutischer Dosierung appliziert. Ziel ist es, einerseits einen Schutz mit Hilfe einer Chemoprophylaxe zu gewinnen, andererseits aber die Entwicklung einer Semiimmunität gegen Malaria zu ermöglichen. So besteht im Gegensatz zu einer dauerhaften Chemoprohylaxe auch nach dem Absetzen der Medikamente ein gewisser Schutz weiter fort. SulfadoxinPyrimethamin (Fansidar $\left.{ }^{\circledR}\right)$ ist ein schon lange verfügbares und relativ preiswertes Medikament, welches mit einer Halbwertszeit von acht bis neun Tagen ausreichend lange im Organismus verbleibt, um durch eine einmalige Applikation eine ausreichende protektive Wirkung über mehrere Wochen zu erreichen. Es wurde jedoch gezeigt, dass insbesondere gegen Ende eines behandlungsfreien Zeitraums die Gefahr einer Malariainfektion zunimmt und sich gegenüber einer Kontrollgruppe sogar ein erhöhtes Risiko im Sinne eines diskreten Rebound-Phänomens ausbilden kann (Marks et al. 2005). Derzeit wird das Prinzip des IPTi in verschiedenen Studien optimiert und überprüft.

Diese Arbeit wurde im Rahmen einer multizentrischen Studie zur Überprüfung der Wirksamkeit von IPTi an einer Studienpopulation aus der Ashanti-Region in Ghana, Westafrika, in Kollaboration mit dem Kumasi Centre for Collaborative Research in Tropical Medicine (KCCR 2010), Kumasi, Ghana, durchgeführt .

\subsection{Genetische Faktoren}

Humane Genvarianten beeinflussen das Risiko und den Verlauf von Malaria im Kindesalter (Mackinnon et al. 2000). So ist ein Einfluss von monogenetischen Faktoren unter anderem für die Thalassämie, die Sichelzellanämie und die Duffy-Blutgruppe (Miller et al. 1975; Flint et al. 1998) beschrieben. 


\subsubsection{Suche und Auswahl der Kandidatengene}

Ausgehend von den Ergebnissen dieser drei Studien wurde für die weitere Selektion der Kandidatengene ausschließlich die Genregion 5q31-33 betrachtet. Innerhalb dieses Bereiches wird ein genetisches Element vermutet, welches das Auftreten einer Parasitämie beeinflusst. Dieser Bereich des Multigenclusters 5q31-33 trägt die Bezeichnung PFBI (Plasmodium falciparum blood infection, [Rihet et al. 1998]). Diskrete Abweichungen der LinkagePeaks in den Studien deuten auf das Vorhandensein verschiedener assoziierter Loci innerhalb der 5q31-33-Region hin. Abbildung 1.5 zeigt linksseitig eine Übersicht der in den Studien verwendeten Satellitenmarker, rechts sind die Positionen der bekannten Gene aufgetragen. Die engere Auswahl der Kandidatengene erfolgte nach Analyse der 5q31-33-Region mit Hilfe der OMIM (Online Mendelian Inheritance in Man)-Datenbank (Schorderet 1991) auf Gene, welche in unmittelbarer Nähe zu den beschriebenen Satellitenmarkern lokalisiert sind oder solchen, deren Produkte einen möglichen Einfluss auf den Verlauf einer Malariainfektion haben könnten.

Es wurden als Kandidaten die Gene der Zytokine Interleukin 4 (IL4) und Interleukin 13 (IL13), welche in einer Cluster-Formation in unmittelbarer Nachbarschaft innerhalb der 5q31-33-Region liegen, sowie das Gen des beta2-adrenergen Rezeptors (ADRB2), welches ebenfalls in unmittelbarer Nähe zu einem der beschriebenen Satellitenmarker lokalisiert ist, ausgewählt.

\subsubsection{Interleukin 4 und Interleukin 13}

Im Bereich des PFBI ist ein Gen-Cluster, welcher die Zytokine Interleukin 4 (IL4) und Interleukin 13

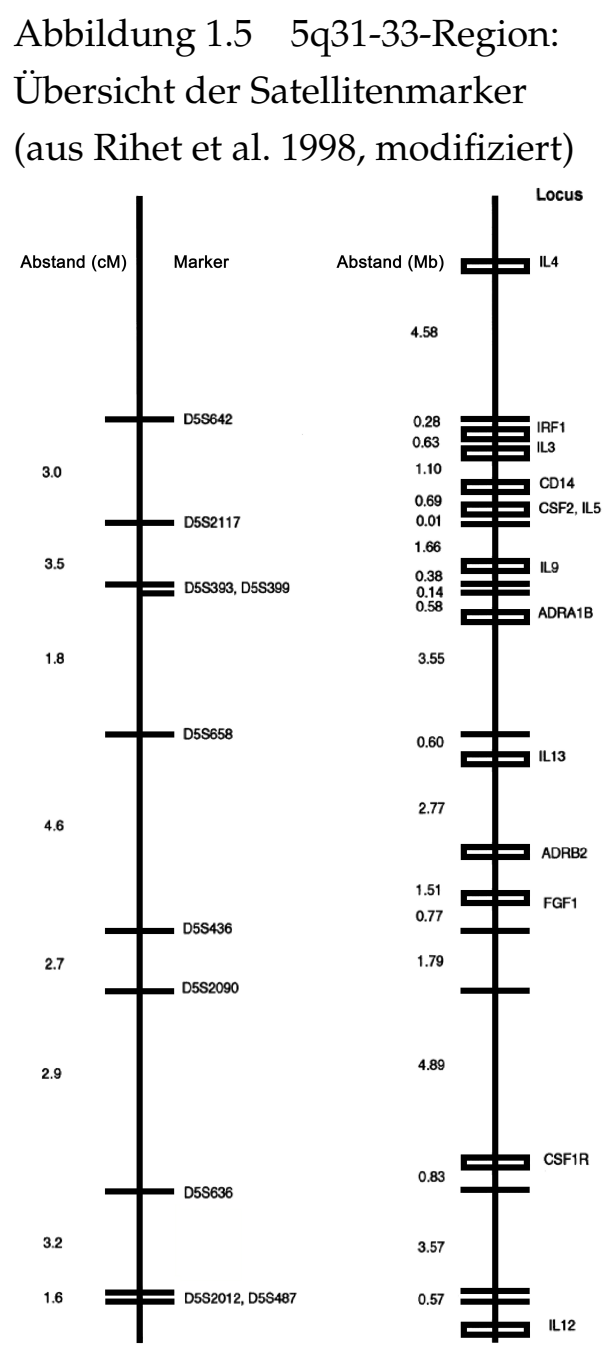


(IL13) kodiert, lokalisiert (Flori et al. 2003). Die für IL4 und IL13 kodierenden Gene liegen in enger Beziehung zueinander auf dem langen Arm von Chromosom fünf. IL4 und IL13 sind zwei Th2-modulierte Zytokine, die eine enge Verwandtschaft aufweisen. So ist eine intergenische Transkription als möglicher Regelmechanismus beschrieben worden (Rogan et al. 2004). Beide Zytokine werden von Th2-Zellen, Mastzellen und basophilen Zellen produziert und haben ähnliche Funktionen. Als Effektoren wirken sie an einem gemeinsamen Rezeptor, der sich aus einer IL4R $\alpha$ - und einer IL13R $\alpha 1$-Untereinheit zusammensetzt. Weiterhin ist IL13 in der Lage, die Wirkung von IL4 über einen alternativen Mechanismus zu entfalten (Palmer-Crocker et al. 1996). IL4 und IL13 induzieren maßgeblich den Klassenwechsel von B-Lymphozyten zu IgE-produzierenden Zellen. So produzieren IL4-/ IL13defiziente Knockout-Mäuse nahezu überhaupt kein IGE (Fish et al. 2005). Es sind bereits verschiedene Einzelbasen-Austausche (engl. single-nucleotid polymorphisms, SNPs) innerhalb dieser Region beschrieben, die einen funktionellen Effekt in der Pathogenese einer Malariainfektion haben. Als Resultat alternativen Spleißens sind für IL4 zwei Isoformen bekannt. Die für die Proteine kodierende Region konstruiert sich aus drei, respektive vier Exons. Die kodierende Region von IL13 setzt sich aus drei Exons zusammen.

Verschiedene Assoziationsstudien haben bereits einen Einfluss von genetischen Varianten des IL4/IL13-Clusters gezeigt. So hat das Vorkommen einer Punktmutation an Position -589 im Bereich der IL4-Promotor-Region einen signifikanten Einfluss auf den IgE-Spiegel im Verlauf einer Malariainfektion (Verra et al. 2004), weiterhin wird ein Einfluss auf die Entstehung von schwerer und zerebraler Malaria beschrieben (Perlmann et al. 1998).

Ein SNP an Position -1112 der IL13-Promotor-Region ist assoziiert mit Schutz vor schwerer Malaria (Ohashi et al. 2003). Neben Malaria sind verschiedene Assoziationen von IL4und IL13-Polymorphismen mit dem Auftreten von Atopie (Haagerup et al. 2002; Hummelshoj et al. 2003), Schistosomiasis (Kouriba et al. 2005) sowie mit idiopathischer pulmonaler Fibrose (IPF, Vasakova et al. 2007) beschrieben.

\subsubsection{Beta2-adrenerger Rezeptor ADRB2}

Das den beta2-adrenergen Rezeptor (ADRB2) kodierende, intronlose Gen ist ebenfalls im Bereich des PFBI lokalisiert. Beta2-adrenerge Rezeptoren sind Bestandteil des vegetativen Nervensystems und werden an verschiedenen Zellen exprimiert. Dementsprechend kön- 
nen sie unterschiedliche Funktionen vermitteln. An der glatten Muskulatur des Gastrointestinaltraktes, der Bronchien, des Uterus sowie der Samenwege führt eine Aktivierung des Rezeptors zu einer Muskelrelaxierung (Taira et al. 2008). Weiterhin vermittelt sie eine Senkung des Gefäßtonus kleiner Arterien sowie der Koronarien. In der quergestreiften Muskulatur führt die Aktivierung hingegen zu einer vermehrten Glykogenolyse sowie einem gesteigerten Muskeltwachstum und einer erhöhten Kontraktionsgeschwindigkeit (Davis et al. 2008), außerdem kann ein Tremor ausgelöst werden (Ahrens 1990). Auch in der Leber kommt es zu einer vermehrten Glykogenolyse, zusätzlich jedoch auch zu einer Glykoneogenese (Philipson 2002). Als weitere Wirkung auf den Gastrointestinaltrakt führt die Aktivierung von ADRB2 zu einem gesteigerten Sphinktertonus (Rathi et al. 2003), einer vermehrten Insulinsekretion des Pankreas (Ahren und Schersten 1986), sowie einer Minderung der Salivation und Eindickung der Saliva (del Rio-Navarro et al. 2001; Sag et al. 2007). Ebenso wie Beta1-Rezeptoren vermitteln Beta2-Rezeptoren positiv inotrope (Steigerung der Kontraktilität des Herzmuskels), dromotrope (Steigerung der Reizüberleitung) sowie chronotrope (Steigerung der Herzfrequenz) Effekte auf das Kreislaufsystem, haben jedoch im Vergleich nur einen relativ geringen Einfluss (Chorzempa und Tabloski 2002). Weiterhin vermitteln sie eine Hemmung der Histaminfreisetzung aus Mastzellen (Wang und Lau 2006), eine Steigerung der Reninsekretion in den Nieren sowie renovaskuläre Dilatation (Imbs et al. 1977; Bakris et al. 2006).

Die Signaltransduktion des ADRB2 ist an ein Guaninnucleotid-bindendes Protein (GProtein) des heterotrimeren Typs gekoppelt, welches aus $\alpha$-, $\beta$ - und $\gamma$-Untereinheiten besteht. Zwei der vier Familien der $\alpha$-Untereinheiten werden auch in Erythrozyten gefunden, $\mathrm{G} \alpha_{s}$ und $\mathrm{G} \alpha_{q}$. Bei der Aktivierung des ADRB2-Rezeptors agiert dieser als GTP-Austauschfaktor (engl. guanine nucleotide exchange factor, GEF) für das G-Protein und vermittelt den Austausch von GDP zu GTP an $\mathrm{G} \alpha_{s}$-Untereinheiten. Darauf wird die $\mathrm{G} \alpha_{s}$-Untereinheit abgespalten und aktiviert weitere Signalpfade, bis sie schließlich durch Hydrolisation inaktiviert wird (Harrison et al. 2003).

Beta2-adrenerge Rezeptoren werden auch auf der Oberfläche von Erythrozyten exprimiert. Ihre Funktion ist hier bisher nicht vollständig geklärt. Jedoch ist ein direkter pathophysiologischer Zusammenhang mit dem Eintritt von Merozoiten in die Erythrozyten nachgewiesen (Harrison et al. 2003). Es wurde beschrieben, dass sich sowohl $\mathrm{G}_{s^{-}}$ Untereinheiten als auch ADRB2 während der Invasion der Erythrozyten durch P. falci- 
parum an der Membran der parasitären Vakuole anreichern. Der Grund für diese Anreicherung ist nicht bekannt. Jedoch hat sich bei Versuchen in der Zellkultur gezeigt, dass eine Hemmung der $\mathrm{G} \alpha_{s}$-Untereinheiten zu einer deutlichen Verminderung von Infektionen führt. Ein ähnlicher Effekt wird durch Blocken des ADRB2-Rezeptors mit Hilfe von Propranolol oder dem Inversen Antagonisten ICI 118,55 (ICI) erreicht. In vivo führen $\mathrm{G}_{S^{-}}$ Antagonisten im Mausmodell zu einer signifikanten Reduktion der Infektionen mit Plasmodium berghei. Eine weitere Studie zeigt in einer Zellkultur an menschlichen Erythrozyten, dass die Applikation von Propranolol das Wachstum von Plasmodium-falciparum-Parasiten während der erythrozytären Phase deutlich vermindern kann (Murphy et al. 2006). Weiterhin reduziert sich die inhibitorische Konzentration von Chloroquin oder Artesimin bei gleichzeitiger Applikation von Propanolol bis um den Faktor 10.

\subsection{Definition und Bestimmung der Phänotypen}

Es wurden die Phänotypen „Klinische Malaria“, „Parasitämie“ und „Moderate Anämie“ betrachtet.

- Der Phänotyp „Klinische Malaria“ ist definiert als Parasitämie von 500 oder mehr Parasiten pro $\mu \mathrm{l}$ in Kombination mit Fieber von $37,5^{\circ} \mathrm{C}$ oder mehr, akut oder innerhalb der vorausgegangenen 48 Stunden.

- Eine „Moderate Anämie“ bezeichnet einen Hämoglobin-Wert von 7,5 g/dl oder weniger.

- Der Phänotyp „Infektion” ist als asexuelle Parasitämie mit P. falciparum definiert. Das Vorhandensein und die Höhe einer Parasitämie wurde in zwei Auswertungen durch verschiedene Untersucher bestimmt. Falls die beiden Auswertungen um mehr als die dreifache Höhe der Parasitämie abwichen oder Unterschiede in der Speziesbestimmung auftraten wurde eine erneute Lesung durchgeführt. 
Konzeption und Durchführung der Studie erfolgte nach den ICH-Richtlinien (engl. international conference on harmonisation of technical requirements for registration of pharmaceuticals for human use [The International Conference on Harmonisation of Technical Requirements for Registration of Pharmaceuticals for Human Use 2010]) und nach guter klinischer Praxis (engl. good clinical practice, GCP [FDA Food and Drug Administration 2010]); sämtliche Arbeitsschritte sind in Standardarbeitsanweisung (engl. standard operating procedures, SOPs) dokumentiert worden.

\subsection{Fragestellung und Zielsetzung}

Die Zielsetzung dieser Dissertation war der Nachweis von genetischen Assoziationen verschiedener Kandidatengene aus einem umschriebenen Bereich auf Chromosom 5 (5q31-33) mit dem Auftreten und der Infektionsdynamik von Malariainfektionen. Weiterhin wurde die Überprüfung des bereits beschriebenen, vor schwerer Malaria schützenden Effektes der IL13-Variante $-1112^{T}$ angestrebt.

Während Punktmutationen im Bereich des Promotors oder der 3'-nicht-translatierten Region (engl. 3'-untranslated-region, 3'-UTR) Einfluss auf die Genexpression ausüben können, unterteilt man Punktmutationen innerhalb eines Exons in funktionelle und nichtfunktionelle Austausche. Funktionelle Austausche führen zu einem Austausch einer Aminosäure in der Proteinsequenz des Genproduktes.

Genetische Assoziationen können zum einen Hinweise auf für den Infektionsverlauf wichtige Enzyme und Stoffwechselwege liefern. So können positive Assoziationen Anreize geben, weiterführende zellbiologische Untersuchungen zu initiieren, um den pathophysiologischen Mechanismus genauer zu erforschen. Einen anderen Hintergrund stellt der direkte Nachweis einer genetischen Komponente dar, die unmittelbar den Verlauf einer Erkrankung beeinflusst. Beispielsweise wird die Sichelzellanämie durch eine Punktmutation des $\beta$-Globulin-Gens auf Chromosom 11 verursacht. Daraus folgt ein Austausch der Aminosäure Glutaminsäure durch Valin an Position 6 der $\beta$-Untereinheit des Hämoglobins. Dies führt dazu, dass die Erythrozyten in desoxigeniertem Zustand eine sichelartige Form annehmen können. Diese Erkrankung nimmt bei homozygoten Merkmalsträgern einen schweren Verlauf und führt häufig vor dem 30. Lebensjahr zum Tode, da es bedingt 
durch die Verformung der Erythrozyten zu Mikroembolien mit schweren Komplikationen wie myokardialen Infarkten oder apoplektischen Insulten kommt. Die heterozygote Form verläuft hingegen milde mit nur geringen Komplikationen. Da die Sichelzellenanämie jedoch vor Malaria schützt, sind die Merkmalsträger in Malaria-Endemiegebieten einer starken positiven Selektion unterworfen, so dass die Allelefrequenz im Vergleich zu Nicht-Risikogebieten einen großen Unterschied aufweist. 
Abbildung 1.4 Lebenszyklus der Malaria (aus Jones und Good 2006, modifiziert)

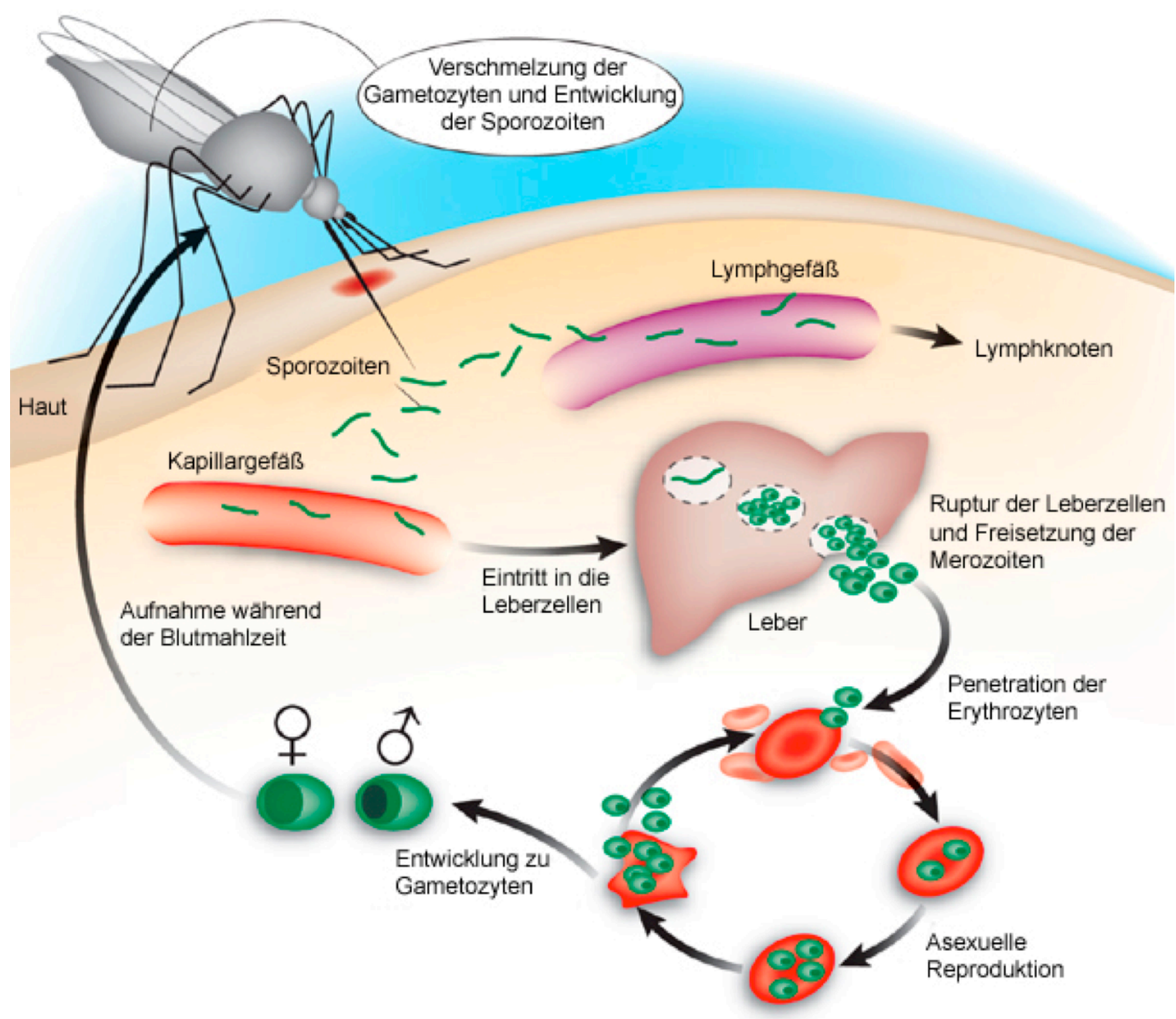




\section{Material und Methoden}

\subsection{Geräte und Materialien}

\subsubsection{Geräte}

Primer und Sensor/Anker Oligonucleotidsequenzen wurden mit der Software „Roche LightCycler ProbeDesign”, Version 2.0.R.33 (Roche Applied Science 2010) erstellt. Die 384-Loch Microtiter-Platten wurden mit einem "Tecan GENESIS Workstation 200" Pipettier-Roboter vorbereitet, welcher mit der "Gemini steering software v3.50" gesteuert wurde (Tecan 2010). Für die Amplifikation der DNA wurden „MWG Primus 96” Thermocycler mit 384-Loch Heizblock eingesetzt (MWG Biotech AG 2010).

\subsubsection{Kits}

- ABI PRISM $\mathrm{TM}_{\mathrm{TM}}$ Big-Dye Terminator Kits (Applied Biosystems 2010)

- MACHEREY-NAGEL NucleoMag 96 Blood-Kit (Macherey-Nagel 2010)

\subsubsection{Enzyme}

Sämtliche Primer und Sonden wurden von der Firma Biomers, Ulm, Deutschland, synthetisiert.

\subsection{Studienpopulation}

Im Rahmen einer Placebo-kontrollierten Studie mit dem Hauptschwerpunkt der Wirksamkeit einer subtherapeutischen Dosis des Medikamentes Fansidar gegen schwere Verläufe 
von Malariainfektionen (Konzept des Intermittent Preventive Treatment in Infants [IPTi], siehe Abschnitt 1.4.2.1) wurden 1070 Kinder aus neun Dörfern des Afigya Sekyere Distrikts in der Ashanti Region in Ghana, Westafrika, rekrutiert. In diesem Bezirk sind Malariaerkrankungen holoendemisch (Kobbe et al. 2006). Ein Kind ist auf Grund von nicht verwertbaren Hämoglobinmessungen aus der Studie ausgeschlossen worden.

Die hinsichtlich genetischer Assoziation tatsächlich auszuwertende Studienpopulation umfasst 1069 Kinder (männlich: 535, weiblich: 534), welche im Alter von zwei bis vier Monaten (Minimum 59 Tage; Maximum 125 Tage; im Mittel 89.3 Tage; 95\%; Konfidenzintervall $[88,6-90,0])$ in die Studie eintraten. 921 Kinder gehörten der Ethnie der Akan an, fünf Kinder der Ethnie der Ewe, und 138 Kinder einem der im Norden Ghanas verbreiteten Stämme. Fünf Kinder konnten keiner Volksgruppe zugeordnet werden. Zum Zeitpunkt der Rekrutierung hatten 18 Kinder eine klinische Malaria, 157 Kinder eine Parasitämie und 22 Kinder eine moderate Anämie. Tabelle 2.1 zeigt eine Übersicht der Studienpopulation.

\subsection{Aufbau der Studie}

In den verschiedenen in die Studie einbezogenen Dörfern wurde an den jeweiligen Kliniktagen eine lokale Sprechstunde errichtet. Nicht erschienene Probanden wurden mit der Hilfe lokal als Village-Worker tätiger Mitarbeiter explizit einbestellt, um eine gute Compliance sowie eine hohe Kontinuität der Untersuchungen zu erzielen.

Von den Eltern aller teilnehmenden Kinder wurde ein Informed Consent -Formular, welches von dem Committee on Human Research, Publications and Ethics, School of Medical Sciences, University of Science and Technology, Kumasi, Ghana, genehmigt wurde, unterzeichnet. Während 18 Monaten wurden die Kinder in monatlichen Abständen überwacht. Ebenso waren zwischenzeitliche Konsultationen, z.B. im Erkrankungsfall möglich.

Die Applikation der Studienmedikation erfolgte bei Studieneintritt, nach sechs, sowie nach 12 Monaten. Nach einem standardisierten Formular wurde der Gesundheitszustand erfasst und Informationen über zwischenzeitliche Krankenhausaufenthalte oder Medikamenteneinnahme gesammelt. Körpergewicht und Größe wurde dokumentiert. Weiterhin wurde Kapillarblut aus Finger oder Ferse gewonnen, um Objektträger zur Malariadiagnostik („Dicker Tropfen” und Ausstrich) anzufertigen, sowie der Hämoglobinwert mittels 
direkter Photometrie bestimmt.

Im Falle einer Erkrankung wurde kostenfrei therapiert. Allfällige Kosten für Krankenhausaufenthalte wurden ebenfalls übernommen. Die innerhalb eines Fensters von 21 Tagen nach Malariatherapie oder Applikation des Studienmedikaments gewonnenen Studiendaten wurden von der Auswertung ausgeschlossen, um einen Einfluss der Medikation auf die Ergebnisse zu minimieren.

Mit Fragebögen wurde der sozioökonomische Hintergrund der teilnehmenden Familien dokumentiert.

Sämtliche Erstdokumentation vor Ort erfolgte handschriftlich, die Datensätze wurden im Anschluss in eine 4D Datenbank für Apple Mac OS X, Version 6.8.5 (4D International 2010), übertragen und archiviert.

Tabelle 2.1 Übersicht über die Studienpopulation, Verteilung pro Monat und Ort der Rekrutierung.

\begin{tabular}{c|cccccccccc} 
Monat & Ort & Afamanaso & Agona & Asamang & Bedomase & Bipoa & Jamasi & Kona & Tano-Odumasi & Wiamoase \\
\hline 1 & 6 & 11 & 14 & 2 & 15 & 28 & 7 & 12 & 26 \\
2 & 3 & 30 & 8 & 3 & 20 & 19 & 12 & 11 & 25 \\
3 & 3 & 13 & 7 & 8 & 5 & 16 & 14 & 11 & 30 \\
4 & 4 & 7 & 5 & 5 & 13 & 12 & 13 & 11 & 13 \\
5 & 6 & 16 & 10 & 3 & 9 & 11 & 10 & 7 & 18 & 17 \\
6 & 7 & 16 & 11 & 6 & 6 & 22 & 6 & 8 & 10 & 13 \\
7 & 8 & 12 & 9 & 4 & 12 & 8 & 18 & 10 & 10 \\
8 & 2 & 5 & 9 & 5 & 10 & 12 & 16 & 10 & 1 \\
9 & 4 & 1 & 9 & 7 & 4 & 6 & 8 & 11 & 16 \\
10 & 6 & 1 & 10 & 2 & 10 & 9 & 18 & 7 & - \\
11 & 1 & 16 & 16 & 2 & 8 & 8 & 17 & 11 & -
\end{tabular}




\subsection{Genetische Analyse}

\subsubsection{DNA-Extraktion}

Die DNA wurde mit Hilfe eines „MACHEREY-NAGEL NucleoMag 96 Blood-Kit” und einem „NucleoMag 96 Magnetic-Seperation System” extrahiert und aufbereitet (MachereyNagel 2010).

\subsubsection{Sequenzierung}

Die für ADRB2 kodierende Abschnitt der 5q31-Region wurden in einem „ABI PRISM ${ }_{\mathrm{TM}}$ 3100 Genetic Analyzer” mit Hilfe eines „ABI PRISM ${ }_{\mathrm{TM}}$ Big-Dye Terminator Kits” sequenziert (Applied Biosystems 2010). Die Sequenzierung gliederte sich in zwei Arbeitsschritte:

- Zunächst wurden die zu sequenzierenden Abschnitte mittel Polymerase-Kettenreaktionen (engl. polymerase chain reactions, PCRs) amplifiziert.

- Im zweiten Schritt erfolgten Sequenzierungs-Reaktionen nach dem Kettenabbruchverfahren (Sanger et al. 1977). Im Anschluss erfolgten die Analysen im Kapillarsequenzierer.

Die kodierende Region des ADRB2-Gens erstreckte sich über 1242 Nukleinsäuren. Um die mutmaßliche Promotorregion mit abzudecken, wurde mit der Sequenzierung im Abstand von 1113 Nukleinsäuren vor dem kodierenden Abschnitt begonnen. Die zu sequenzierende Region wurde in fünf sich überlappende Abschnitte mit Längen von je 499, 467, 689, 485 und 677 Nukleinsäuren unterteilt (Abb. 2.1). Das Design der benötigten vorwärtsund rückwärts-Primer erfolgte mit Hilfe der Software "Primer3” (Rozen und Skaletsky 2000). Überschneidungen der Primer mit weiteren komplementären Abschnitten wurden mit Hilfe des Basic Local Alignment Search Tool (BLAST, [Gaeta 2000]) des National Center for Biotechnology Information (NCBI, [Cates 2006]) ausgeschlossen.

\subsubsection{Optimierung der Assays der DNA-Amplifizierung}

Im nächsten Schritt erfolgte die Optimierung der Assays der DNA-Amplifizierung. Für die Etablierung der PCR-Reaktionen wurden verschiedene Assays mit unterschiedlichen 
Abbildung 2.1 ADRB2: Übersicht der sequenzierten Abschnitte (NCBI Zugriffsnummer NT_029289), Teil 1

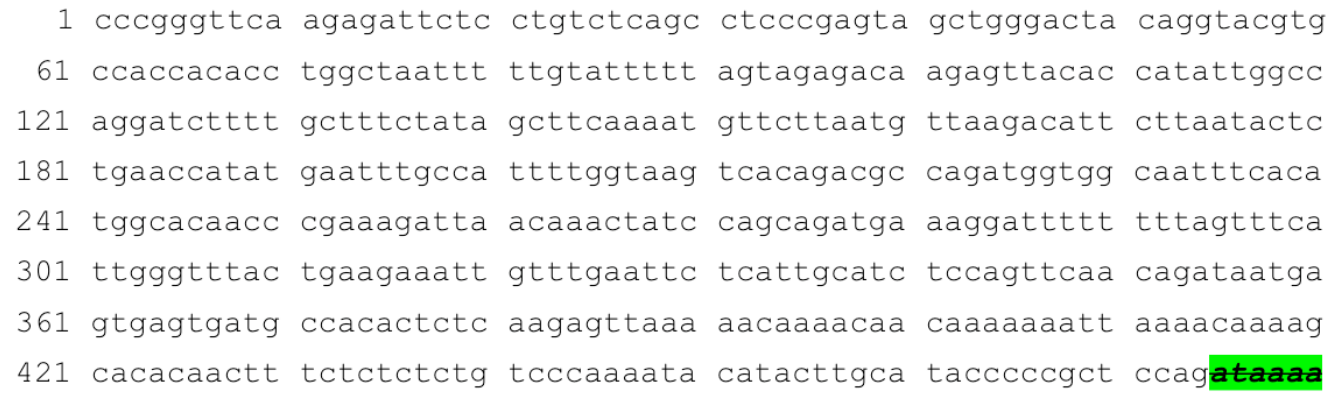


Abbildung 2.2 ADRB2: Übersicht der sequenzierten Abschnitte, Teil 2

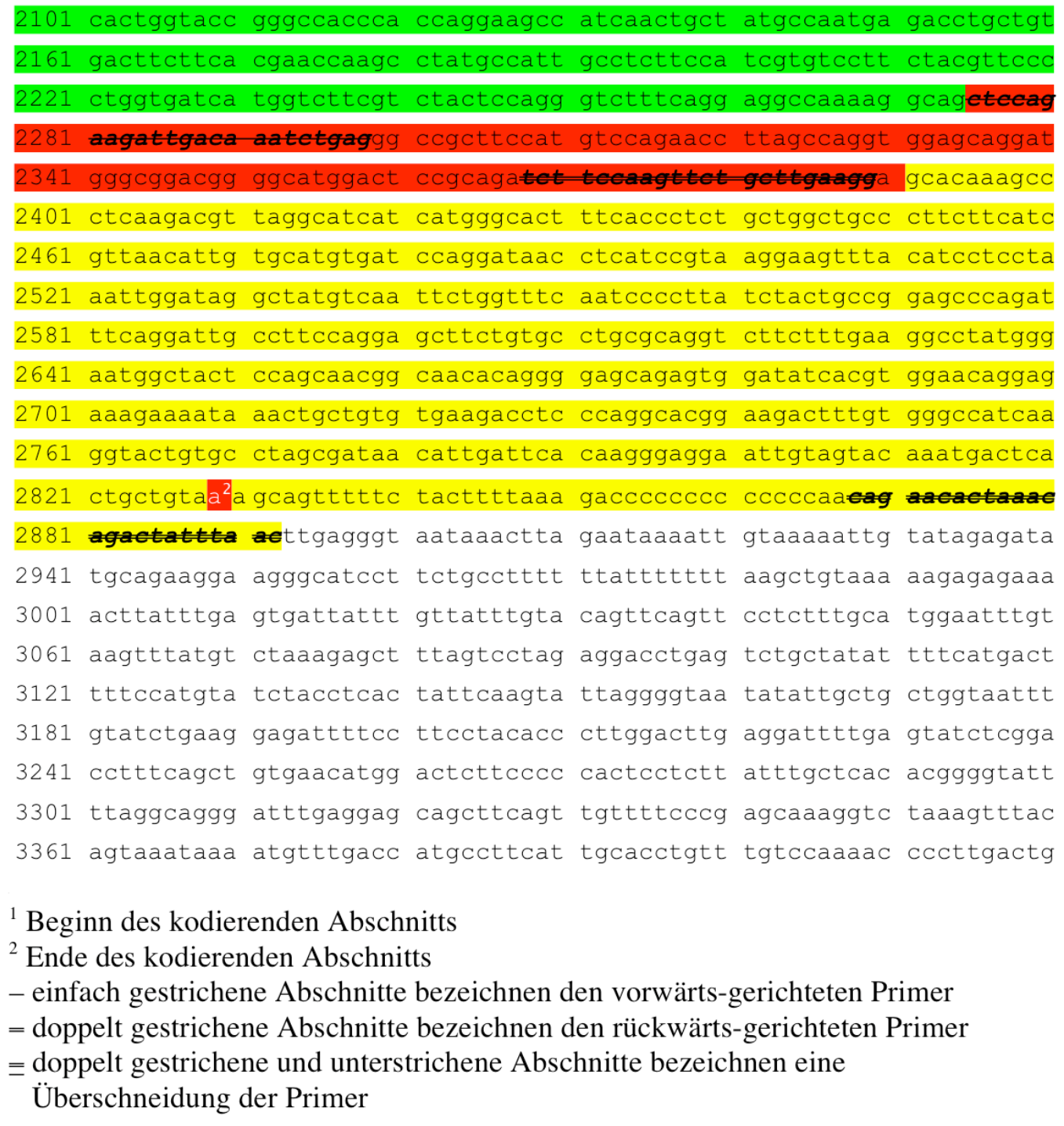

Farbliche Kennzeichnung: Grün - Abschnitt 1 und 4, Gelb - Abschnitt 2 und 5, Lila - Abschnitt 3, Rot, Überschneidungen der Abschnitte. 
Konzentrationen von $\mathrm{MgCl}_{2}$ mit und ohne Zugabe von Solution S (1x) in einem Gradientenzykler mit unterschiedlicher Glühtemperatur (engl. annealing-temperatures) $\left(61^{\circ} \mathrm{C} \pm 5^{\circ} \mathrm{C}\right.$, Stufen $0,8-1^{\circ} \mathrm{C}$ ) optimiert.

1,5 $\mu L$ des PCR-Produktes wurden mit $2 \mu L$ Farbstoff auf 1,5\%-iges Agarosegel aufgetragen. In Abbildung 2.3 ist exemplarisch ein solches Agarosegel gezeigt; deutlich erkennbar die unterschiedlichen Resultate in Abhängigkeit von den verschiedenen Konzentrationen und Temperaturen. An Hand der Schärfe und Intensität der Banden lassen sich die opitmalen Bedingungen erkennen. Die besten Resultate wurden mit den in Tabelle 6.1-6.5 dargestellten Assays und den in 6.7 gezeigten Thermozykler-Protokollen erzielt.

Auf diese Weise werden mit einer Wahrscheinlichkeit von 99\% die Varianten detektiert, die eine minimale Allelfrequenz (MAF) von 5\% oder mehr aufweisen. Dies lässt sich an Hand folgender Rechnung belegen:

Vorkommen der Variante Anzahl der untersuchten Chromosomen $\Longrightarrow 0,95^{92}=0,0089 \approx 1 \%$

Somit liegt die Wahrscheinlichkeit, eine Variante, welche eine minimale Allelfrequenz von $5 \%$ aufweist, nicht zu finden, bei etwa einem Prozent. Demzufolge liegt die Detektionswahrscheinlichkeit für solch eine Variante bei $100 \%-1 \%=99 \%$.

\subsubsection{Sephadex-Aufreinigung}

Nach Amplifizierung der DNA wurden die Produkte über "Sephadex G-50" aufgereinigt, um nicht inkorporierte dNTP und Primerreste sowie überschüssige Taq-Polymerase zu eliminieren.

Als Vorbereitung hierzu wurden 96-Loch-Platten mit Sephadex befüllt und durch Zugabe von $300 \mathrm{ml}$ Wasser für die Chromatographie (LiChrosolv ${ }^{\circledR}$, auch engl. high performance liquid chromatographie Wasser oder „HPLC Wasser”) über eine Dauer von 3h aufgequollen. Im Anschluss wurden die Platten für 5 Minuten mit einer Geschwindigkeit von 2900 Umdrehungen pro Minute (engl. rounds per minute, RPM) zentrifugiert. 
Abbildung 2.3 Optimierung der PCR: Auftragen der Produkte aus verschiedenen Protokollen auf das Agarosegel, Erläuterungen siehe Abschnitt 2.4.2.1

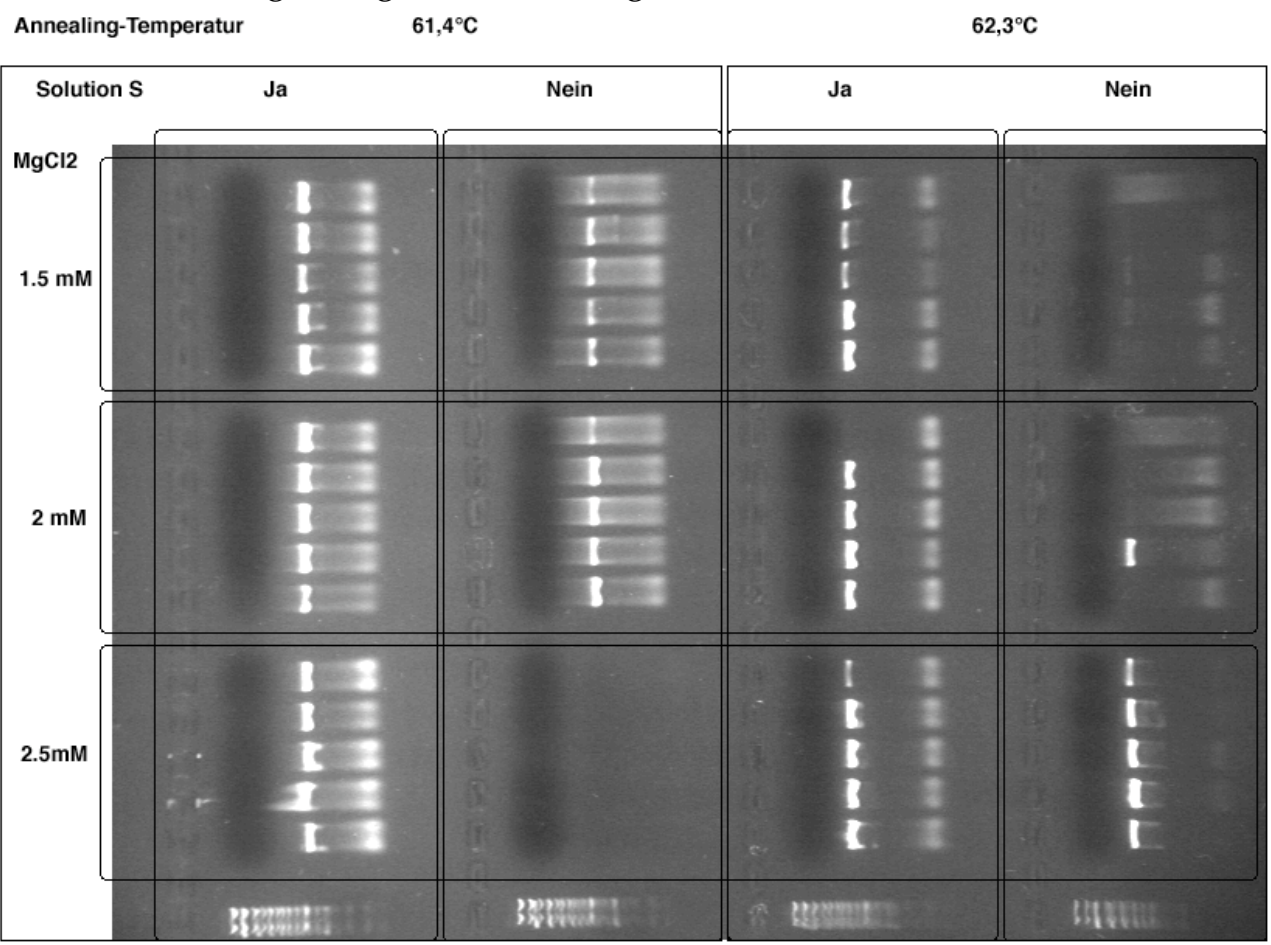


Nach diesen Vorbereitungen wurden die Amplifikate auf das Sephadex aufgetragen und durch erneute Zentrifugation der Platten mit 2900 rpm über eine Dauer von 5 Minuten aufgereinigt.

\subsubsection{Big-Dye-Reaktion und Ablauf der Sequenzierung}

Nach Etablierung der PCR-Assays der Big-Dye-Reaktion analog der schon beschriebenen Vorgehensweise wurde die Reaktion entsprechend dem in 6.6 und 6.8 dargestellten Protokoll durchgeführt.

Nach erneuter Aufreinigung des Produktes mittels Sephadex wurde die Sequenzierung von $4 \mu \mathrm{L}$ Produkt mit $12 \mu \mathrm{L}$ Ladepuffer in einem ABI PRISM TM $_{3100}$ Genetic Analyzer durchgeführt (Applied Biosystems 2010). Das Alignement der Sequenzdaten mit den Referenzdatensätzen aus dem OMIM (Schorderet 1991) erfolgte mit der Software

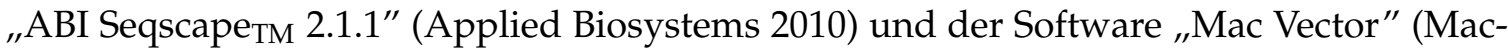
Vector, Inc 2010).

\subsection{Genotypisierung}

\subsubsection{Fluoreszenz-Resonanzenergietransfer (FRET)}

Die Genotypisierung wurde mittels Fluoreszenz-Resonanzenergietransfer (engl.fluorescence resonance energy transfer, FRET) auf einem ROCHE „LightTyper ${ }_{\mathrm{TM}}$ (Roche Applied Science 2010) durchgeführt. Bei dieser Methodik wurden einer asymmetrischen PCR zusätzlich zwei fluoreszierende Sonden beigefügt, welche innerhalb des zu amplifizierenden $\mathrm{Ab}$ schnittes banden. Eine dieser beiden Oligonukleotid-Sonden, der Sensor, überspannte die zu untersuchende Punktmutation und war in ihrer Sequenz entweder dem Wildtyp oder der Mutation komplementär. Die zweite Sonde, der Anker (engl. anchor), band im Abstand von wenigen Base an den DNA-Strang, so dass das mit dem Fluorophor Fluorescein markierte Ende des Sensors dem mit Cyanin (Cy5) markierten Ende des Ankers gegenüberliegt. Bei dem Design der Sonden war zu beachten, dass die Schmelztemperatur des Sensors um mindestens $2^{\circ} \mathrm{C}$ unterhalb der des Ankers lag. Die Höhe der Schmelztemperaturen wurde maßgeblich durch die Länge der Oligonukleotide und die Anzahl der mit 
abgedeckten GC-Dreifachbindungen bestimmt, daher waren diese Faktoren im Rahmen der Auswahl der Sonden zu beachten.

Mit Hilfe des „LightTypers ${ }_{\mathrm{TM}}$ ” wurden die Proben nach Amplifizierung kontinuierlich in $0,05^{\circ} \mathrm{C}$-Schritten erwärmt. Gleichzeitig wurde das Cyanin von einem Laser mit einer Wellenlänge von $475 \mathrm{~nm} \pm 20 \mathrm{~nm}$ angeregt. Die Emission wurde von einem InterferenzFilter mit Messbereich von $600 \mathrm{~nm} \pm 50 \mathrm{~nm}$ erfasst. Sobald die Schmelztemperatur des Sensors, welche durch das Vorliegen oder Fehlen der durch ihn abgedeckten Punktmutation beeinflusst wurde, erreicht war, löste sich dieser von dem DNA-Strang ab. Die Emission sistierte in der Folge. Auf diese Weise ließen sich mit Hilfe des „LightTypers TM" die unterschiedlichen Genotypen durch Bestimmung der Schmelzkurven ableiten.

Die Primer und Sonden wurden mit Hilfe der Software „Roche LightCycler ProbeDesign", Version 2.0.R.33 (Roche Applied Science 2010) gestaltet, erneut wurden Überschneidungen mit weiteren komplementären Genabschnitten mit Hilfe von NCBI/BLAST (Gaeta 2000) ausgeschlossen. Alternativ zu dem oben beschriebenen Design war auch eine Markierung des Ankers mit Fluorophor und der Sonde mit Cy5 möglich. Eine Übersicht der verwendeten Primer zeigt Tabelle 2.2.

Analog zu den Schritten im Rahmen der Sequenzierung wurden die LightTyper-Assays mit unterschiedlichen Konzentrationen der Enzyme sowie unterschiedlichen AnnealingTemperaturen erprobt und etabliert. Die Tabellen 6.9 bis 6.15 zeigen eine Übersicht der Primer, das verwendete Thermozykler-Protokoll ist in Tabelle 6.16 dargestellt.

\subsection{Statistik}

Multivariate logistische Regressionsanalysen wurden mit der Software „Stata/MP 10" durchgeführt (StataCorp LP 2010). Der Effekt durch die Applikation des Studienmedikamentes im Rahmen der Placebo-kontrollierten Studie wurde in Form einer Kovariaten berücksichtigt, um ein mögliches Confounding zu vermeiden. Nach dem proportionalen Hazard-Modell von Cox wurde der "Risikoquotient” (engl. hazard ratio, HR) berechnet, der das Verhältnis von zwei Hazardwerten zueinander angibt (Cox 1972). Auf diese Weise ließen sich die Wahrscheinlichkeiten der Zeit bis zum erstmaligen oder einzigen Auftreten eines Ereignisses in Abhängigkeit des Genotyps vergleichen. Das Risiko eines 
multiplen Auftretens von Ereignissen wurde als "Quotient der Inzidenzraten" (engl. incidence rate ratio, IRR) durch Poisson-Regression bestimmt. Abweichungen vom HardyWeinberg-Gleichgewicht der Einzelvarianten wurden mit Hilfe eines ergänzenden StataModuls berechnet (Shephard 2005). Mit der Software „UNPHASED” wurden die Haplotypen bestimmt und Assoziationen und Quotenverhältnisse (engl. odds ratio, OR) berechnet (Dudbridge 2008). Die Software „Plink” wurde für die Abschätzung der Frequenzen von genetischen Varianten verwendet, die den bereits typisierten benachbart lagen und deren Frequenz sich über die Kopplungsungleichgewichte abschätzen ließ (Purcell et al. 2007; Nothnagel et al. 2009). Die Kopplungsungleichgewichte zwischen den einzelnen Varianten sowie die grafische Übersicht der Haplotypenstruktur wurden mit der Software „Haploview", Version 4.1, berechnet und erstellt (Barrett et al. 2005). Nominale p-Werte wurden nach der Bonferroni-Methode mit der Anzahl der typisierten Varianten auf multiples Testen korrigiert. P-Werte unter 0,05 wurden als statistisch signifikant betrachtet, bei den Effektmaßzahlen wurde der 95\%-Vertrauensbereich angegeben. 
Tabelle 2.2 LightTyper: Übersicht der verwendeten Primer

\begin{tabular}{|c|c|c|}
\hline SNP & Primer & Sequenz \\
\hline $\begin{array}{l}\text { IL13 -1112 } \\
\text { rs1800925 }\end{array}$ & $\begin{array}{l}\text { vorwärts Primer } \\
\text { rückwärts Primer } \\
\text { Anker } \\
\text { Sensor }\end{array}$ & $\begin{array}{l}\text { GAGAAATCTTGACATCAACACC } \\
\text { CAGAATGAGTGCTGTGGAG } \\
\text { Cy5-AAAGGCGACATGGCTGCAGG-Phosphat } \\
\text { CTTCTAGGAAAACGAGGGAAGAGCAG-Fluorescein }\end{array}$ \\
\hline $\begin{array}{l}\text { IL13 R110Q } \\
\text { rs20541 }\end{array}$ & $\begin{array}{l}\text { vorwärts Primer } \\
\text { rückwärts Primer } \\
\text { Anker } \\
\text { Sensor }\end{array}$ & $\begin{array}{l}\text { CTTCAATAGTCAGGTCCTGT } \\
\text { TCACGTGCTGACCTCTTTG } \\
\text { Cy5-CGAAAAAGTTTCTTTAAATGTAAGAGCAGGTCCTT-Phosphat } \\
\text { AGTTTCAGTTGAACCGTCCCT-Fluorescein }\end{array}$ \\
\hline $\begin{array}{l}\text { IL4 -1098 } \\
\text { rs2243248 }\end{array}$ & $\begin{array}{l}\text { vorwärts Primer } \\
\text { rückwärts Primer } \\
\text { Anker } \\
\text { Sensor }\end{array}$ & $\begin{array}{l}\text { AGGCAATGAGCACCTTAT } \\
\text { GCTCTGAGATTACAGGTGTGA } \\
\text { AATGGAACCTAAACAACTCCTCAGCTAATTAGGAA-Fluorescein } \\
\text { Cy5-AGAGCTACCGTCTTACCAACTTACAAA-Phosphat }\end{array}$ \\
\hline $\begin{array}{c}\text { IL4 }-589 \\
\text { rs2243250 }\end{array}$ & $\begin{array}{l}\text { vorwärts Primer } \\
\text { rückwärts Primer } \\
\text { Anker } \\
\text { Sensor }\end{array}$ & $\begin{array}{l}\text { AGAATAGACCTACCTTGCCA } \\
\text { CTGCATAGAGGCAGAATAAC } \\
\text { GATACGACCTGTCCTTCTCAAAACACCTAAACTTG-Fluorescein } \\
\text { Cy5-AGAACATTGTCCCCCAGTGC-Phosphat }\end{array}$ \\
\hline $\begin{array}{c}\text { IL4 -33 } \\
\text { rs2070874 }\end{array}$ & $\begin{array}{l}\text { vorwärts Primer } \\
\text { rückwärts Primer } \\
\text { Anker } \\
\text { Sensor }\end{array}$ & $\begin{array}{l}\text { CAATGTAAACTCATTTTCCCTCG } \\
\text { GGGAGGTGAGACCCATTAATA } \\
\text { TTGTCAGCATTGCATCGTTAGCTTCTCCTGATAAA-Fluorescein } \\
\text { Cy5-AATTGCCTCACATTGTCACTGCAA-Phosphat }\end{array}$ \\
\hline $\begin{array}{c}\text { ADRB2 R16G } \\
\text { rs1042713 }\end{array}$ & $\begin{array}{l}\text { vorwärts Primer } \\
\text { rückwärts Primer } \\
\text { Anker } \\
\text { Sensor }\end{array}$ & $\begin{array}{l}\text { CCCAGCCAGTGCGCTCA } \\
\text { CCACCACCCACACCTCG } \\
\text { Cy5-CAGCAAGAAGGCGCTGCCGT-Phosphat } \\
\text { CGCATGGCTTCCATTGGGTG-Fluorescein }\end{array}$ \\
\hline $\begin{array}{c}\text { ADRB2 Q27E } \\
\text { rs1042714 }\end{array}$ & $\begin{array}{l}\text { vorwärts Primer } \\
\text { rückwärts Primer } \\
\text { Anker } \\
\text { Sensor }\end{array}$ & $\begin{array}{l}\text { GCGCTCACCTGCCAGAC } \\
\text { ATGCCCACCACCCACAC } \\
\text { AGCCATGCGCCGGACCACGA-Fluorescein } \\
\text { Cy5-GTCACGCAGCAAAGGGACG-Phosphat }\end{array}$ \\
\hline $\begin{array}{c}\text { ADRB2 +3670 } \\
\text { rs7702861 }\end{array}$ & $\begin{array}{l}\text { vorwärts Primer } \\
\text { rückwärts Primer } \\
\text { Anker } \\
\text { Sensor }\end{array}$ & $\begin{array}{l}\text { GCACTTTCAAGAACTTGAGAAAT } \\
\text { CAGATGAGTAAACGGAAGTCG } \\
\text { Cy5-CACCCACCACCCCACTCTCTCTCTC-Phosphate } \\
\text { GAGCCCCСCTCCAACCTC-Fluorescein }\end{array}$ \\
\hline $\begin{array}{c}\text { ADRB2 +3803 } \\
\text { rs } 4705271\end{array}$ & $\begin{array}{l}\text { vorwärts Primer } \\
\text { rückwärts Primer } \\
\text { Anker } \\
\text { Sensor }\end{array}$ & $\begin{array}{l}\text { TGAAGTTGGGTGAGGCG } \\
\text { ACCAAATAGTACTTCACAGCAT } \\
\text { AATTTGAGGCCAGTACAGGTGGTATCTAAGCTCTG-Fluorescein } \\
\text { Cy5-TCCCCTCTGAATTTATACAGTTGTTAATTTACAGG-Phosphat }\end{array}$ \\
\hline
\end{tabular}




\section{Ergebnisse}

\subsection{Interleukin 4 und Interleukin 13}

Im folgenden Abschnitt werden Verteilung und Assoziation der Varianten der Gene von Interleukin 4 und Interleukin 13 mit den verschiedenen Phänotypen, „klinische Malaria”, "Infektion" und „moderate Anämie”, beschrieben. Die Genotypfrequenzen der typisierten Einzelvarianten weichen nicht signifikant von den Genotypfrequenzen ab, die nach dem Hardy-Weinberg-Gesetz erwartet werden (Tabelle 3.1). In Abbildung 3.1 ist die Verteilung der Einzelvarianten dargestellt. Die SNP IL4 -589 (rs2243250) und IL4 +33 (rs2070874) zeigen ein Kopplungsungleichgewicht (engl. linkage disequilibrium, LD) mit einem $R^{2}$-Wert von 0,26; somit lässt sich das Auftreten von $26 \%$ der Varianten durch lineare Regression erklären. Nach der Vier-Gameten-Regel (Wang et al. 2002) bilden diese beiden Varianten einen Haplotyp-Block. Das Auftreten der übrigen Einzelvarianten weist keinen linearen Zusammenhang auf. In Tabelle 3.2 sind die Frequenzen der häufigsten Haplotypen dargestellt.

Tabelle 3.1 IL4/IL13-Varianten: Hardy-Weinberg-Test

\begin{tabular}{lccc} 
& \multicolumn{2}{c}{ Anzahl der Homozygoten } & \\
\cline { 2 - 3 } & Beobachtet & Erwartet & Hardy-Weinberg-Test (p-Wert) \\
\hline IL13 & & & \\
rs1800925 & 317 & 316,7 & 0,97 \\
rs20541 & 694 & 694,2 & 0,97 \\
IL4 & & & \\
rs2243248 & 650 & 648 & 0,67 \\
rs2243250 & 569 & 565,1 & 0,51 \\
rs2070874 & 288 & 302,7 & 0,06 \\
\hline
\end{tabular}


Abbildung 3.1 Linkage der Varianten aus der IL4/IL13-Region

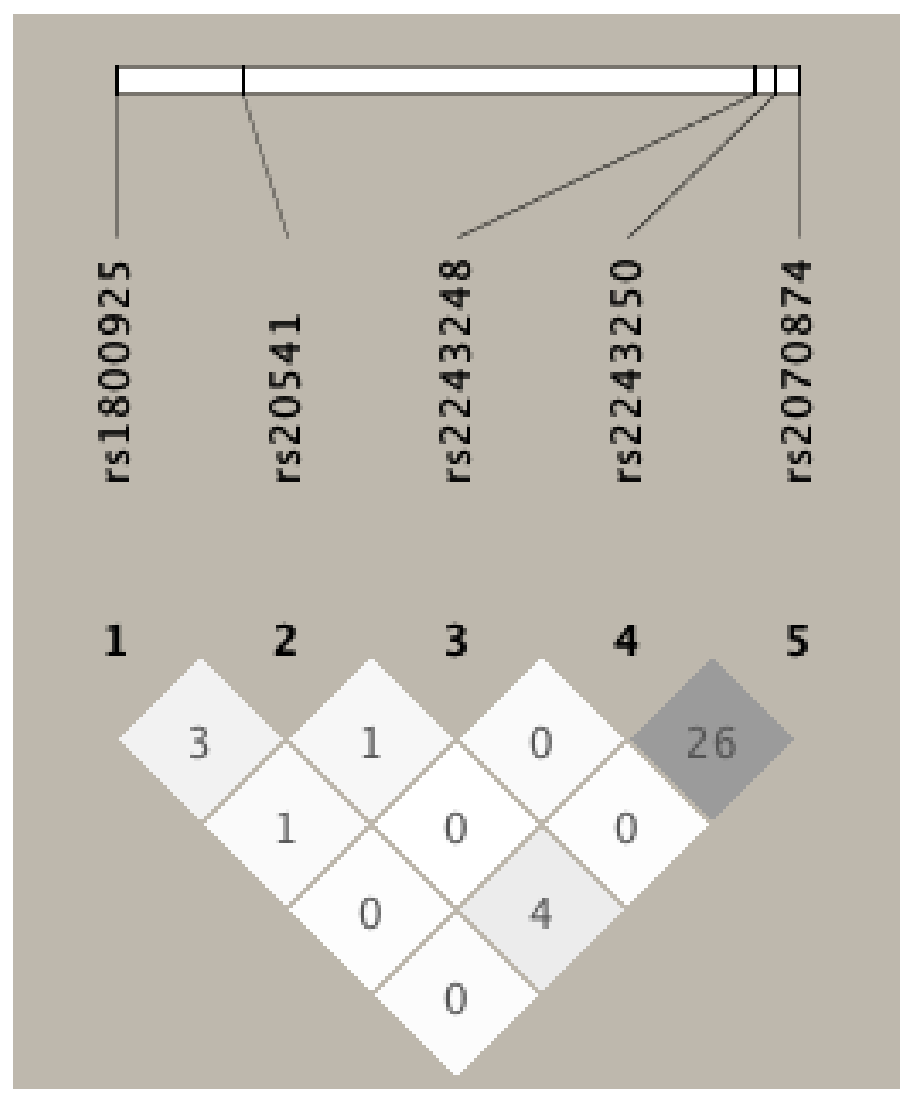


Tabelle 3.2 IL4/IL13-Region: Übersicht der häufigsten Haplotypen

\begin{tabular}{|c|c|c|c|c|c|}
\hline \multirow[b]{2}{*}{ 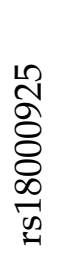 } & \multirow[b]{2}{*}{ 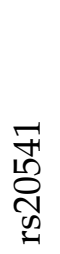 } & \multirow[b]{2}{*}{ 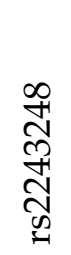 } & \multicolumn{2}{|c|}{ BLOCK1 } & \\
\hline & & & 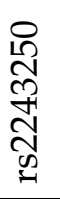 & 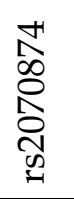 & Freq \\
\hline $\mathrm{C}$ & $\mathrm{C}$ & $\mathrm{T}$ & $\mathrm{T}$ & $\mathrm{T}$ & 0,172 \\
\hline $\mathrm{T}$ & $\mathrm{C}$ & $\mathrm{T}$ & $\mathrm{T}$ & C & 0,129 \\
\hline $\mathrm{C}$ & $\mathrm{C}$ & $\mathrm{T}$ & $\mathrm{T}$ & C & 0,126 \\
\hline $\mathrm{C}$ & $\mathrm{C}$ & $\mathrm{T}$ & $\mathrm{C}$ & C & 0,095 \\
\hline $\mathrm{T}$ & $\mathrm{C}$ & $\mathrm{T}$ & $\mathrm{T}$ & $\mathrm{T}$ & 0,088 \\
\hline $\mathrm{T}$ & $\mathrm{T}$ & $\mathrm{T}$ & $\mathrm{T}$ & $\mathrm{T}$ & 0,067 \\
\hline $\mathrm{C}$ & $\mathrm{C}$ & G & $\mathrm{T}$ & $\mathrm{T}$ & 0,064 \\
\hline $\mathrm{T}$ & $\mathrm{C}$ & $\mathrm{T}$ & $\mathrm{C}$ & $\mathrm{C}$ & 0,049 \\
\hline $\mathrm{C}$ & $\mathrm{T}$ & $\mathrm{T}$ & $\mathrm{T}$ & $\mathrm{T}$ & 0,039 \\
\hline $\mathrm{C}$ & $\mathrm{C}$ & G & $\mathrm{C}$ & C & 0,034 \\
\hline $\mathrm{T}$ & $\mathrm{C}$ & G & $\mathrm{C}$ & C & 0,027 \\
\hline $\mathrm{C}$ & $\mathrm{C}$ & G & $\mathrm{T}$ & C & 0,024 \\
\hline $\mathrm{T}$ & $\mathrm{T}$ & $\mathrm{T}$ & $\mathrm{C}$ & C & 0,023 \\
\hline $\mathrm{T}$ & $\mathrm{C}$ & G & $\mathrm{T}$ & C & 0,018 \\
\hline $\mathrm{C}$ & $\mathrm{T}$ & $\mathrm{T}$ & $\mathrm{C}$ & C & 0,018 \\
\hline $\mathrm{T}$ & $\mathrm{C}$ & G & $\mathrm{T}$ & $\mathrm{T}$ & 0,010 \\
\hline
\end{tabular}

Tabelle 3.3 zeigt die Assoziation der untersuchten Einzelvarianten mit dem Zeitraum bis zum Auftreten der ersten Infektion, der ersten klinischen Malaria und der ersten moderaten Anämie (Hämoglobin weniger als 7,5 g/dl). Der Genotyp IL13 -1112 ${ }^{T T}$ (rs1800925) zeigt mit einem Risikoquotienten (engl. hazard ratio, HR) von 1,24 und einem p-Wert von 0,025 ein erhöhtes Risiko für den Phänotyp „Infektion”. Dieses Ergebnis hält einer Korrektur auf multiples Testen nach Bonferroni mit dem Faktor fünf, der Anzahl der genotypisierten Einzelvarianten, jedoch nicht stand, und ist daher eher als ein Trend zu bewerten. In Abbildung 3.2 sind die Ergebnisse für diese Variante in Form einer Kaplan-Meier-Kurve dargestellt. Deutlich zu erkennen ist, dass die Kurve der homozygoten Merkmalsträger (TT) stärker abfällt. Dies entspricht einer stärkeren Abnahme des Prozentsatzes der noch Gesunden pro Zeiteinheit als bei heterozygoten Trägern der Variante oder Trägern des 


\section{Wildtyps.}

In der Tabelle 3.4 sind die genetischen Assoziationen für das wiederholte Auftreten eines Ereignisses aufgetragen. Der Begriff "Quotient der Inzidenzraten” (engl. incidence rate ratio, IRR) bezeichnet das Verhältnis der Mittelwerte der Inzidenzraten, die sich aus dem wiederholten Auftreten eines Ereignisses ergeben.

Sowohl die Genotypen IL13 $-1112^{C T}$ (rs1800925 ${ }^{C T}$ ) als auch IL13 $-1112^{T T}$ (rs1800925 ${ }^{T T}$ ) sind mit einem signifikant höheren Risiko für das Auftreten einer Infektion als der Wildtyp IL13 - $1112^{\mathrm{CC}}$ verbunden ( $\mathrm{p}=0,002, \mathrm{p}_{\text {korrigiert }}\left[\mathrm{p}_{\mathrm{korr}}\right]=0,01, \mathrm{IRR}=1,11$ bzw. 1,15). Hingegen zeigt der Genotyp IL13 $-1112^{C T}$ (rs1800925 ${ }^{C T}$ ) einen Trend in Richtung eines Schutzes vor dem Auftreten von Episoden „moderater Anämie” (IRR =0,83, p = 0,013, $\left.\mathrm{p}_{\text {korr }}=0,065\right)$, der homozygote Genotyp IL13 -1112 ${ }^{T T}$ (rs1800925 ${ }^{T T}$ ) ebenfalls einen Trend in die gleiche Richtung (IRR $=0,86, p=0,11$ ). Der ermittelte Haplotyp, bestehend aus den Einzelvarianten rs2243250 und rs207874, ist mit keinem der untersuchten Phänotypen assoziiert (Tabelle 3.5). 


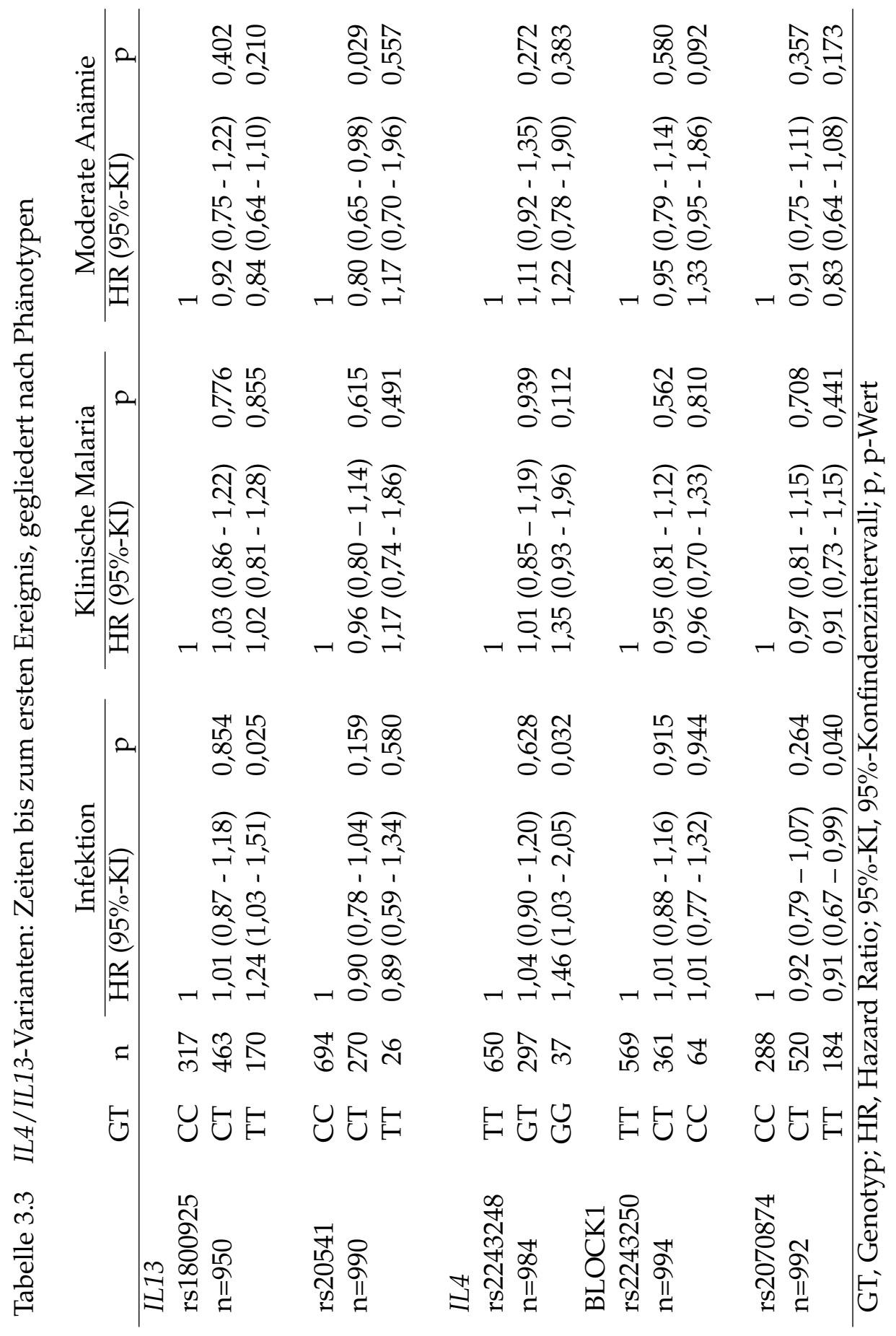


Abbildung 3.2 Kaplan-Meier-Kurve, Variante IL13 -1112 (rs1800925), Phänotyp „Infektion”

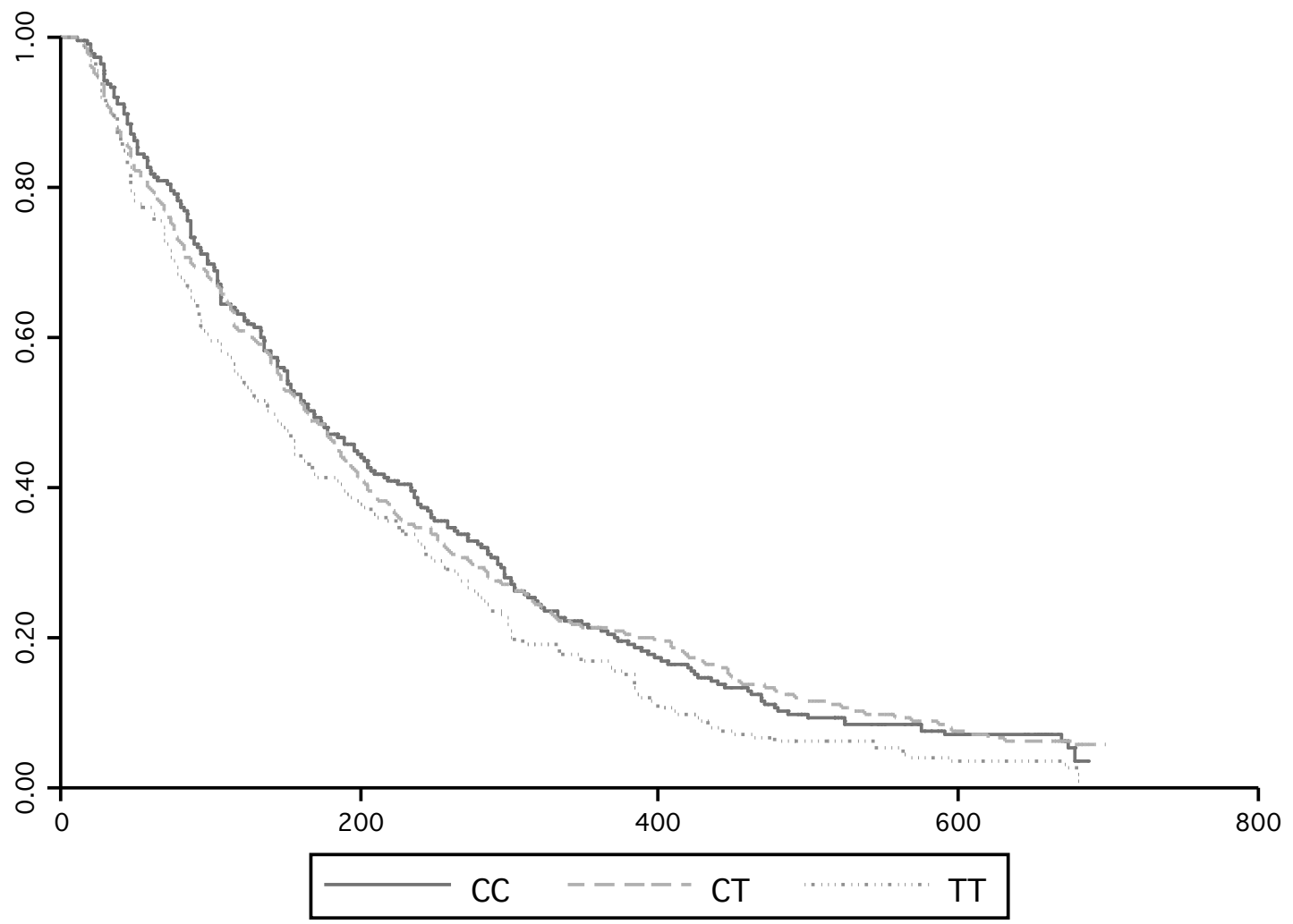




\begin{tabular}{|c|c|c|c|c|c|}
\hline 2 & $\begin{array}{l}\text { mo } \\
0 \\
0\end{array}$ & 雾产 & $\begin{array}{l}0 \\
0 \\
0 \\
0 \\
0 \\
0 \\
0\end{array}$ & 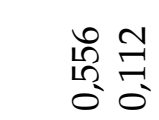 & तે \\
\hline 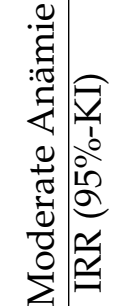 & 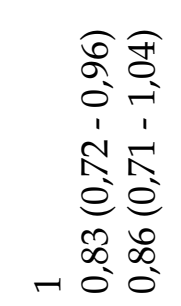 & 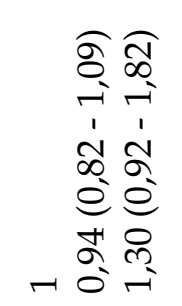 & 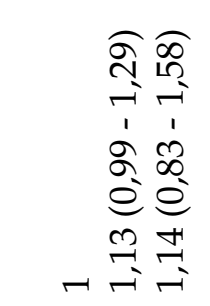 & 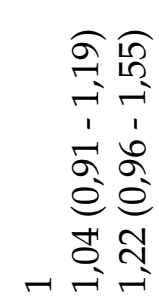 & 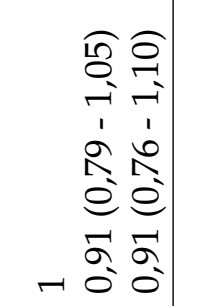 \\
\hline 䒕 & 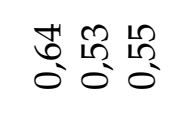 & 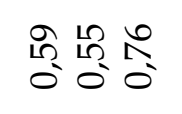 & 占 & 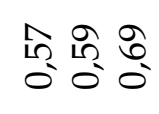 & $\begin{array}{l}0 \\
0 \\
0 \\
0\end{array}$ \\
\hline 2 & 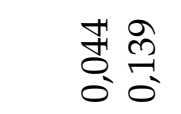 & 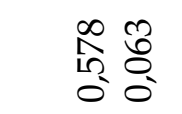 & 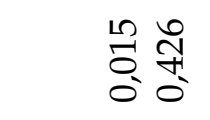 & & \\
\hline 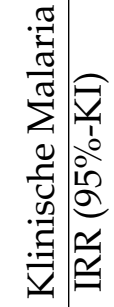 & 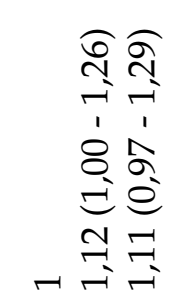 & 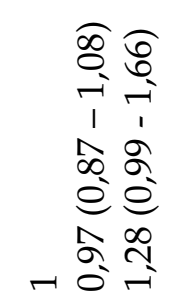 & 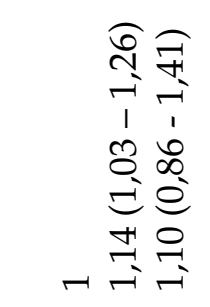 & 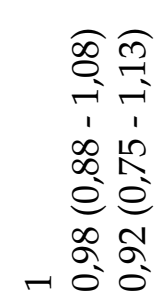 & 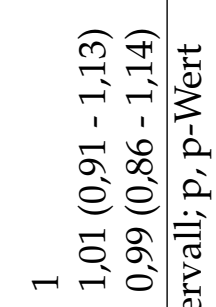 \\
\hline$\frac{\frac{\nu}{\pi}}{\widetilde{\pi}}$ & 冚芯兽 & 콕: & 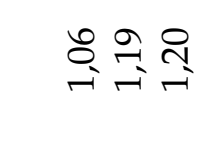 & $\underset{;}{7} \underset{-}{8}$ & \\
\hline 2 & 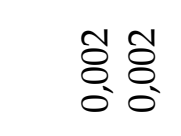 & 츙영 & 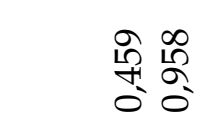 & 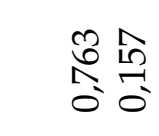 & \\
\hline 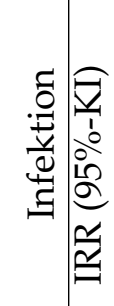 & 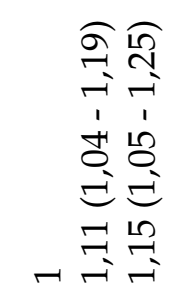 & 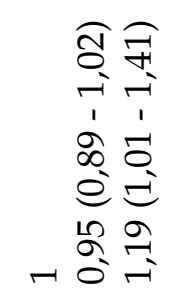 & 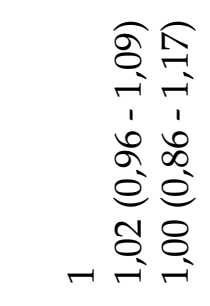 & 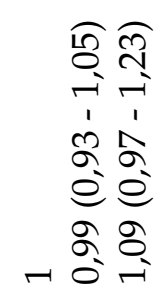 & \\
\hline 䒕 & 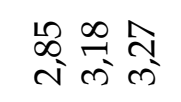 & 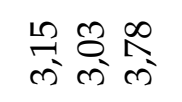 & 웅 & $\begin{array}{l}\approx 0 \\
\text { ले के }\end{array}$ & \\
\hline$=$ & 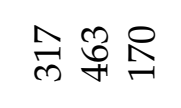 & 형옷요 & 员愈命 & 㝒 & \\
\hline U & U与 & 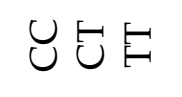 & 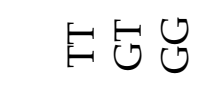 & $E \forall$ & \\
\hline & 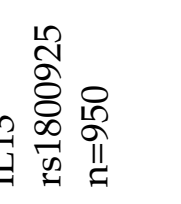 & 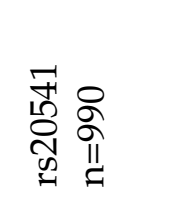 & 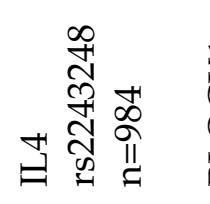 & 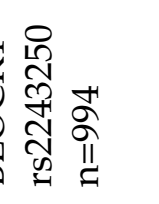 & 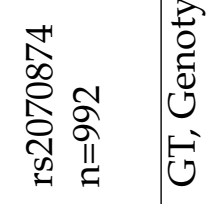 \\
\hline
\end{tabular}


Tabelle 3.5 IL4: Assoziationen des Haplotyp-Blockes BLOCK1 mit dem Phänotyp „klinische Malaria”

BLOCK1 (SNP rs2243250 und SNP rs2070874)

\begin{tabular}{llllll} 
Haplotyp & Fälle $(\%)$ & Kontrollen $(\%)$ & OR & $95 \%-K I$ & $p_{\text {nom }}$ \\
\hline C-C & $454(24,6)$ & $38(24,6)$ & 1,00 & $(0,68-1,47)$ & 0,995 \\
T-C & $574(31,1)$ & $38(24,7)$ & 1,38 & $(0,94-2,02)$ & 0,098 \\
T-T & $818(44,3)$ & $78(50,7)$ & 0,78 & $(0,56-1,08)$ & 0,1298 \\
\hline
\end{tabular}

OR, Odds Ratio; 95\%-KI, 95\%-Konfidenzintervall; $\mathrm{p}_{\text {nom }}$, nominaler p-Wert

\subsection{Beta2-adrenerger Rezeptor ADRB2}

Im Rahmen der Sequenzierung wurden die Einzelvarianten rs1042718 A/C, rs41354346 C/T, rs1042720 A/G, rs2053044 A/G, rs17108803 G/T, rs12654778 A/G, rs17334228 C/T, rs11959427 C/T, rs33947624 A/G, rs1042713 A/G und rs1042714 C/G identifiziert und bestätigt. Bisher unbekannte Single-Nukleotid-Polymorphismen oder Deletionen wurden nicht gefunden. Die Einzelvariante rs1042713 zeigt mit einem p-Wert von 0,01 eine Abweichung vom Hardy-Weinberg-Gleichgewicht. Dieser p-Wert hält jedoch einer BonferroniKorrektur auf multiples Testen mit dem Faktor 10, der Anzahl der typisierten Einzelvarianten, nicht stand (Tabelle 3.6). Bei eventuellen Assoziationen dieser Variante wäre dieses Ergebnis weiter in Betracht zu ziehen. Nach der vier-Gameten-Regel lassen sich aus der Verteilung der Einzelvarianten drei Haplotypen konstruieren, welche jeweils der PromotorRegion, dem Exon, und der 3'-UTR entsprechen und sich auf diese Regionen abbilden. Weiterhin zeigen drei SNPs (rs1777827, rs2400707 und rs7702861) ein hohes Kopplungsungleichgewicht (engl. linkage disequilibrium, LD) mit benachbarten Varianten (rs12654778, LD $\left(R^{2}\right)=99$, rs2053044, LD $\left(R^{2}\right)=100$ bzw. rs4705271, LD $\left.\left(R^{2}\right)=94\right)$, Abbildung 3.3. Für die weiteren Berechnungen wird jeweils nur eine der Varianten berücksichtigt, da aufgrund des hohen Kopplungsungleichgewichtes die benachbarten Varianten in 99\%, 100\% bzw. 94\% jeweils gemeinsam vorkommen. Somit kann in den Assoziationsanalysen der Korrekturfaktor für multiples Testen um den Faktor drei auf den Faktor sieben reduziert werden. 
Tabelle 3.6 ADRB2-Varianten: Hardy-Weinberg-Test

\begin{tabular}{lccc} 
& \multicolumn{2}{c}{ Anzahl der Homozygoten } & \\
\cline { 2 - 3 } & Beobachtet & Erwartet & Hardy-Weinberg-Test (p-Wert) \\
\hline rs17778257 & 654 & 650,3 & 0,45 \\
rs2400707 & 318 & 320,7 & 0,72 \\
rs2053044 & 327 & 330,6 & 0,64 \\
rs12654778 & 647 & 644 & 0,55 \\
rs1042713 & 276 & 256,3 & 0,01 \\
rs1042714 & 800 & 801,4 & 0,64 \\
rs7702861 & 261 & 270,2 & 0,24 \\
rs4705271 & 236 & 245,6 & 0,21 \\
rs1864931 & 586 & 593,3 & 0,19 \\
rs3857420 & 262 & 268 & 0,44 \\
\hline
\end{tabular}

Tabelle 3.7 zeigt das Vorkommen der häufigsten Kombinationen der Varianten des ADRB2-Gens. In Tabelle 3.8 sind die Assoziationen der Einzelvarianten mit der Zeit bis zum Auftreten des ersten Vorkommens eines der drei Phänotypen „klinische Malaria”, „moderate Anämie” oder „Infektion” gezeigt. Nach Korrektur auf multiples Testen zeigen homozygote Träger des A-Allels der Einzelvariante ADRB2 -654 (rs12654778) eine signifikante Assoziation mit dem Auftreten einer klinischen Malaria $\left(H R=1,67, \mathrm{p}=0,005, \mathrm{p}_{\text {korr }}\right.$ $=0,035)$. Für die Genotypen $+3803^{A A}$ (rs4705271) und $+4894^{T T}$ (rs3857420) zeigt sich ein signifikanter protektiver Effekt $\left(\mathrm{HR}=0,71, \mathrm{p}=0,003 ; \mathrm{HR}=0,73, \mathrm{p}=0,007, \mathrm{p}_{\mathrm{korr}}=0,049\right)$. In der Abbildung 3.4 sind die korrespondierenden Kaplan-Meier-Kurven dargestellt. Der Buchstabe "A" bezeichnet die Kurven für die Variante -654 (rs12654778). Deutlich zu erkennen ist, dass Träger des AA-Genotyps eher eine klinische Malaria-Episode erleiden, während heterozygote Träger (AG) und Träger des Wildtyps (GG) keinen wesentlich unterschiedlichen Verlauf aufweisen. Die Kurven der Variante +3803 (rs4705271) und +4894 (rs3857420) sind mit den Buchstaben "G" und „F" markiert. Auch bei diesen Varianten unterscheiden sich die Verläufe deutlich, die Kurven der Genotypen $r 33857420^{T T}$ sowie rs4705271 ${ }^{A A}$ fallen deutlich später ab. Die Tabelle 3.9 zeigt die Berechnungen für das mehrfache Auftreten der Ereignisse. Für den Phänotyp „klinische Malaria” zeigt der Genotyp $+4894^{A A}$ ( $r$ 3857420) erneut ein vermindertes Risiko (IRR $=0,81, \mathrm{p}=0,003, \mathrm{p}_{\text {korr }}=0,021$ ), weiterhin der Genotyp $+3803^{T T}$ (rs4705271) (IRR =0,79, p =0,0009, $\left.\mathrm{p}_{\mathrm{korr}}=0,0063\right)$. 
Abbildung 3.3 Linkage der Varianten aus der ADRB2-Region

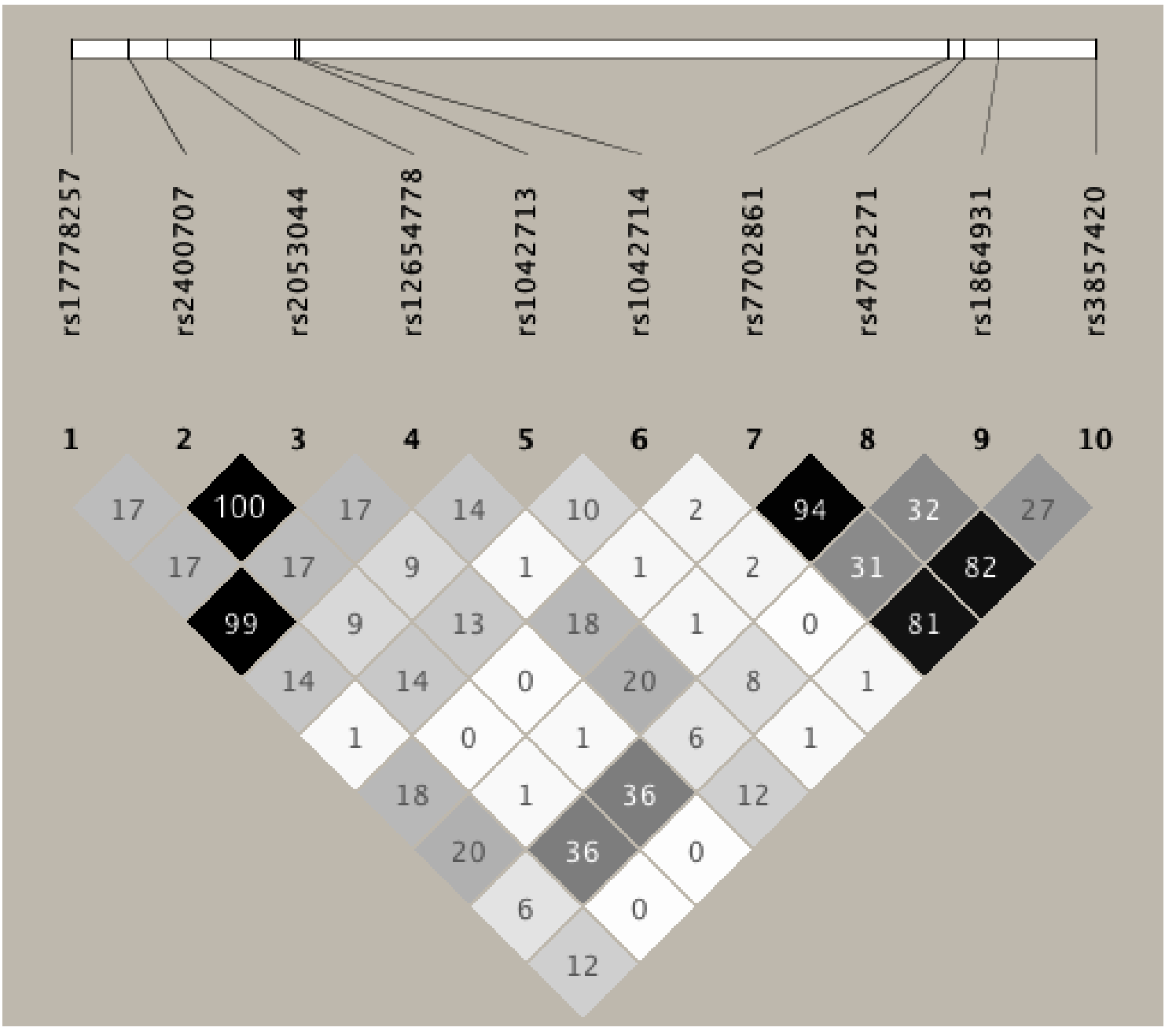

Für den Phänotyp „Infektion” zeigt sich bei den Genotypen $+3803^{T T}$ (rs4705271) und $+4088^{T T}$ (rs1864931) ein signifikanter protektiver Effekt (IRR $=0,86, \mathrm{p}=0,0005, \mathrm{p}_{\mathrm{korr}}=$ 0,$0035 ;$ IRR $=0,75, p=0,0008, p_{\text {korr }}=0,0056$ ), für die heterozygoten Merkmalsträger $+3803^{C T}$ (rs4705271) und $+4088^{C T}$ (rs1864931) ergeben sich nach Korrektur auf multiples Testen jedoch keine signifikanten $p$-Werte (IRR $=0,92, p=0,015, p_{\text {korr }}=0,105 ; \operatorname{IRR}=0,92, p=0,012$, 
Tabelle 3.7 ADRB2-Region: Übersicht der häufigsten Haplotypen

\begin{tabular}{|c|c|c|c|c|c|c|c|}
\hline \multicolumn{2}{|c|}{ BLOCK1 } & \multicolumn{2}{|c|}{ BLOCK2 } & \multicolumn{3}{|c|}{ BLOCK3 } & \\
\hline 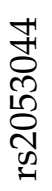 & 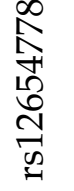 & 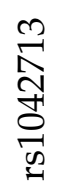 & 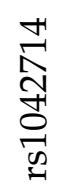 & 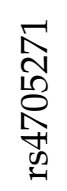 & 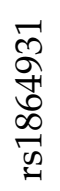 & 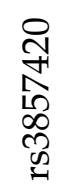 & Frequenz \\
\hline$G$ & $\mathrm{G}$ & G & $\mathrm{C}$ & $\mathrm{A}$ & $\mathrm{C}$ & $\mathrm{T}$ & 0,241 \\
\hline A & G & $\mathrm{A}$ & $\mathrm{C}$ & $\mathrm{A}$ & $\mathrm{T}$ & $\mathrm{T}$ & 0,177 \\
\hline G & $\mathrm{A}$ & A & $\mathrm{C}$ & $\mathrm{C}$ & $\mathrm{C}$ & $\mathrm{C}$ & 0,143 \\
\hline G & G & G & $\mathrm{C}$ & C & $\mathrm{C}$ & $\mathrm{C}$ & 0,129 \\
\hline A & G & $\mathrm{A}$ & $\mathrm{C}$ & $\mathrm{C}$ & $\mathrm{C}$ & $\mathrm{C}$ & 0,117 \\
\hline A & G & G & G & $\mathrm{C}$ & $\mathrm{C}$ & $\mathrm{C}$ & 0,050 \\
\hline A & G & G & G & $\mathrm{A}$ & $\mathrm{T}$ & $\mathrm{T}$ & 0,030 \\
\hline G & A & A & $\mathrm{C}$ & $\mathrm{C}$ & $\mathrm{C}$ & $\mathrm{T}$ & 0,024 \\
\hline
\end{tabular}

$\left.\mathrm{p}_{\mathrm{korr}}=0,084\right)$. Für den SNP $+4894^{A A}$ (rs3857420) ergibt die Assoziationsanalyse einen protektiven Trend, da auch dieses Ergebnis einer Korrektur auf multiples Testen nicht standhält (IRR $\left.=0,90, \mathrm{p}=0,02, \mathrm{p}_{\mathrm{korr}}=0,14\right)$. Homozygote Träger des A-Allels der PromotorVariante -654 (rs12654778) zeigen einen Trend für ein vermehrtes Auftreten von Infektionen (IRR $=1,21, \mathrm{p}=0,009$, $\mathrm{p}_{\mathrm{korr}}=0,063$ ). Im Übrigen zeigt sich bei heterozygoten Trägern der Genotypen $+3803^{C T}$ (rs4705271) und $+4894^{A C}$ (rs3857420) ein erhöhtes Risiko für den Phänotyp „moderate Anämie” (IRR = 1,28, $p=0,002$, $\mathrm{p}_{\mathrm{korr}}=0,014$; IRR $=1,34, \mathrm{p}=0,001$, $\left.\mathrm{p}_{\mathrm{korr}}=0,007\right)$.

Die sich auf den Promotor- und 3-UTR-Bereich abbildenden Haplotyp-Blöcke sind signifikant mit einem erhöhten Risiko einer Malariaerkrankung assoziiert (Tabelle 3.10, rs2053044 ${ }^{G}$-rs $12654778^{G}$, OR $=1,39, p_{\text {korr }}=0,026, p_{\text {global korrigiert }}\left[p_{\text {global korr }}\right]=0,048$; rs40705271 ${ }^{C}$-rs $1864931^{C}$-rs3857420 ${ }^{C}$, OR $=1,31, p_{\text {korr }}=0,012$, p $_{\text {global korr }}=0,018$ ). 


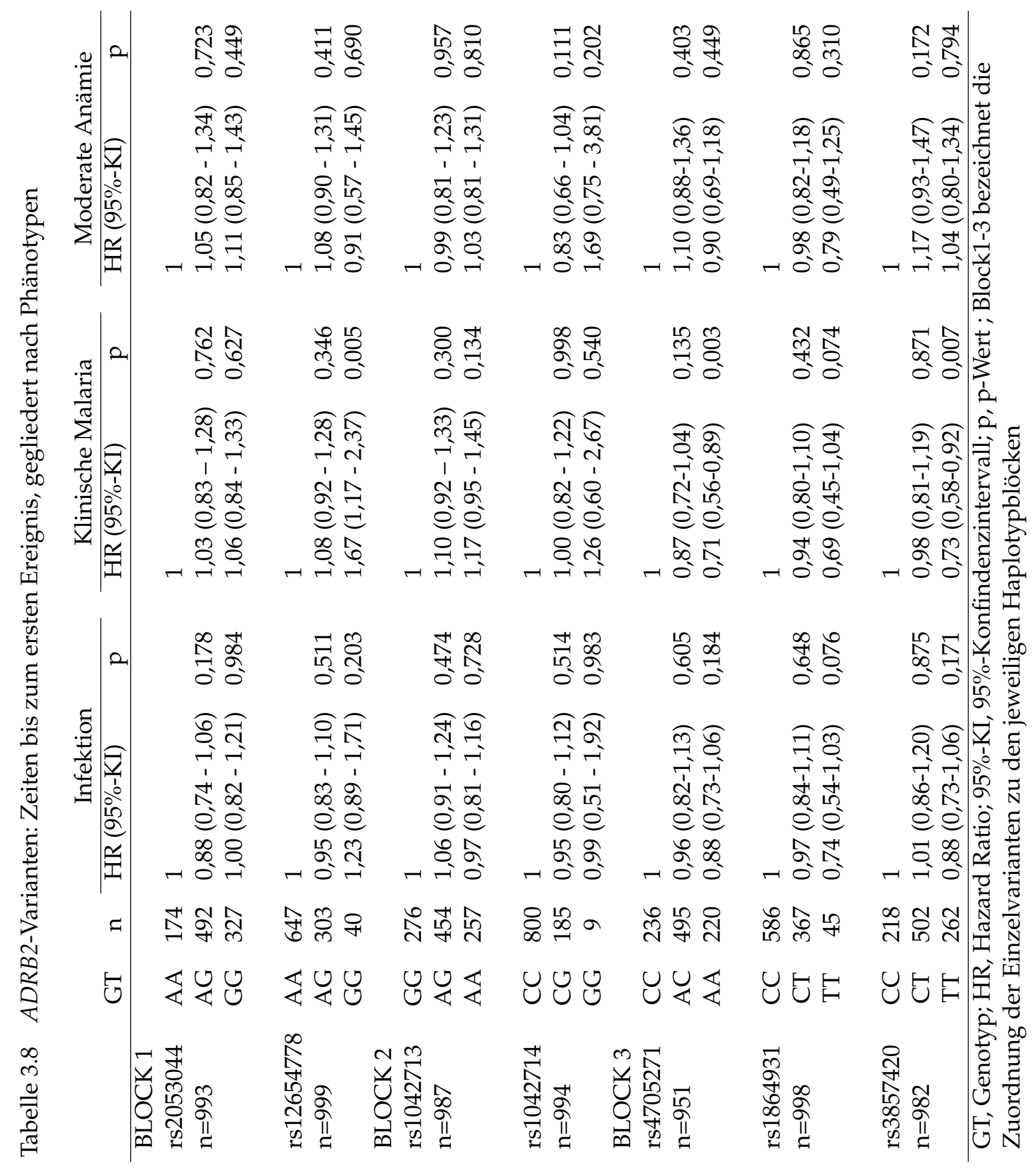


Abbildung 3.4 Übersicht der Kaplan-Meier-Kurven für verschiedene Varianten aus der ADRB2-Region, Erläuterungen siehe Abschnitt 3.2
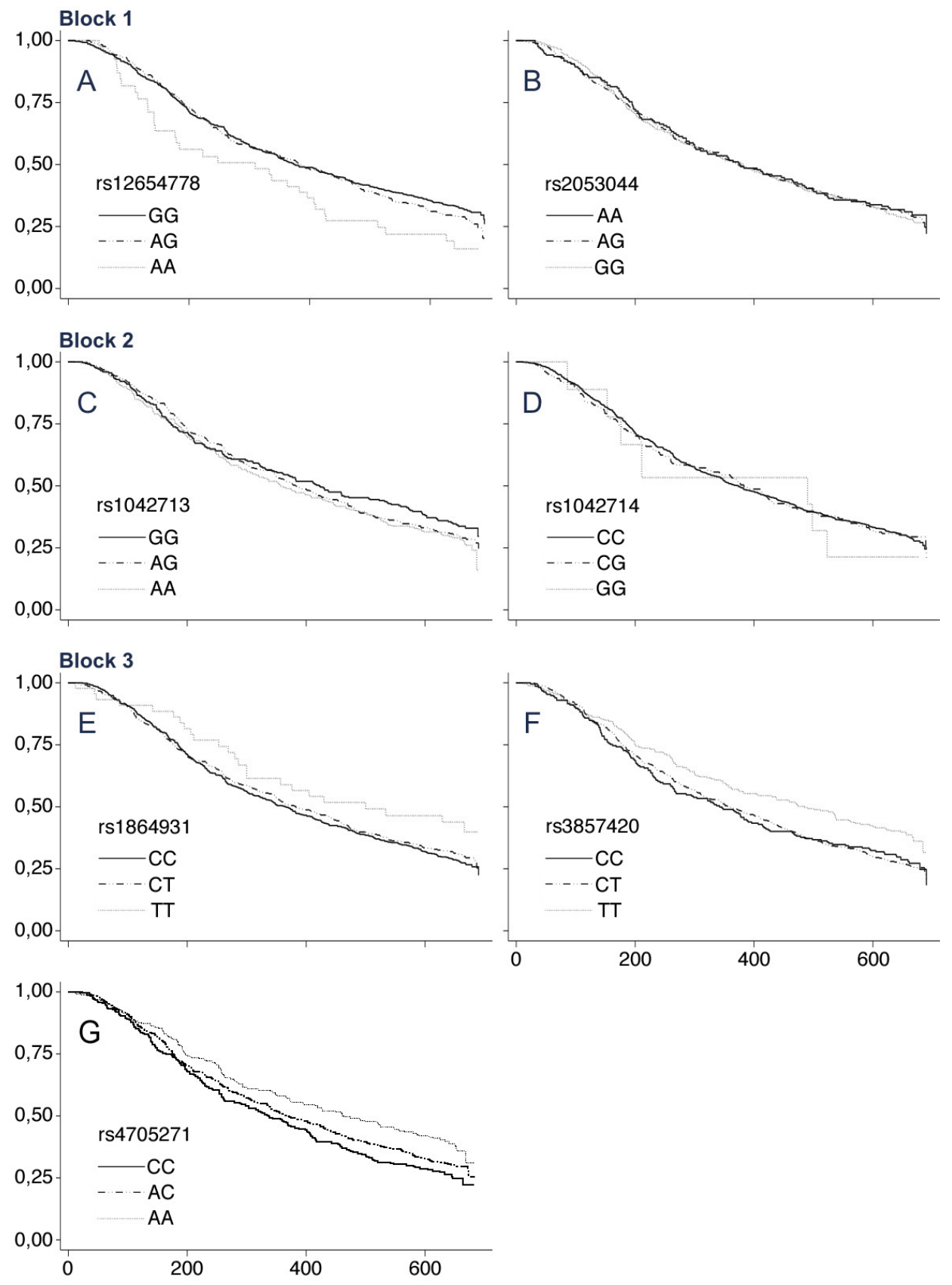


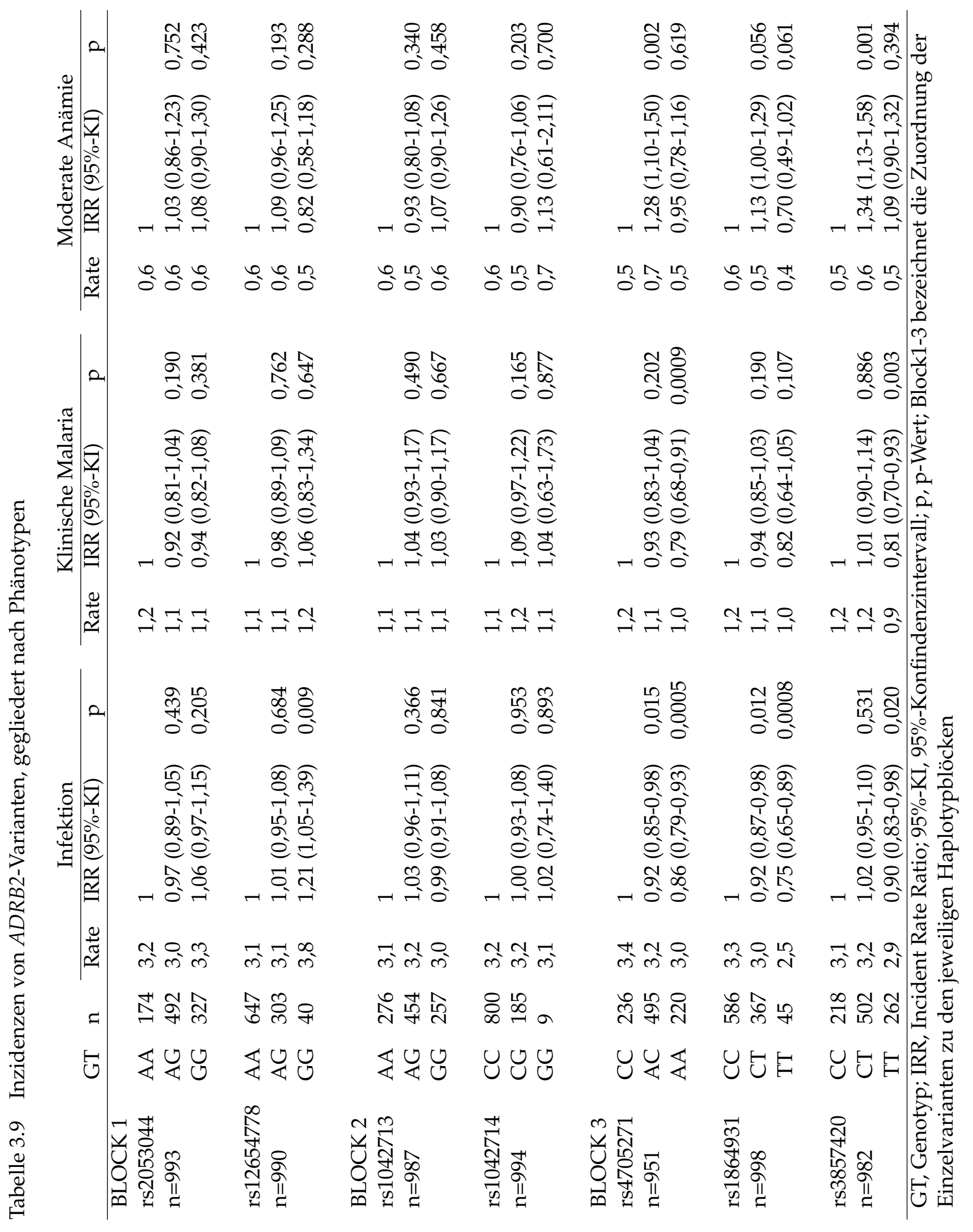


Tabelle 3.10 ADRB2-Region: Assoziationen der einzelnen Haplotypblöcke,

Phänotyp „Klinische Malaria”

BLOCK 1 (Promotor, SNP rs2053044 und SNP rs12654778)

\begin{tabular}{lllllll} 
Haplotyp & Fälle $(\%)$ & Kontrollen $(\%)$ & OR & $95 \%-K I$ & $p_{\text {nom }}$ & pkorr $_{\text {k }}$ \\
\hline A-A & $562,8(0,41)$ & $297,5(0,44)$ & 0,89 & $(0,74-1,08)$ & 0,324 & \\
G-A & $511,7(0,38)$ & $268,8(0,40)$ & 0,91 & $(0,75-1,11)$ & 0,303 & \\
G-G & $283,4(0,21)$ & $107,8(0,16)$ & 1,39 & $(1,08-1,78)$ & 0,0091 & 0,026
\end{tabular}

BLOCK 2 (Exon, SNP rs1042713 und SNP rs1042714)

\begin{tabular}{lllllll} 
Haplotyp & Fälle $(\%)$ & Kontrollen $(\%)$ & OR & $95 \%-K I$ & $p_{\text {nom }}$ & pkorr $_{\text {k }}$ \\
\hline A-C & $671,6(0,50)$ & $317,6(0,47)$ & 1,11 & $(0,92-1,33)$ & 0,443 & \\
G-C & $545,1(0,40)$ & $289,4(0,43)$ & 0,90 & $(0,74-1,08)$ & 0,255 & \\
G-G & $137,2(0,10)$ & $67,2(0,10)$ & 1,02 & $(0,74-1,39)$ & 0,911 &
\end{tabular}

BLOCK 3 (3'-UTR, SNP rs4705271, SNP rs186493, und SNP rs3857420)

\begin{tabular}{lllllll} 
Haplotyp & Fälle $(\%)$ & Kontrollen $(\%)$ & OR & $95 \%-K I$ & $p_{\text {nom }}$ & p korr \\
\hline C-C-C & $678,6(0,50)$ & $293,2(0,44)$ & 1,31 & $(1,09-1,58)$ & 0,0043 & 0,012 \\
C-T-C & $62,3(0,05)$ & $30(0,04)$ & 1,03 & $(0,66-1,64)$ & 0,877 & \\
A-T-C & $322,9(0,24)$ & $178,2(0,26)$ & 0,87 & $(0,71-1,08)$ & 0,213 & \\
A-T-T & $288,2(0,21)$ & $173(0,26)$ & 0,78 & $(0,63-0,97)$ & 0,027 & \\
\hline
\end{tabular}

OR, Odds Ratio; 95\%-KI, 95\%-Konfidenzintervall; $\mathrm{p}_{\text {nom }}$, nominaler $\mathrm{p}$-Wert; $\mathrm{p}_{\text {korr }}$, korrigierter p-Wert nach 1000 Permutationen.

Korrigierter globaler p-Wert nach 1000 Permutationen: BLOCK $1=0,048$; BLOCK $3=0,018$ 


\section{Diskussion}

Kinder unter fünf Jahren sind mit einer Mortalität von 1-2\% am häufigsten durch letale Verläufe einer Malaria gefährdet (WHO 1997a, b; Trigg und Kondrachine 1998). Regelmäßig werden auch asymptomatische Verläufe beobachtet, obwohl eine Parasitämie über eine lange Zeit nachgewiesen wird (Greenwood et al. 1987). Der Grund für den unterschiedlichen Verlauf ist oft nicht bekannt (Greenwood B et al. 1991). Es wird vermutet, dass der Verlauf einer Infektion zum einen von verschiedenen wirtsgenetischen Faktoren und der individuellen Ausprägung der Immunantwort abhängt, zum anderen aber auch mit der Variabilität der Malaria-Parasiten zusammenhängt (Hill et al. 1997; Gupta et al. 1994; Plebanski et al. 2002). Das Risiko des Auftretens einer schwer verlaufenden Malaria tropica korreliert maßgeblich mit dem Auftreten und dem Verlauf der ersten Infektionen im Kleinkindalter (Luty et al. 1999). Auf Grund dieser Tatsachen wurde für diese Arbeit eine Kinderkohorte als Studienpopulation ausgewählt.

Die protektive anti-parasitäre Immunität steigt in holoendemischen Regionen mit dem Grad der Exposition, während ein relativer Schutz gegen eine klinische Malaria schon nach ein bis zwei Infektionen vorhanden ist (Gupta et al. 1999). Dies spricht für die Hypothese, dass der Verlauf der ersten Infektionen im Kindesalter das Risiko einer schweren Malaria maßgeblich beeinflusst. Während der ersten Lebensmonate besteht durch maternale Antikörper und noch vorhandenes fetales Hämoglobin $(\mathrm{HbF})$ ein partieller Schutz gegen eine schwere Malaria. Nach dieser Zeit steigt bei Infektionen zunehmend das Risiko von schweren Verlaufsformen. Mit jeder überstandenen Infektion nimmt dann das Risiko einer komplizierten Malaria ab (Phillips 2001). Die schwere Anämie wird zumeist in früher Kindheit, um das zweite Lebensjahr, beobachtet. Sie stellt die häufigste Komplikation in Regionen mit hoher Transmission, definiert durch eine entomologische Inokulationsrate größer 100 infektiöse Stiche pro Jahr, dar. Hingegen wird eine zerebrale Malaria vor allem bei älteren Kindern um das dritte bis vierte Lebensjahr beobachtet. Sie tritt in erster Linie bei Erstma- 
nifestation in Regionen mit niedrigerer Transmissionsrate (entomologische Inokulationsrate kleiner 15 Infektionen pro Jahr) auf. Diese Beobachtung unterstützt die Hypothese, dass das Risiko eines schweren Verlaufs mit der Häufigkeit von Reinfektionen abnimmt. In dem Gebiet meiner Studienpopulation besteht eine hohe Malaria-Transmissionsrate. Somit sind Komplikationen der Malaria in erster Linie bei Kleinkindern und in der Form einer schwere Anämie zu erwarten. Die in die Studie eingeschlossenen Kinder bilden somit durch ihr Alter zwischen drei und 18 Monaten diese Risikogruppe optimal ab.

Mit Hilfe eines auf epidemiologischen Daten basierenden Modells lässt sich der Einfluss von Wirtsfaktoren auf die Frequenz und die Ausprägung von Malariainfektionen auf ca. 10\% bzw. 15\% schätzen (Mackinnon et al. 2000). Dass genetische Merkmale einen starken Einfluss auf Verlauf und Ausprägung von Malariainfektionen ausüben können, wird am Beispiel der Duffy-Blutgruppe deutlich. Ein Fehlen dieses Merkmals verleiht eine starke Resistenz gegen durch Plasmodium vivax verursachte Infektionen (Miller et al. 1975). Allerdings zeigt eine neuere Studie, dass gelegentlich auch bei Trägern des DuffyBlutgruppenmerkmals Infektionen mit Plasmodium vivax auftreten können (Menard et al. 2010). Die Sichelzellanämie und Thalassämie sind weitere Beispiele für genetisch vererbte Faktoren, die vor schweren Verläufen einer Malaria schützen (Flint et al. 1998). Assoziationen von genetischen Wirtsfaktoren mit dem Risiko einer zerebralen Malaria oder einer schweren Malariaanämie sind bereits mehrfach beschrieben worden (Hill 1998; Modiano et al. 1996; Hill 2001; Domarle et al. 2002; May et al. 2007). Teilweise konnten die pathophysiologischen Zusammenhänge nachgewiesen werden (Williams et al. 1996; Hill et al. 1992; Knight et al. 1999). Der Einfluss von Genpolymorphismen auf die Entwicklung einer Immunität gegen Malaria ist ebenfalls nachgewiesen worden (Kwiatkowski 2000). Weitere, an einer Kinderkohorte aus Gabun durchgeführte Studien haben ergeben, dass Varianten von Kandidatengenen die Rate an Reinfektionen und das Risiko schwerer Komplikationen im Rahmen einer Infektion beeinflussen können (Kun et al. 2001; May et al. 2001, 2000, 1999; Lell et al. 1999; Kun et al. 1999).

Kopplungsanalysen zeigten bereits in einer relativ kleinen Studienpopulation von 25 Kindern in neun Familien aus Süd-Kamerun eine Tendenz zu Gunsten einer Kopplung des distalen Bereiches der 5q31 Region (D5S636, $\mathrm{p}=$ 0,06) mit der Höhe der Plasmodiumfalciparum (P.f.)-Parasitämie im Blut (Garcia et al. 1998) . Kurz darauf wurde in einer deutlich größeren Population in Burkina Faso (153 Probanden aus 34 Familien) eine signifikan- 
te Kopplung im Bereich der 5q31-Region (D5S393, $\mathrm{p}=$ 0,008; D5S658, $\mathrm{p}=$ 0,005) mit der Höhe der Parasitämie nachgewiesen (Rihet et al. 1998). In einer ebenso in Burkina Faso durchgeführten Folgestudie mit 292 Probanden ergaben Kopplungsanalysen mit der P.f.Parasitämie erneut multiple signifikante $\mathrm{p}$-Werte im Bereich der 5q31-Region (D5S636 [p = 0,0017], D5S673 [ $p=0,042$ ], D5S2012 [ $p=0,027$ ] und IL12b [p = 0,024], Flori et al. 2003).

In dieser Arbeit wurde der Zusammenhang zwischen dem Vorkommen verschiedener Einzel-Nukleotid-Variationen (engl. single-nucleotid polymorphisms, SNPs) im Bereich der Chromosomenregion 5q31 und der Häufigkeit und Klinik von Plasmodium-falciparum-Infektionen und klinischer Malaria in einer Studienpopulation von 1069 ghanaischen Kindern untersucht.

Das Auftreten von positiven oder negativen Assoziationen genetischer Varianten kann wertvolle Hinweise auf Pathomechanismen geben, die im Verlauf einer Malaria eine wichtige Rolle spielen. Auf Grund der Hinweise aus vorausgegangenen Studien wurden die Interleukine 4 und 13 sowie der beta2-adrenerge Rezeptor ADRB2 als Kandidaten für die Assoziationsanalysen ausgewählt.

Eine Limitation bei solchen Kandidatengen-Analysen ist, dass nur ausgewählte Varianten untersucht werden und daher mögliche kausale Varianten übersehen werden könnten. Liegen die Varianten in ausreichend geringer Distanz zueinander, besteht jedoch die Möglichkeit, aus der dbSNP-Datenbank (Sherry et al. 2001) Informationen über die Haplotypstruktur der jeweiligen Genabschnitte abzufragen und durch Imputation mit diesen Daten die nicht typisierten Einzelvarianten in silico herzuleiten (Purcell et al. 2007; Nothnagel et al. 2009).

Eine mögliche Fehlerquelle entsteht dadurch, dass mit der Anzahl der ausgesuchten Kandidaten der Bonferroni-Faktor für die Korrektur auf multiples Testen steigt. Bei zu hohem Korrekturfaktor besteht die Gefahr, vorhandene genetische Assoziationen durch zu strenge Korrektur zu übersehen (Rice et al. 2008).

In der vorliegenden Arbeit wurden ausschließlich genetische Assoziationen behandelt. Der abschließende Nachweis eines Einflusses von Genvarianten durch zusätzliche Funktionsuntersuchungen steht somit noch aus. Jedoch geben die in dieser Arbeit gefundenen Ergebnisse Anreize, weitere funktionelle Untersuchungen zu unternehmen und einen Einfluss der Varianten auf molekularer Ebene aufzuzeigen.

Der Erfolg der Genotypisierung lag für alle untersuchten Varianten bei $>95 \%$ der un- 
tersuchten Proben. Die Genauigkeit der LightTyper-Methode wird als sehr hoch eingeschätzt (Frances et al. 2005). Jedoch ist die PCR ein sehr sensitives Verfahren, welches das Risiko einer Kontamination birgt. Um dieses Risiko zu minimieren, wurden auf den 384Loch-Platten zusätzlich mehrere Negativ-Kontrollen aufgetragen. Als weitere Hilfe zur Abschätzung der Qualität der Genotypisierungsdaten dient die Überprüfung des HardyWeinberg-Gleichgewichts. Zeigt sich hier ein signifikantes Ungleichgewicht $(p<0,05)$, könnte dies auf eine fehlerhafte Typisierung hinweisen. Allerdings kann das Hardy-WeinbergGleichgewicht auch durch weitere Faktoren, wie beispielsweise den ethnischen Hintergrund der Studienpopulation, beeinflusst werden. Daher wurde die Studienpopulation für die Berechnung des Hardy-Weinberg-Gleichgewichts auf die drei größten ethnischen Gruppen der ghanaischen Population, Akan, Northerners und Ewe, stratifiziert. Weitere mögliche Fehlerquellen, die den Erfolg einer PCR beeinflussen können, sind eine verminderte Qualität der eingesetzten DNA durch eine schlechte DNA-Extraktion oder eine Störung der Reaktion durch inhibitorische Substanzen.

In der nun folgenden Diskussion werden die Kandidatengene nacheinander abgehandelt. Zum Abschluss folgt eine Zusammenfassung der Ergebnisse. 


\subsection{Interleukin 4 und Interleukin 13}

Interleukine haben als Mediatoren des Immunsystems eine wichtige Funktion in der Regulation der Immunantwort. Sie können sowohl eine aktivierende als auch eine inhibitorische Wirkung ausüben und werden unter anderem von T-Zellen produziert. T-Lymphozyten werden in CD8-positive zytotoxische T-Zellen, und CD4-positive T-Helferzellen, welche wiederum in zwei Klassen (Th1 und Th2) untergliedert sind, unterteilt. Interleukin 4 und Interleukin 13 sind Zytokine der Klasse 2 und werden von Th2-T-Helferzellen produziert. Sie nehmen eine regulatorische Funktion in der Antikörperproduktion wahr und stimulieren Mastzellen und eosinophile Granulozyten. Th1-Zellen tragen zu der Aktivierung von Makrophagen bei. Th1- und Th2-Zellen hemmen sich gegenseitig. So führt die Ausschüttung von IL4 durch Th2-Zellen zu einer Inhibition von Th1-Zellen. Die Ausschüttung von IL13 hat einen inhibitorischen Effekt auf die Zytokinproduktion durch Makrophagen (Minty et al. 1993). IL4 und IL13 regulieren die Differenzierung von Immunglobulinen von dem IgG zu dem IgE-Isotyp (Zurawski und de Vries 1994).

Die unmittelbare Nachbarschaft der Gene von Interleukin 4 und Interleukin 13 auf Chromosom 5 und die teils identische Wirkung ihrer Produkte auf die Aktivierung von BLymphozyten zu Antikörper-produzierenden Zellen zeigt die enge funktionelle Verwandtschaft (Palmer-Crocker et al. 1996). Es ist eine gemeinsame Regulation der Expression beider Gene durch intergenische Transkription bekannt (Rogan et al. 2004).

Für das Allel IL13 $-1112^{T}\left(\right.$ rs1800925 $5^{T}$ ) ist ein protektiver Effekt auf das Auftreten einer schweren Malaria beschrieben worden (Ohashi et al. 2003). In dieser Studie war die schwere Malaria durch eines der folgenden Kriterien definiert: Hohe Parasitämie (>100 000 Parasiten/ $\mu \mathrm{l}$ ), Hypoglykämie (Glukose $<22 \mathrm{nmol} / \mathrm{l}$ ), schwere Anämie (Hämatokrit $<20 \%$ ), ein niedriger Hämoglobinwert $(<7,0 \mathrm{~g} / \mathrm{dl})$ oder ein Serum-Kreatinin-Spiegel von mehr als $3,0 \mathrm{mg} / \mathrm{dl}$. Der einzige mit den aktuellen Studiendaten direkt vergleichbare Parameter ist die schwere Anämie, da Messwerte zu den übrigen Parametern in der vorliegenden Studie zur leichten Malaria nicht zur Verfügung stehen. Ziel war somit die Bestätigung des protektiven Effektes dieser im Bereich des Promotors von Interleukin 13 lokalisierten Einzelvariante vor dem Auftreten einer Anämie.

Weiterhin wurden vier weitere Einzelvarianten aus der IL4/IL13-Region auf mögliche Assoziationen untersucht. Einschlusskriterien waren zum einen die aus der dbSNP (Sherry 
et al. 2001) ermittelten minimalen Allelfrequenzen in der afrikanischen Population, zum anderen schon bekannte Assoziationen einzelner Varianten mit weiteren Erkrankungen. Übersicht der für die Assoziationsanalyse ausgewählten Einzelvarianten aus der IL4/IL13Region:

1. IL 13 -1112 C/T (rs1800925): Für diese Variante, die innerhalb der Promotor-Region des IL13-Gens lokalisiert ist, wurde bereits ein protektiver Effekt beschrieben: Träger des rs $1800925^{T}$ Allels zeigen mit einem Quotenverhältnis (engl. odds ratio, OR) von 0,51 einen signifikanten Schutz vor dem Auftreten einer schweren Malaria ( $\mathrm{p}=$ 0,0032, Ohashi et al. 2003). Wesentliche Limitationen dieser Studie sind jedoch zum einen die relativ geringe Anzahl von nur 361 Probanden, wie auch die relativ unscharfe Spezifizierung des Phänotyps „Schwere Malaria” durch entweder eine hohe Parasitämie, durch eine Hypoglykämie oder durch das Auftreten einer schweren Anämie.

2. IL13 Exon4 R110Q (rs20541): Diese Variante liegt in dem kodierenden Abschnitt des IL13-Gens und führt zu einem Austausch der basischen Aminosäure Arginin gegen die saure Aminosäure Glutamin an Position 110 des Proteins. Diese sogenannte Fehlsinnmutation (engl. missense mutation) könnte eine Konfirmationsänderung des Proteins und in der Folge eine Beeinträchtigung oder sogar einen Verlust der Funktion zur Folge haben. So sind bei Atopikern bei Trägern des IL13 110Gln-Allels erhöhte IgE-Spiegel beobachtet worden (Hoffjan et al. 2004). So ist ebenso ein Einfluss dieser Variante auf die Immunantwort im Rahmen einer Malariainfektion denkbar, da ein Zusammenhang von genetischem Schutz vor Asthma und Suszeptibilität für Malaria und andere parasitäte Erkrankungen vermutet wird (Barnes et al. 2005).

3. IL4 -1098 G/T (rs2243248): Für diese Variante ist ein Einfluss auf das Verhältnis von CD4-positiven zu CD8-positiven T-Lymphozyten im Rahmen einer idiopathischen pulmonalen Fibrose (IPF), der häufigsten Form einer idiopathischen interstitiellen Pneumonie, beschrieben (Vasakova et al. 2007). Dieses Ergebnis lässt einen möglichen Einfluss der Variante auf die spezifische zelluläre Abwehr vermuten. Jedoch ist die geringe Fallzahl von $n=30$ als wesentliche Einschränkung der Aussagekraft dieser Studie zu sehen. 
4. IL4 -589 C/T (rs2243250): Für diese Variante ist eine Korrelation mit dem IgE-Spiegel im Verlauf einer schweren Malaria beschrieben (Verra et al. 2004). So zeigen die Träger $(n=300)$ des rs2243250 -Allels signifikant erhöhte IgE-Spiegel $(p=0,018)$. Die Kontrollen mit milder Malaria $(n=280)$ zeigen hingegen keinen signifikanten Unterschied. In der aktuellen Studie ist jedoch vorstellbar, dass auf Grund der größeren Fallzahl auch bei der milden Malaria ein Unterschied ersichtlich wird. In einer weiteren Studie wurde innerhalb der Ethnie der Fulani eine signifikante Assoziation des rs2243250 ${ }^{T}$-Allels mit erhöhten IgG-Spiegeln gegen das Circumsporozoit-Antigen (engl. circumsporozoite protein, CSP) und das Plasmodium-falciparum-332-Antigen (Ag332) der Malaria gemessen ( $n=51$, Luoni et al. 2001). Insbesondere bei der letztgenannten Studie ist jedoch die Aussagekraft und die Vergleichbarkeit mit der aktuellen Studie durch die geringe Fallzahl sowie durch die Tatsache limitiert, dass explizit Mitglieder einer Ethnie ausgewählt wurden, die in der Studienregion der aktuellen Studie nur sehr selten vorkommt.

5. IL4 +33 C/T (rs2070874): Für diese Variante ist eine Korrelation mit dem Auftreten von rheumatoider Arthritis beschrieben (Suppiah et al. 2006). Weibliche Träger des rs2070874 ${ }^{T}$-Allels haben ein vermindertes Risiko, an einer rheumatoiden Arthritis zu erkranken. $(p=0,02)$. Auch bei dem Phänotyp der juvenilen idiopathischen Arthritis ist ein Trend für eine Assoziation zu erkennen. Somit scheint ein Einfluss dieser Punktmutation auf die Entwicklung von Autoimmunkrankheiten zu bestehen, wenn auch bei dieser Studie die Aussagekraft durch die Einschränkung auf weibliche Patienten und eine Gesamtfallzahl von 366 und nur 165 Kontrollen eingeschränkt ist. Auf einen möglichen Zusammenhang zwischen Autoimmunerkrankungen und der Suszeptibilität zu Malaria wurde bereits verwiesen (Barnes et al. 2005).

Sämtliche für diese Studie ausgewählten Varianten kommen in der afrikanischen Population in ausreichend starker Allelfrequenz vor, so dass statistisch signifikante Ergebnisse erzielt werden können.

Bei den vorliegenden Ergebnissen ergibt sich ein im Vergleich zu der vorausgegangenen Studie von Ohashi et al. (2003) überraschendes Bild, da die Träger der Genvarianten IL13 $-1112^{C T}$ und IL13 $-1112^{T T}$ (rs1800925 $5^{C T}$ und rs1800925 ${ }^{T T}$ ) zu häufigeren Infektionen neigen ( $p_{\text {nom }}=0,002, p_{\text {korr }}=0,01, \mathrm{IRR}=1,11$ bzw. IRR = 1,15, Tabelle 3.4) als der Wildtyp, während 
dieser Variante bisher ein protektiver Effekt zugeschrieben wurde. Weiterhin zeigen Träger der Genvariante rs1800925 ${ }^{T T}$ eine verkürzte Zeit bis zum Auftreten der ersten Infektion (HR = 1,24; $\mathrm{p}_{\text {nom }}=0,025 ; \mathrm{p}_{\mathrm{korr}}=0,125 ;$ Tabelle 3.3, Abbildung 3.2), wenngleich diese Beobachtung nur als Trend zu beurteilen ist, da die Signifikanz einer Korrektur auf multiples Testen mit dem Faktor fünf nicht standhält. Hingegen war bei den Trägern dieser Genotypen vorher ein offenbar gegenteiliger Effekt, nämlich ein Schutz vor dem Auftreten einer schweren Malaria, beobachtet worden (Ohashi et al. 2003). Da der Phänotyp einer „Schweren Malaria" in der vorausgegangenen Studie in erster Linie durch das Auftreten einer Anämie definiert wurde, ist ein direkter Vergleich mit dem Phänotyp „Infektion” der aktuellen Studiengruppe nicht möglich. Ein Vergleich mit dem Phänotyp „Moderate Anämie” ist jedoch möglich. So ist auch in den aktuellen Beobachtungen für hetero- und homozygote Träger des rs $1800925^{T}$-Allels ein Trend in Richtung einer Protektion vor dem Auftreten einer moderaten Anämie erkennbar $\left(\mathrm{IRR}=0,83\right.$; $\mathrm{p}_{\text {nom }}=0,013 ; \mathrm{p}_{\mathrm{kor}}=0,065$ und IRR = 0,86; $\mathrm{p}_{\text {nom }}=0,110$, Tabelle 3.4). Bei T-Zellen von Trägern des rs $1800925^{T}$-Allels wurde eine geringere Inhibition der IL13-Produktion durch CD3-Antikörper als bei den Wildtypen gemessen. Die rs1800925 $5^{T}$-Mutation hat die Bildung einer "Yin-Yang 1"-Bindungsstelle zur Folge. Dieser Transkriptionsfaktor kann sowohl inhibitorisch als auch stimulierend wirken (Lace et al. 2009). Weiterhin kommt es zu einem Funktionsverlust einer inhibitorischen "STAT6"-Bindungsstelle (van der Pouw Kraan et al. 1999). Sowohl in vitro als auch am Mausmodell konnte eine gesteigerte Aktivität des IL13-Promotors sowie einer erhöhten Expression von IL13 bei Trägern des rs $1800925^{T}$-Allels verifiziert werden (Cameron et al. 2006). Da IL13 als Zytokin der Klasse 2 eine inhibitorische Wirkung auf die Th1-Zellen und somit auf die Aktivierung von Makrophagen hat, könnte eine erhöhte Expression von IL13 bei Trägern des rs $1800925^{T}$-Allels durch die Hemmung der Makrophagen die Wahrscheinlichkeit, dass die Infektion durch die Immunantwort beseitigt wird, verringern. Es ist somit vorstellbar, dass durch die im Verhältnis zum Wildtyp erhöhte Frequenz an Parasitämien und den damit verbundenem Verlust an Erythrozyten eine Adaption in Form einer gesteigerten Hämatopoese stattfindet, um eine Kompensation zu erzielen. Da P.f.-Infektionen mit einer Suppression der Erythropoese einher gehen können (Doermer et al. 1983), könnte eine bereits erhöhte Hämatopoese diesen Effekt kompensieren und somit das Risiko, an einer schweren Anämie zu erkranken, verringern. Es wäre also eine mögliche Hypothese, dass Träger des rs $1800925^{T}$-Allels zwar zum einen zu häufigeren Infektionen neigen, da es 
zu einer gesteigerten Expression von IL13 und somit zu einer Hemmung von Makrophagen kommt, sie andererseits aber durch eine ausgeprägtere Hämatopoese den Verlust von Erythrozyten besser kompensieren können und so vor schweren Anämien geschützt sind.

Des Weiteren zählen IL4 und IL13 zu den anti-inflammatorisch wirksamen Zytokinen. Im Rahmen einer Infektion mit Plasmodium falciparum kommt es zu einer Ausschüttung pro-inflammatorischer Zytokine, die eine wichtige Rolle in der Pathogenese der zerebralen Malaria, aber auch der Malaria-assoziierten Anämie zu spielen scheinen (Francischetti et al. 2008). Bei inflammatorischen Reaktionen werden pro-koagulative Effekte beobachtet (Hemmer et al. 1991), welche zu der Enstehung einer Anämie beitragen können. Im Tierversuch zeigen CD4-defiziente Mäuse, die in der Folge geringere Spiegel pro-inflammatorisch wirksamer Zytokine entwickeln, keine Zeichen einer zerebralen Malaria (Grau et al. 1986; Yanez et al. 1996). Somit könnte eine erhöhte Expression von IL13 durch die Unterdrückung der inflammatorischen Reaktion das Risiko einer Anämie verringern.

Der genaue Mechanismus, der hinter den beobachteten Effekten, die mit dem Vorkommen des rs $1800925^{T T}$-Genotyps assoziiert sind, steht, kann durch diese rein wirtsgenetische Assoziationsstudie nicht gezeigt werden. Es wäre jedoch vorstellbar, durch funktionelle Untersuchungen am Mausmodell, beispielsweise bei IL13-Knockout-Mäusen, nachzuweisen, dass erhöhte IL13-Spiegel tatsächlich zu einem erhöhten Risiko einer Infektion führen. Ein anderer Ansatz wäre, die Wirkung häufig wiederkehrender P.f.-Infektionen auf die Hämatopoese z.B. durch Knochenmarkspunktionen oder Messung des Anteils der Retikulozyten zu untersuchen. 


\subsection{Beta2-adrenerger Rezeptor ADRB2}

Der übiquitär vorkommende beta2-adrenerge Rezeptor ADRB2 scheint im Verlauf einer Malariainfektion eine wichtige Funktion zu spielen. So führt die Blockade des ADRB2Rezeptors auf Erythrozyten in vitro oder die Applikation eines Rezeptor-Antagonisten in Mäusen in vivo zu einer deutlich verminderten Infektionsrate (Murphy et al. 2006). Der beta2-adrenerge Rezeptor ist an ein G-Protein gekoppelt.

Das für den adrenergen beta2-Rezeptor kodierende Gen ist ebenso wie die Gene der Interleukine 4 und 13 auf Chromosom 5 lokalisiert (Sheppard et al. 1983). Es besteht aus nur einem Exon und hat eine Länge von 1242 Basenpaaren (Kobilka et al. 1987; Isaza et al. 2005). Das gesamte Exon sowie Bereiche der 5'- und 3'-Region wurde sequenziert, um bisher noch nicht beschriebene Varianten im Bereich des ADRB2-Gens zu detektieren. Der sequenzierte Abschnitt hat eine Gesamtlänge von ca. 3000 Basenpaaren. Die Sequenzierung wurde an 46 zufällig ausgewählten Proben einer anderen Studie aus dem gleichen Studiengebiet durchgeführt, je 23 Kontrollen und 23 Fälle mit klinischer Malaria.

Als Kandidaten für die Genotypisierung wurden zunächst die beiden Genvarianten ADRB2 R16G (rs1042713) und ADRB2 Q27E (rs1042714) ausgewählt, die einen Aminosäureaustausch im ADRB2-Protein zur Folge haben. Diese Varianten zeigten keine signifikanten Assoziationen mit dem Auftreten und dem Verlauf einer Malaria. Zusätzlich wurden sechs weitere Einzelvarianten aus der Promotor-Region und dem 3'-untranslatierten Abschnitt typisiert, welche sich in ihrer Allelfrequenz bei Afrikanern erheblich von der Frequenz bei Europäern unterschieden (ADRB2 rs17778257 [-1818], ADRB2 rs2400707 [-1343], ADRB2 rs2053044 [-1023], ADRB2 rs12654778 [-654], ADRB2 rs1864931 [+4088], ADRB2 rs3857420 [+4894]). Die Analyse der Daten ergab zunächst, dass jeweils zwei Varianten im Bereich des Promotors ein hohes Kopplungsungleichgewicht (engl. linkage disequilibrium, LD) aufwiesen (rs17778257 und rs12654778, LD = 99, rs2400707 und rs2053044, LD = 100). Da in der Assoziationsanalyse kein wesentlicher Unterschied zwischen den gekoppelten Varianten zu erwarten war, wurden die Varianten rs17778257 und rs2400707 nicht weiter betrachtet. Mit Hilfe der Software Plink (Purcell et al. 2007; Nothnagel et al. 2009) wurden durch eine in-silico-Genotypisierung durch Imputation der Informationen aus der Haplotypstruktur und den Genotypen der benachbarten Varianten die zusätzlichen Kandidaten $A D R B 2$ rs7702861 und ADRB2 rs4705271 identifiziert. Da auch diese beiden Varianten 
in einem hohen Kopplungsungleichgewicht zueinander standen (LD = 0,94), war es ausreichend, für die Assoziationsuntersuchung nur eine der beiden Varianten, rs4705271, zu betrachten.

Homozygote Träger des Allels rs $12654778^{T}$ hatten ein deutlich erhöhtes Risiko, an einer Malaria zu erkranken $\left(\mathrm{HR}=1,67, \mathrm{p}_{\mathrm{korr}}=0,035\right)$. Hingegen war der Genotyp TT der 3'UTR-Variante rs3857420 mit einem verminderten Risiko verbunden. Homozygote Träger des rs4705271 ${ }^{T}$-Allels zeigten mit einer HR von 0,71 ein deutlich geringeres Risiko, an einer Malaria zu erkranken $\left(p_{n o m}=0,003, p_{k o r r}=0,021\right)$. Auch für das Auftreten wiederholter Infektionen war das Risiko deutlich vermindert (IRR $=0,79, p_{\text {nom }}=0,0009, p_{\text {korr }}=0,0063$ ).

Eine Analyse der DNA-Sequenz im Bereich der Einzelvarianten mit Hilfe der Software „Promo” (Messeguer et al. 2002) ließ Rückschlüsse auf potentielle TranskriptionsfaktorBindungsstellen zu. Das C-Allel der 3'-UTR-Einzelvariante rs4705271 führt zu der Bildung einer zusätzlichen Bindungsstelle für den Transkriptionsfaktor "GR-alpha”, die möglicherweise eine geringere Expression des ADRB2-Gens zur Folge hat. Träger des G-Allels der mit dieser Variante durch ein starkes LD verbundenen Einzelmutation rs7702861 besitzen zwei zusätzlichen potentielle Bindungsstellen, für den Transkriptionsfaktor "GR-alpha”, und den Transkriptionsverstärker "AP-2alphaA". Das T-Allel der Variante rs3857420 führt zu einer zusätzliche Bindungsstelle für den Transkriptionsfaktor „FOXP3”, der die Expression von Genen steigern kann. Träger des Allels rs17778257 ${ }^{A}$ besitzen eine zusätzliche potentielle „TFII-I" Bindungsstelle. Dies ist ein Faktor, der ebenfalls die Gen-Expression fördert. Die Varianten rs12654778 und rs18649431 sind offenbar mit keiner Änderung der potentiellen Transkriptionsfaktor-Bindungsstellen verbunden.

Es zeigten sich verschiedene Assoziationen im Bereich des Promotors und der 3'- untranslatierten Region des ADRB2-Gens. Sämtliche der in dieser Studie mit dem Auftreten oder dem Verlauf einer Malaria assoziierten Einzelvarianten lagen entweder in einem potentiell funktionellen Bereich der DNA, der mögliche Bindungsstellen für Transkriptionsfaktoren beinhaltet, oder hatten ein hohes Kopplungsungleichgewicht mit einer potentiell funktionellen Einzelvariante. Daher ist durchaus wahrscheinlich, dass es durch die Basenaustausche, direkt oder indirekt, zu einer Beeinflussung der Genexpression des beta2adrenergen Rezeptors kam. Da eine medikamentöse Blockade des ADRB2-Rezeptors am Mausmodell, wie auch an humanen Zellen, zu einer verminderten parasitären Infektion von Erythrozyten führt (Harrison et al. 2003; Murphy et al. 2006), ist gut vorstellbar, dass 
eine verringerte Expression des Rezeptors einen ähnlichen Effekt zur Folge haben könnte.

Um diese rein empirischen Beobachtungen zu stützen, wäre der nächste Schritt eine funktionelle Analyse der Promotor-Aktivität mit Hilfe eines Luziferase-Assays (Gould und Subramani 1988). Eine weitere Möglichkeit stellt die Erfassung der ADRB2-Rezeptordichte auf Erythrozyten mit Hilfe von fluoreszierenden Antikörpern im FACS (engl. fluorescenceactivated cell sorter)-System dar. Auf diese Weise könnte über den Nachweis des ADRB2Rezeptors auf der Erythrozytenoberfläche die Rezeptordichte mit der Suszeptibilität für Malaria in Verbindung gesetzt werden und eine Korrelation der Dichte mit dem jeweiligen ADRB2-Genotyp erfolgen.

Eine Studie hat gezeigt, dass durch den zusätzlichen Einsatz von Betablockern im Rahmen einer Malariatherapie die einzusetzende Dosis des Standardtherapeutikums signifikant reduziert werden kann (Murphy et al. 2006). Möglicherweise könnte die zusätzliche Applikation von Betablockern dadurch einer Resistenzentwicklung von Plasmodien gegenüber Malariamedikamenten entgegen wirken. Weiterhin wäre vorstellbar, dass auch das Risiko von unerwünschten Wirkungen von Malariamedikamenten durch eine gegebenenfalls mögliche Reduzierung der Dosis bei Gabe in Kombination mit Betablockern verringert werden könnte.

Die Therapieresistenz stellt ein zunehmendes Problem in der Behandlung der Malaria dar. Ein Hauptgrund für die Entwicklung therapieresistenter Plasmodien liegt in der Anwendung der vorhandenen Medikamente in Monotherapie, häufig auch aus Kostengründen. Auf Grund dieser fortschreitenden Resitenzentwicklung ist letztendlich die Entwicklung neuer Therapiekonzepte unabdingbar. Ein Einsatz von Betablockern als Ergänzung zu der Malaria-Standardtherapie könnte helfen, den Zeitrahmen für die Entwicklung neuer Malariatherapeutika oder einer Malaria-Impfung zu erweitern. Würde die Evidenz für einen positiven Effekt von Betablockern in der Malaria-Therapie im Rahmen weiterer Studien und klinischer Tests bestätigt, wäre ein großflächigerer Einsatz ethisch vertretbar. Letztlich wäre auch aus ökonomischer Sicht die Therapie mit Betablockern zu befürworten, da die Kosten in einem auch für Entwicklungsländer finanzierbaren Rahmen lägen. Eine mögliche Einschränkung des Einsatzes von Betablockern in Kombination mit Standard -Therapeutika gegen Malaria stellt die Nebenwirkung der QT-Zeit-Verlängerung durch Chinin oder Lariam dar. Da Betablocker keinen direkten Einfluss auf die QT-Zeit der kardialen Reizüberleitung haben, aber bei einem angeborenen Long-QT-Syndrom so- 
gar therapeutisch eingesetzt werden können (Hayoun et al. 1995), wäre eine Kombination von Chinin oder Lariam und Betablockern dennoch denkbar. Jedoch sollte diese Therapie unter kontrollierten klinischen Bedingungen etabliert werden, um das Risiko der kardialen Komplikationen zu minimieren. 


\section{Zusammenfassung}

In dieser Arbeit wurden Assoziationen von Einzelvarianten der Gene IL4, IL13 und ADRB2 mit der Inzidenz von Malaria und Anämie bei Kindern aus Ghana untersucht.

1. Eine bereits beschriebene Assoziation einer Einzelvariante an Position -1112 der IL13Promotorregion mit Protektion vor dem Auftreten schwerer Anämien im Verlauf von Malariainfektionen konnte nicht eindeutig identifiziert werden. Jedoch ist das T-Allel dieser Genvariante auch in dieser Studie mit einem Trend in Richtung eines Schutzes vor moderaten Anämien verbunden. Allerdings zeigen die Träger dieser Genvariante gleichzeitig ein erhöhtes Risiko für das Auftreten von Plasmodium-falciparum-Parasitämien. Diese konträren Beobachtungen lassen sich möglicherweise durch eine gesteigerte Hämatopoese erklären. So ist vorstellbar, dass die bei Trägern der Genvariante IL13 $-1112^{T}$ im Vergleich zum Wildtyp häufigeren Parasitämien eine kompensatorische Steigerung der Hämatopoese zur Folge haben, wodurch sich wiederum ein Schutz vor dem Auftreten schwerer Anämien erklären ließe.

2. Es wurden Assoziationen mehrerer unabhängiger Einzelvarianten der ADRB2-Promotor- und 3' -UTR-Region mit dem Auftreten von Malaria-Episoden nachgewiesen. Möglicherweise wird durch diese Varianten die Expression des ADRB2-Gens und damit die Dichte von beta2-adrenergen Rezeptoren auf Erythrozyten beeinflusst. Dies könnte bei der Kontrolle von Plasmodium-falciparum-Infektionen und der Entstehung der Malaria eine Rolle spielen, da die Parasiten bei der Invasion der Erythrozyten funktionelle Teile des ADRB2-Rezeptors nutzen.

Somit wurden mehrere genetische Assoziationen identifiziert, die unabhängig voneinander Einfluss auf den Verlauf einer Malaria nehmen können.

Während im Falle der Promotor-Variante an Position -1112 des IL13-Gens eine bereits bekannte genetische Assoziation nicht eindeutig repliziert werden konnte, jedoch in Form 
eines Trends zu erkennen ist, wirft der genaue Zusammenhang zwischen den beiden beobachteten Effekten, Schutz vor Anämie, aber gleichzeitig das erhöhte Risiko einer Parasitämie, noch Fragen auf, die in dieser Arbeit nicht abschließend beantwortet werden konnten und durch funktionelle Untersuchungen geklärt werden sollten.

Im Falle des ADRB2-Gens wird ein bereits an Mäusen in vivo beschriebener Mechanismus auf der Ebene der genetischen Assoziationsuntersuchung am Menschen bestätigt. 


\section{Anhang: Tabelle 6.1-6.16}

Tabelle 6.1 Mastermix Abschnitt 1

\begin{tabular}{|c|cc|c|cc|}
\hline & & & $\mu \mathrm{L} / \mathrm{rxn}$ & finale Konzentration & \\
\hline \hline 10x Puffer BD, ohne $\mathrm{MgCl}_{2}$ & & & 1,00 & $1 \mathrm{x}$ & \\
\hline Solution S & & & 1,00 & $1 \mathrm{x}$ & \\
\hline $\mathrm{MgCl}_{2}$ & 25 & $\mathrm{mM}$ & 0,80 & 2 & $\mathrm{mM}$ \\
\hline vorwärts-Primer & 10 & $\mathrm{pmol} / \mu \mathrm{l}$ & 1,00 & 1,00 & $\mu \mathrm{M}$ \\
\hline rückwärts-Primer & 10 & $\mathrm{pmol} / \mu \mathrm{l}$ & 1,00 & 1,00 & $\mu \mathrm{M}$ \\
\hline $\mathrm{dNTPs}$ & 10 & $\mathrm{mM} \mathrm{each}$ & 0,20 & 200 & $\mu \mathrm{M}$ \\
\hline Taq-Polymerase & 5 & $\mathrm{U} / \mu \mathrm{l}$ & 0,20 & 1,00 & $\mathrm{U} / \mathrm{rxn}$ \\
\hline DNA & 5 & $\mathrm{ng} / \mu \mathrm{l}$ & 2,00 & 10,00 & $\mathrm{ng} / \mathrm{rxn}$ \\
\hline destilliertes Wasser & & & 2,80 & & \\
\hline Gesamt-Volumen & & & 10,00 & & \\
\hline
\end{tabular}

Tabelle 6.2 Mastermix Abschnitt 2

\begin{tabular}{|c|cc|c|cc|}
\hline & & & $\mu \mathrm{L} / \mathrm{rxn}$ & \multicolumn{2}{|c|}{ finale Konzentration } \\
\hline \hline 10x Puffer BD, ohne $\mathrm{MgCl}_{2}$ & & & 1,00 & $1 \mathrm{x}$ & \\
\hline Solution S & & & 1,00 & $1 \mathrm{x}$ & \\
\hline $\mathrm{MgCl}_{2}$ & 25 & $\mathrm{mM}$ & 1,00 & 2,5 & $\mathrm{mM}$ \\
\hline vorwärts-Primer & 10 & $\mathrm{pmol} / \mu \mathrm{l}$ & 1,00 & 1,00 & $\mu \mathrm{M}$ \\
\hline rückwärts-Primer & 10 & $\mathrm{pmol} / \mu \mathrm{l}$ & 1,00 & 1,00 & $\mu \mathrm{M}$ \\
\hline $\mathrm{dNTPs}$ & 10 & $\mathrm{mM}$ each & 0,20 & 200 & $\mu \mathrm{M}$ \\
\hline Taq-Polymerase & 5 & $\mathrm{U} / \mu \mathrm{l}$ & 0,20 & 1,00 & $\mathrm{U} / \mathrm{rxn}$ \\
\hline DNA & 5 & $\mathrm{ng} / \mu \mathrm{l}$ & 2,00 & 10,00 & $\mathrm{ng} / \mathrm{rxn}$ \\
\hline destilliertes Wasser & & & 2,60 & & \\
\hline Gesamt-Volumen & & & 10,00 & & \\
\hline
\end{tabular}


Tabelle 6.3 Mastermix Abschnitt 3

\begin{tabular}{|c|cc|c|cc|}
\hline & & & $\mu \mathrm{L} / \mathrm{rxn}$ & \multicolumn{2}{|c|}{ finale Konzentration } \\
\hline \hline 10x Puffer $\mathrm{BD}$, ohne $\mathrm{MgCl}_{2}$ & & & 1,00 & $1 \mathrm{x}$ & \\
\hline Solution S & & & 1,00 & $1 \mathrm{x}$ & \\
\hline $\mathrm{MgCl}_{2}$ & 25 & $\mathrm{mM}$ & 0,60 & 1,5 & $\mathrm{mM}$ \\
\hline vorwärts-Primer & 10 & $\mathrm{pmol} / \mu \mathrm{l}$ & 1,00 & 1,00 & $\mu \mathrm{M}$ \\
\hline rückwärts-Primer & 10 & $\mathrm{pmol} / \mu \mathrm{l}$ & 1,00 & 1,00 & $\mu \mathrm{M}$ \\
\hline $\mathrm{dNTPs}$ & 10 & $\mathrm{mM}$ each & 0,20 & 200 & $\mu \mathrm{M}$ \\
\hline Taq-Polymerase & 5 & $\mathrm{U} / \mu \mathrm{l}$ & 0,20 & 1,00 & $\mathrm{U} / \mathrm{rxn}$ \\
\hline DNA & 5 & $\mathrm{ng} / \mu \mathrm{l}$ & 2,00 & 10,00 & $\mathrm{ng} / \mathrm{rxn}$ \\
\hline destilliertes Wasser & & & 3,00 & & \\
\hline Gesamt-Volumen & & & 10,00 & & \\
\hline
\end{tabular}

Tabelle 6.4 Mastermix Abschnitt 4

\begin{tabular}{|c|cc|c|cc|}
\hline & & & $\mu \mathrm{L} / \mathrm{rxn}$ & \multicolumn{2}{|c|}{ finale Konzentration } \\
\hline \hline 10x Puffer BD, ohne $\mathrm{MgCl}_{2}$ & & & 1,00 & $1 \mathrm{x}$ & \\
\hline Solution S & & & 1,00 & $1 \mathrm{x}$ & \\
\hline $\mathrm{MgCl}_{2}$ & 25 & $\mathrm{mM}$ & 0,80 & 2 & $\mathrm{mM}$ \\
\hline vorwärts-Primer & 10 & $\mathrm{pmol} / \mu \mathrm{l}$ & 1,00 & 1,00 & $\mu \mathrm{M}$ \\
\hline rückwärts-Primer & 10 & $\mathrm{pmol} / \mu \mathrm{l}$ & 1,00 & 1,00 & $\mu \mathrm{M}$ \\
\hline $\mathrm{dNTPs}$ & 10 & $\mathrm{mM}$ each & 0,20 & 200 & $\mu \mathrm{M}$ \\
\hline Taq-Polymerase & 5 & $\mathrm{U} / \mu \mathrm{l}$ & 0,20 & 1,00 & $\mathrm{U} / \mathrm{rxn}$ \\
\hline DNA & 5 & $\mathrm{ng} / \mu \mathrm{l}$ & 2,00 & 10,00 & $\mathrm{ng} / \mathrm{rxn}$ \\
\hline destilliertes Wasser & & & 2,80 & & \\
\hline Gesamt-Volumen & & & 10,00 & & \\
\hline
\end{tabular}


Tabelle 6.5 Mastermix Abschnitt 5

\begin{tabular}{|c|cc|c|cc|}
\hline & & & $\mu \mathrm{L} / \mathrm{rxn}$ & finale Konzentration & \\
\hline \hline 10x Puffer BD, ohne $\mathrm{MgCl}_{2}$ & & & 1,00 & $1 \mathrm{x}$ & \\
\hline $\mathrm{MgCl}_{2}$ & 25 & $\mathrm{mM}$ & 0,60 & 1,5 & $\mathrm{mM}$ \\
\hline vorwärts-Primer & 10 & $\mathrm{pmol} / \mu \mathrm{l}$ & 1,00 & 1,00 & $\mu \mathrm{M}$ \\
\hline rückwärts-Primer & 10 & $\mathrm{pmol} / \mu \mathrm{l}$ & 1,00 & 1,00 & $\mu \mathrm{M}$ \\
\hline $\mathrm{dNTPs}$ & 10 & $\mathrm{mM} \mathrm{each}$ & 0,20 & 200 & $\mu \mathrm{M}$ \\
\hline Taq-Polymerase & 5 & $\mathrm{U} / \mu \mathrm{l}$ & 0,20 & 1,00 & $\mathrm{U} / \mathrm{rxn}$ \\
\hline DNA & 5 & $\mathrm{ng} / \mu \mathrm{l}$ & 2,00 & 10,00 & $\mathrm{ng} / \mathrm{rxn}$ \\
\hline destilliertes Wasser & & & 4,00 & & \\
\hline Gesamt-Volumen & & & 10,00 & & \\
\hline
\end{tabular}

Tabelle 6.6 Mastermix Big-Dye-Reaktion

\begin{tabular}{|c|cc|c|cc|}
\hline & & & $\mu \mathrm{L} / \mathrm{rxn}$ & finale Konzentration & \\
\hline \hline Big-Dye & & & 4,00 & $1 \mathrm{x}$ & \\
\hline vorwärts-Primer & 10 & $\mathrm{pmol} / \mu \mathrm{l}$ & 0,50 & 1,00 & $\mu \mathrm{M}$ \\
\hline rückwärts-Primer & 10 & $\mathrm{pmol} / \mu \mathrm{l}$ & 0,50 & 1,00 & $\mu \mathrm{M}$ \\
\hline PCR-Produkt & 10 & $\mathrm{mM}$ each & 1,00 & 200 & $\mu \mathrm{M}$ \\
\hline destilliertes Wasser & & & 10,00 & & \\
\hline Gesamt-Volumen & & & 20,00 & & \\
\hline
\end{tabular}

Tabelle 6.7 Sequenzierung: Thermozykler-Protokolle

\begin{tabular}{|c|c|c|c|c|c|c|}
\hline & Zeit & 1. Abschnitt & 2. Abschnitt & 3. Abschnitt & 4. Abschnitt & 5 . Abschnitt \\
\hline \hline Initiale Denaturierung & $5^{\prime}$ & $95,0^{\circ} \mathrm{C}$ & $95,0^{\circ} \mathrm{C}$ & $95,0^{\circ} \mathrm{C}$ & $95,0^{\circ} \mathrm{C}$ & $95,0^{\circ} \mathrm{C}$ \\
\hline \hline Anzahl Zyklen & & $34 \mathrm{x}$ & $34 \mathrm{x}$ & $34 \mathrm{x}$ & $34 \mathrm{x}$ & $34 \mathrm{x}$ \\
\hline Denaturierung & $30^{\prime \prime}$ & $94,0^{\circ} \mathrm{C}$ & $94,0^{\circ} \mathrm{C}$ & $94,0^{\circ} \mathrm{C}$ & $94,0^{\circ} \mathrm{C}$ & $94,0^{\circ} \mathrm{C}$ \\
\hline Annealing & $1^{\prime}$ & $57,6^{\circ} \mathrm{C}$ & $62,3^{\circ} \mathrm{C}$ & $62,3^{\circ} \mathrm{C}$ & $53,0^{\circ} \mathrm{C}$ & $59,3^{\circ} \mathrm{C}$ \\
\hline Extension & $1^{\prime}$ & $72,0^{\circ} \mathrm{C}$ & $72,0^{\circ} \mathrm{C}$ & $72,0^{\circ} \mathrm{C}$ & $72,0^{\circ} \mathrm{C}$ & $72,0^{\circ} \mathrm{C}$ \\
\hline \hline Terminale Extension & $10^{\prime}$ & $72,0^{\circ} \mathrm{C}$ & $72,0^{\circ} \mathrm{C}$ & $72,0^{\circ} \mathrm{C}$ & $72,0^{\circ} \mathrm{C}$ & $72,0^{\circ} \mathrm{C}$ \\
\hline
\end{tabular}


Tabelle 6.8 Big-Dye-Reaktion: Thermozykler-Protokoll

\begin{tabular}{|c|c|c|}
\hline & Zeit & Big-Dye \\
\hline \hline Initiale Denaturierung & $3^{\prime}$ & $96,0^{\circ} \mathrm{C}$ \\
\hline \hline Anzahl Zyklen & & $25 \mathrm{x}$ \\
\hline Denaturierung & $30^{\prime \prime}$ & $96,0^{\circ} \mathrm{C}$ \\
\hline Annealing & $15^{\prime}$ & $50,0^{\circ} \mathrm{C}$ \\
\hline Extension & $4^{\prime}$ & $60,0^{\circ} \mathrm{C}$ \\
\hline
\end{tabular}

Tabelle 6.9 LightTyper Assay: IL13 -1112

\begin{tabular}{|c|c|c|c|c|c|}
\hline FirePol-Mix & & & $\mu \mathrm{L} / \mathrm{rxn}$ & finale Konzentration & \\
\hline 10x Puffer BD, ohne $\mathrm{MgCl}_{2}$ & & & 1,00 & $1 \mathrm{x}$ & \\
\hline Solution S & & & 1,00 & $1 \mathrm{x}$ & \\
\hline $\mathrm{MgCl}_{2}$ & 25 & $\mathrm{mM}$ & 0,80 & 2 & $\mathrm{mM}$ \\
\hline vorwärts-Primer & & $\mathrm{pmol} / \mu \mathrm{l}$ & 1,00 & 1,00 & $\mu \mathrm{M}$ \\
\hline rückwärts-Primer & 10 & $\mathrm{pmol} / \mu \mathrm{l}$ & 1,00 & 1,00 & $\mu \mathrm{M}$ \\
\hline Anker-Oligonucleotid & 5 & $\mathrm{pmol} / \mu \mathrm{l}$ & 0,50 & 0,25 & $\mu \mathrm{M}$ \\
\hline Sensor-Oligonucleotid & 5 & $\mathrm{pmol} / \mu \mathrm{l}$ & 0,50 & 0,25 & $\mu \mathrm{M}$ \\
\hline dNTPs & 10 & $\mathrm{mM}$ each & 0,20 & 200 & $\mu \mathrm{M}$ \\
\hline Taq-Polymerase & 5 & $\mathrm{U} / \mu \mathrm{l}$ & 0,20 & 1,00 & $\mathrm{U} / \mathrm{rxn}$ \\
\hline DNA & 5 & $\mathrm{ng} / \mu \mathrm{l}$ & 2,00 & 10,00 & $\mathrm{ng} / \mathrm{rxn}$ \\
\hline destilliertes Wasser & & & 1,80 & & \\
\hline Gesamt-Volumen & & & 10,00 & & \\
\hline
\end{tabular}


Tabelle 6.10 LightTyper Assay: IL13 R110Q

\begin{tabular}{|c|cc|c|cc|}
\hline FirePol-Mix & & & $\mu \mathrm{L} / \mathrm{rxn}$ & finale Konzentration & \\
\hline \hline 10x Puffer BD, ohne $\mathrm{MgCl}_{2}$ & & & 1,00 & $1 \mathrm{x}$ & \\
\hline Solution S & & & 1,00 & $1 \mathrm{x}$ & \\
\hline $\mathrm{MgCl}_{2}$ & 25 & $\mathrm{mM}$ & 0,80 & 2 & $\mathrm{mM}$ \\
\hline vorwärts-Primer & 10 & $\mathrm{pmol} / \mu \mathrm{l}$ & 0,20 & 0,20 & $\mu \mathrm{M}$ \\
\hline rückwärts-Primer & 10 & $\mathrm{pmol} / \mu \mathrm{l}$ & 1,00 & 1,00 & $\mu \mathrm{M}$ \\
\hline Anker-Oligonucleotid & 5 & $\mathrm{pmol} / \mu \mathrm{l}$ & 0,50 & 0,25 & $\mu \mathrm{M}$ \\
\hline Sensor-Oligonucleotid & 5 & $\mathrm{pmol} / \mu \mathrm{l}$ & 0,50 & 0,25 & $\mu \mathrm{M}$ \\
\hline dNTPs & 10 & $\mathrm{mM}$ each & 0,20 & 200 & $\mu \mathrm{M}$ \\
\hline Taq-Polymerase & 5 & $\mathrm{U} / \mu \mathrm{l}$ & 0,20 & 1,00 & $\mathrm{U} / \mathrm{rxn}$ \\
\hline DNA & 5 & $\mathrm{ng} / \mu \mathrm{l}$ & 2,00 & 10,00 & $\mathrm{ng} / \mathrm{rxn}$ \\
\hline destilliertes Wasser & & & 2,60 & & \\
\hline Gesamt-Volumen & & & 10,00 & & \\
\hline
\end{tabular}

Tabelle 6.11 LightTyper Assay: IL4 -1098

\begin{tabular}{|c|cc|c|cc|}
\hline FirePol-Mix & & & $\mu \mathrm{L} / \mathrm{rxn}$ & finale Konzentration & \\
\hline \hline 10x Puffer BD, ohne $\mathrm{MgCl}_{2}$ & & & 1,00 & $1 \mathrm{x}$ & \\
\hline Solution S & & & 1,00 & $1 \mathrm{x}$ & $\mathrm{mM}$ \\
\hline $\mathrm{MgCl}_{2}$ & 25 & $\mathrm{mM}$ & 0,80 & 2 & $\mu \mathrm{M}$ \\
\hline vorwärts-Primer & 10 & $\mathrm{pmol} / \mu \mathrm{l}$ & 1,00 & 1,00 & $\mu \mathrm{M}$ \\
\hline rückwärts-Primer & 10 & $\mathrm{pmol} / \mu \mathrm{l}$ & 0,20 & 0,20 & $\mu \mathrm{M}$ \\
\hline Anker-Oligonucleotid & 5 & $\mathrm{pmol} / \mu \mathrm{l}$ & 0,50 & 0,25 & $\mu \mathrm{M}$ \\
\hline Sensor-Oligonucleotid & 5 & $\mathrm{pmol} / \mu \mathrm{l}$ & 0,50 & 0,25 & $\mathrm{U} / \mathrm{rxn}$ \\
\hline dNTPs & 10 & $\mathrm{mM}$ each & 0,20 & 200 & \\
\hline Taq-Polymerase & 5 & $\mathrm{U} / \mu \mathrm{l}$ & 0,20 & 1,00 & \\
\hline DNA & 5 & $\mathrm{ng} / \mu \mathrm{l}$ & 2,00 & 10,00 & \\
\hline destilliertes Wasser & & & 2,60 & & \\
\hline Gesamt-Volumen & & & 10,00 & & \\
\hline
\end{tabular}


Tabelle 6.12 LightTyper Assay: IL4 -33

\begin{tabular}{|c|cc|c|cc|}
\hline FirePol-Mix & & & $\mu \mathrm{L} / \mathrm{rxn}$ & finale Konzentration & \\
\hline \hline 10x Puffer BD, ohne $\mathrm{MgCl}_{2}$ & & & 1,00 & $1 \mathrm{x}$ & \\
\hline Solution S & & & 1,00 & $1 \mathrm{x}$ & \\
\hline $\mathrm{MgCl}_{2}$ & 25 & $\mathrm{mM}$ & 1,20 & 3 & $\mathrm{mM}$ \\
\hline vorwärts-Primer & 10 & $\mathrm{pmol} / \mu \mathrm{l}$ & 0,20 & 0,20 & $\mu \mathrm{M}$ \\
\hline rückwärts-Primer & 10 & $\mathrm{pmol} / \mu \mathrm{l}$ & 1,00 & 1,00 & $\mu \mathrm{M}$ \\
\hline Anker-Oligonucleotid & 5 & $\mathrm{pmol} / \mu \mathrm{l}$ & 0,50 & 0,25 & $\mu \mathrm{M}$ \\
\hline Sensor-Oligonucleotid & 5 & $\mathrm{pmol} / \mu \mathrm{l}$ & 0,50 & 0,25 & $\mu \mathrm{M}$ \\
\hline dNTPs & 10 & $\mathrm{mM}$ each & 0,20 & 200 & $\mu \mathrm{M}$ \\
\hline Taq-Polymerase & 5 & $\mathrm{U} / \mu \mathrm{l}$ & 0,20 & 1,00 & $\mathrm{U} / \mathrm{rxn}$ \\
\hline DNA & 5 & $\mathrm{ng} / \mu \mathrm{l}$ & 2,00 & 10,00 & $\mathrm{ng} / \mathrm{rxn}$ \\
\hline destilliertes Wasser & & & 2,20 & & \\
\hline Gesamt-Volumen & & & 10,00 & & \\
\hline
\end{tabular}

Tabelle 6.13 LightTyper Assay: IL4 -589

\begin{tabular}{|c|cc|c|cc|}
\hline FirePol-Mix & & & $\mu \mathrm{L} / \mathrm{rxn}$ & \multicolumn{2}{|c|}{ finale Konzentration } \\
\hline \hline 10x Puffer BD, ohne $\mathrm{MgCl}_{2}$ & & & 1,00 & $1 \mathrm{x}$ & \\
\hline Solution $\mathrm{S}$ & & & 1,00 & $1 \mathrm{x}$ & $\mathrm{mM}$ \\
\hline $\mathrm{MgCl}_{2}$ & 25 & $\mathrm{mM}$ & 0,80 & 2 & $\mu \mathrm{M}$ \\
\hline vorwärts-Primer & 10 & $\mathrm{pmol} / \mu \mathrm{l}$ & 1,00 & 1,00 & $\mu \mathrm{M}$ \\
\hline rückwärts-Primer & 10 & $\mathrm{pmol} / \mu \mathrm{l}$ & 1,00 & 1,00 & $\mu \mathrm{M}$ \\
\hline Anker-Oligonucleotid & 5 & $\mathrm{pmol} / \mu \mathrm{l}$ & 0,50 & 0,25 & $\mu \mathrm{M}$ \\
\hline Sensor-Oligonucleotid & 5 & $\mathrm{pmol} / \mu \mathrm{l}$ & 0,50 & 0,25 & $\mathrm{U} / \mathrm{rxn}$ \\
\hline dNTPs & 10 & $\mathrm{mM}$ each & 0,20 & 200 & \\
\hline Taq-Polymerase & 5 & $\mathrm{U} / \mu \mathrm{l}$ & 0,20 & 1,00 & \\
\hline DNA & 5 & $\mathrm{ng} / \mu \mathrm{l}$ & 2,00 & 10,00 & \\
\hline destilliertes Wasser & & & 1,80 & & \\
\hline Gesamt-Volumen & & & 10,00 & & \\
\hline
\end{tabular}


Tabelle 6.14 LightTyper Assay: ADRB2 R16G

\begin{tabular}{|c|cc|c|cc|}
\hline FirePol-Mix & & & $\mu \mathrm{L} / \mathrm{rxn}$ & finale Konzentration & \\
\hline \hline 10x Puffer BD, ohne $\mathrm{MgCl}_{2}$ & & & 1,00 & $1 \mathrm{x}$ & \\
\hline Solution S & & & 1,00 & $1 \mathrm{x}$ & \\
\hline $\mathrm{MgCl}_{2}$ & 25 & $\mathrm{mM}$ & 0,80 & 2 & $\mathrm{mM}$ \\
\hline vorwärts-Primer & 10 & $\mathrm{pmol} / \mu \mathrm{l}$ & 1,00 & 1,00 & $\mu \mathrm{M}$ \\
\hline rückwärts-Primer & 10 & $\mathrm{pmol} / \mu \mathrm{l}$ & 0,20 & 1,00 & $\mu \mathrm{M}$ \\
\hline Anker-Oligonucleotid & 5 & $\mathrm{pmol} / \mu \mathrm{l}$ & 0,50 & 0,25 & $\mu \mathrm{M}$ \\
\hline Sensor-Oligonucleotid & 5 & $\mathrm{pmol} / \mu \mathrm{l}$ & 0,50 & 0,25 & $\mu \mathrm{M}$ \\
\hline dNTPs & 10 & $\mathrm{mM}$ each & 0,20 & 200 & $\mu \mathrm{M}$ \\
\hline Taq-Polymerase & 5 & $\mathrm{U} / \mu \mathrm{l}$ & 0,20 & 1,00 & $\mathrm{U} / \mathrm{rxn}$ \\
\hline DNA & 5 & $\mathrm{ng} / \mu \mathrm{l}$ & 2,00 & 10,00 & $\mathrm{ng} / \mathrm{rxn}$ \\
\hline destilliertes Wasser & & & 2,60 & & \\
\hline Gesamt-Volumen & & & 10,00 & & \\
\hline
\end{tabular}

Tabelle 6.15 LightTyper Assay: ADRB2 Q27E

\begin{tabular}{|c|cc|c|cc|}
\hline FirePol-Mix & & & $\mu \mathrm{L} / \mathrm{rxn}$ & finale Konzentration & \\
\hline \hline 10x Puffer BD, ohne $\mathrm{MgCl}_{2}$ & & & 1,00 & $1 \mathrm{x}$ & \\
\hline Solution $\mathrm{S}$ & & & 1,00 & $1 \mathrm{x}$ & $\mathrm{mM}$ \\
\hline $\mathrm{MgCl}_{2}$ & 25 & $\mathrm{mM}$ & 0,80 & 2 & $\mu \mathrm{M}$ \\
\hline vorwärts-Primer & 10 & $\mathrm{pmol} / \mu \mathrm{l}$ & 0,20 & 1,00 & $\mu \mathrm{M}$ \\
\hline rückwärts-Primer & 10 & $\mathrm{pmol} / \mu \mathrm{l}$ & 1,00 & 1,00 & $\mu \mathrm{M}$ \\
\hline Anker-Oligonucleotid & 5 & $\mathrm{pmol} / \mu \mathrm{l}$ & 0,50 & 0,25 & $\mu \mathrm{M}$ \\
\hline Sensor-Oligonucleotid & 5 & $\mathrm{pmol} / \mu \mathrm{l}$ & 0,50 & 0,25 & $\mathrm{U} / \mathrm{rxn}$ \\
\hline dNTPs & 10 & $\mathrm{mM}$ each & 0,20 & 200 & \\
\hline Taq-Polymerase & 5 & $\mathrm{U} / \mu \mathrm{l}$ & 0,20 & 1,00 & \\
\hline DNA & 5 & $\mathrm{ng} / \mu \mathrm{l}$ & 2,00 & 10,00 & \\
\hline destilliertes Wasser & & & 2,60 & & \\
\hline Gesamt-Volumen & & & 10,00 & & \\
\hline
\end{tabular}


Tabelle 6.16 LightTyper: Thermozykler-Protokoll

\begin{tabular}{|c|c|c|}
\hline & Zeit & \\
\hline \hline Initiale Denaturierung & $3^{\prime}$ & $94^{\circ} \mathrm{C}$ \\
\hline \hline Anzahl Zyklen & & $45 \mathrm{x}$ \\
\hline Denaturierung & $20^{\prime \prime}$ & $94^{\circ} \mathrm{C}$ \\
\hline Annealing & $30^{\prime \prime}$ & $55^{\circ} \mathrm{C}$ \\
\hline Extension & $30^{\prime \prime}$ & $72^{\circ} \mathrm{C}$ \\
\hline \hline Terminale Extension & $5^{\prime}$ & $72^{\circ} \mathrm{C}$ \\
\hline
\end{tabular}




\section{Literaturverzeichnis}

Ahren B, Schersten B (1986): Beta 2-adrenoceptor induced increase of plasma insulin levels in man: evidence of direct and indirect B-cell stimulation and liver effects. Diabetes $\operatorname{Res} \underline{3}, 443-445$

Ahrens RC (1990): Skeletal muscle tremor and the influence of adrenergic drugs. J Asthma $27,11-20$

Applied Biosystems (2010): Applied Biosystems ABI PRISM 3100-Avant Genetic Analyzer. Verfügbar unter http://docs . appliedbiosystems.com/pebiodocs/00105067. pdf Abrufdatum: 28.6.2010

Bakris GL, Hart P, Ritz E (2006): Beta blockers in the management of chronic kidney disease. Kidney Int 70, 1905-1913

Barnes KC, Grant AV, Gao P (2005): A review of the genetic epidemiology of resistance to parasitic disease and atopic asthma: common variants for common phenotypes? Curr Opin Allergy Clin Immunol $\underline{5}, 379-385$

Barrett JC, Fry B, Maller J, Daly MJ (2005): Haploview: analysis and visualization of ld and haplotype maps. Bioinformatics 21, 263-265

Cameron L, Webster RB, Strempel JM, Kiesler P, Kabesch M, Ramachandran H, Yu L, Stern DA, Graves PE, Lohman IC et al. (2006): Th2 cell-selective enhancement of human il13 transcription by il13-1112c $>t$, a polymorphism associated with allergic inflammation. J Immunol 177, 8633-8642

Cates S (2006): Ncbi: National center for biotechnology information. Verfügbar unter http://www.cdc.gov/ncidod/EID/vol11no01/04-0519.htm Abrufdatum: 28.6.2010 
Chorzempa A, Tabloski P (2002): Post myocardial infarction treatment in the older adult. Dimens Crit Care Nurs 21, 20-25

Cox DR (1972): Regression models and life-tables. J Roy Statist Soc Ser B ㅆ4, 187-220

4D International (2010): 4D 6.8. Verfügbar unter http: //www . de.4d. com Abrufdatum: 28.6.2010

Davis E, Loiacono R, Summers RJ (2008): The rush to adrenaline: drugs in sport acting on the beta-adrenergic system. Br J Pharmacol 154, 584-597

Doermer P, Dietrich M, Kern P, Horstmann RD (1983): Ineffective erythropoiesis in acute human P. falciparum malaria. Blut $\underline{46}, 279-288$

Domarle O, Migot-Nabias F, Pilkington H, Elissa N, Toure FS, Mayombo J, Cot M, Deloron $P$ (2002): Family analysis of malaria infection in dienga, gabon. Am J Trop Med Hyg 66, 124-129

Dudbridge F (2008): Likelihood-based association analysis for nuclear families and unrelated subjects with missing genotype data. Hum Hered $\underline{66}, 87-98$

Enserink M (2008): Epidemiology. lower malaria numbers reflect better estimates and a glimmer of hope. Science $\underline{321}, 1620$

FDA Food and Drug Administration (2010): GCP - Good Clinical Practice Handbooks. Verfügbar unter http: //www.gmppublications.com/store/GCP.html Abrufdatum: 28.6.2010

Fish SC, Donaldson DD, Goldman SJ, Williams CM, Kasaian MT (2005): Ige generation and mast cell effector function in mice deficient in il-4 and il-13. J Immunol 174, 7716 7724

Flint J, Harding RM, Boyce AJ, Clegg JB (1998): The population genetics of the haemoglobinopathies. Baillieres Clin Haematol 11, 1-51

Flori L, Kumulungui B, Aucan C, Esnault C, Traore AS, Fumoux F, Rihet P (2003): Linkage and association between plasmodium falciparum blood infection levels and chromosome 5q31-q33. Genes Immun $\underline{4}, 265-268$ 
Frances F, Corella D, Sorli JV, Guillen M, Gonzalez JI, Portoles O (2005): Validating a rapid method for detecting common polymorphisms in the APOA5 gene by melting curve analysis using LightTyper. Clin Chem 51, 1279-1282

Francischetti IM, Seydel KB, Monteiro RQ (2008): Blood coagulation, inflammation, and malaria. Microcirculation $\underline{15}, 81-107$

Gaeta BA (2000): Blast on the web. Biotechniques $\underline{28}, 436,438,440$

Garcia A, Marquet S, Bucheton B, Hillaire D, Cot M, Fievet N, Dessein AJ, Abel L (1998): Linkage analysis of blood plasmodium falciparum levels: interest of the 5q31-q33 chromosome region. Am J Trop Med Hyg 58, 705-709

General Medical Council (2010): Good Medical Practice (GMP). Verfügbar unter http: //www.ecompendium.nhs.uk/good-medical-practice.asp Abrufdatum: 28.6.2010

Gould SJ, Subramani S (1988): Firefly luciferase as a tool in molecular and cell biology. Anal Biochem 175, 5-13

Grau GE, Piguet PF, Engers HD, Louis JA, Vassalli P, Lambert PH (1986): L3T4+ T lymphocytes play a major role in the pathogenesis of murine cerebral malaria. J Immunol 137, 2348-2354

Greenwood BM, Bradley AK, Greenwood AM, Byass P, Jammeh K, Marsh K, Tulloch S, Oldfield FS, Hayes R (1987): Mortality and morbidity from malaria among children in a rural area of the gambia, west africa. Trans R Soc Trop Med Hyg $\underline{81}, 478-486$

Greenwood B, Marsh K, Snow R (1991): Why do some african children develop severe malaria? Parasitol Today $7,277-281$

Gupta S, Trenholme K, Anderson RM, Day KP (1994): Antigenic diversity and the transmission dynamics of plasmodium falciparum. Science 263, 961-963

Gupta S, Snow RW, Donnelly CA, Marsh K, Newbold C (1999): Immunity to non-cerebral severe malaria is acquired after one or two infections. Nat Med $\underline{5}, 340-343$ 
Haagerup A, Bjerke T, Schiotz PO, Binderup HG, Dahl R, Kruse TA (2002): Asthma and atopy - a total genome scan for susceptibility genes. Allergy $\underline{57}, 680-686$

Harrison T, Samuel BU, Akompong T, Hamm H, Mohandas N, Lomasney JW, Haldar K (2003): Erythrocyte g protein-coupled receptor signaling in malarial infection. Science $\underline{301}, 1734-1736$

Hayoun B, Lupoglazoff JM, Magnier S, Denjoy I, Casasoprana A (1995): [Congenital long QT syndrome: an elective indication for betablocker treatment. Apropos of 5 cases]. Arch Mal Coeur Vaiss $\underline{88}, 737-742$

Hemmer CJ, Kern P, Holst FG, Radtke KP, Egbring R, Bierhaus A, Nawroth PP, Dietrich M (1991): Activation of the host response in human Plasmodium falciparum malaria: relation of parasitemia to tumor necrosis factor/cachectin, thrombin-antithrombin III, and protein C levels. Am J Med 91, 37-44

Heussler VT, Rottenberg S, Schwab R, Kuenzi P, Fernandez PC, McKellar S, Shiels B, Chen ZJ, Orth K, Wallach D et al. (2002): Hijacking of host cell ikk signalosomes by the transforming parasite theileria. Science 298, 1033-1036

Hill AV (1998): The immunogenetics of human infectious diseases. Annu Rev Immunol 16, 593-617

Hill AV (2001): The genomics and genetics of human infectious disease susceptibility. Annu Rev Genomics Hum Genet 2, 373-400

Hill AV, Elvin J, Willis AC, Aidoo M, Allsopp CE, Gotch FM, Gao XM, Takiguchi M, Greenwood BM, Townsend AR et al. (1992): Molecular analysis of the association of hla-b53 and resistance to severe malaria. Nature $\underline{360}, 434-439$

Hill AV, Jepson A, Plebanski M, Gilbert SC (1997): Genetic analysis of host-parasite coevolution in human malaria. Philos Trans R Soc Lond B Biol Sci 352, 1317-1325

Hoffjan S, Ostrovnaja I, Nicolae D, Newman DL, Nicolae R, Gangnon R, Steiner L, Walker K, Reynolds R, Greene D et al. (2004): Genetic variation in immunoregulatory pathways and atopic phenotypes in infancy. J Allergy Clin Immunol 113, 511-518 
Hummelshoj T, Bodtger U, Datta P, Malling HJ, Oturai A, Poulsen LK, Ryder LP, Sorensen PS, Svejgaard E, Svejgaard A (2003): Association between an interleukin-13 promoter polymorphism and atopy. Eur J Immunogenet 30, 355-359

Imbs JL, Miesch F, Schwartz J, Velly J, Leclerc G, Mann A, Wermuth CG (1977): A potent new beta2-adrenoceptor blocking agent. Br J Pharmacol 60, 357-362

Isaza C, Henao J, Ramirez E, Cuesta F, Cacabelos R (2005): Polymorphic variants of the beta2-adrenergic receptor (adrb2) gene and adrb2-related propanolol-induced dyslipidemia in the colombian population. Methods Find Exp Clin Pharmacol 27, 237-244

Jones MK, Good MF (2006): Malaria parasites up close. Nat Med 12, 170-171

KCCR (2010): Kumasi Centre for Collaborative Research in Tropical Medicine. Verfügbar unter http://www . kccr. com Abrufdatum: 28.6.2010

Knight JC, Udalova I, Hill AV, Greenwood BM, Peshu N, Marsh K, Kwiatkowski D (1999): A polymorphism that affects oct- 1 binding to the tnf promoter region is associated with severe malaria. Nat Genet 22, 145-150

Kobbe R, Neuhoff R, Marks F, Adjei S, Langefeld I, von Reden C, Adjei O, Meyer CG, May J (2006): Seasonal variation and high multiplicity of first plasmodium falciparum infections in children from a holoendemic area in ghana, west africa. Trop Med Int Health 11, 613-619

Kobilka BK, Dixon RA, Frielle T, Dohlman HG, Bolanowski MA, Sigal IS, Yang-Feng TL, Francke U, Caron MG, Lefkowitz RJ (1987): cdna for the human beta 2-adrenergic receptor: a protein with multiple membrane-spanning domains and encoded by a gene whose chromosomal location is shared with that of the receptor for platelet-d erived growth factor. Proc Natl Acad Sci U S A $\underline{84}$, 46-50

Kochar DK, Saxena V, Singh N, Kochar SK, Kumar SV, Das A (2005): Plasmodium vivax malaria. Emerging Infect Dis $\underline{11}, 132-134$

Kouriba B, Chevillard C, Bream JH, Argiro L, Dessein H, Arnaud V, Sangare L, Dabo A, Beavogui AH, Arama C et al. (2005): Analysis of the 5q31-q33 locus shows an associa- 
tion between il13-1055c/t il-13-591a/g polymorphisms and schistosoma haematobium infections. J Immunol 174, 6274-6281

Kun JF, Klabunde J, Lell B, Luckner D, Alpers M, May J, Meyer C, Kremsner PG (1999): Association of the icam-1kilifi mutation with protection against severe malaria in lambarene, gabon. Am J Trop Med Hyg 61, 776-779

Kun JF, Mordmuller B, Perkins DJ, May J, Mercereau-Puijalon O, Alpers M, Weinberg JB, Kremsner PG (2001): Nitric oxide synthase 2(lambarene) (g-954c), increased nitric oxide production, and protection against malaria. J Infect Dis 184, 330-336

Kwiatkowski D (2000): Genetic susceptibility to malaria getting complex. Curr Opin Genet Dev $\underline{10}, 320-324$

Lace MJ, Yamakawa Y, Ushikai M, Anson JR, Haugen TH, Turek LP (2009): Cellular factor YY1 downregulates the human papillomavirus $16 \mathrm{E} 6 / \mathrm{E} 7$ promoter, P97, in vivo and in vitro from a negative element overlapping the transcription-initiation site. J Gen Virol 90, 2402-2412

Lell B, May J, Schmidt-Ott RJ, Lehman LG, Luckner D, Greve B, Matousek P, Schmid D, Herbich K, Mockenhaupt FP et al. (1999): The role of red blood cell polymorphisms in resistance and susceptibility to malaria. Clin Infect Dis 28, 794-799

Luoni G, Verra F, Arca B, Sirima BS, Troye-Blomberg M, Coluzzi M, Kwiatkowski D, Modiano D (2001): Antimalarial antibody levels and il4 polymorphism in the fulani of west africa. Genes Immun 2, 411-414

Luty AJ, Lell B, Schmidt-Ott R, Lehman LG, Luckner D, Greve B, Matousek P, Herbich K, Schmid D, Migot-Nabias F et al. (1999): Interferon-gamma responses are associated with resistance to reinfection with plasmodium falciparum in young african children. J Infect Dis $\underline{179}, 980-988$

Macherey-Nagel (2010): NucleoMag 96 Blood. Verfügbar unter http: //www .mn-net. com/Products/NucleicAcidPurification/DNAfrombloodandbiologicalfluids/ NucleoMag96Blood/tabid/1350/language/en-US/Default .aspx Abrufdatum: 28.6.2010 
Mackinnon MJ, Gunawardena DM, Rajakaruna J, Weerasingha S, Mendis KN, Carter R (2000): Quantifying genetic and nongenetic contributions to malarial infection in a sri lankan population. Proc Natl Acad Sci U S A 97, 12661-12666

MacVector, Inc (2010): MacVector 7.2.2. Verfügbar unter http://www . macvector . com Abrufdatum: 28.6.2010

Marks F, von Kalckreuth V, Kobbe R, Adjei S, Adjei O, Horstmann RD, Meyer CG, May J (2005): Parasitological rebound effect and emergence of pyrimethamine resistance in plasmodium falciparum after single-dose sulfadoxine-pyrimethamine. J Infect Dis 192, 1962-1965

May J, Meyer CG, Kun JF, Lell B, Luckner D, Dippmann AK, Bienzle U, Kremsner PG (1999): Hla class ii factors associated with plasmodium falciparum merozoite surface antigen allele families. J Infect Dis $\underline{179}, 1042-1045$

May J, Lell B, Luty AJ, Meyer CG, Kremsner PG (2000): Plasma interleukin-10:tumor necrosis factor (tnf)-alpha ratio is associated with tnf promoter variants and predicts malarial complications. J Infect Dis $\underline{182}, 1570-1573$

May J, Lell B, Luty AJ, Meyer CG, Kremsner PG (2001): Hla-dqb1*0501-restricted th1 type immune responses to plasmodium falciparum liver stage antigen 1 protect against malaria anemia and reinfections. J Infect Dis $\underline{183}, 168-172$

May J, Evans JA, Timmann C, Ehmen C, Busch W, Thye T, Agbenyega T, Horstmann RD (2007): Hemoglobin variants and disease manifestations in severe falciparum malaria. JAMA 297, 2220-2226

Menard D, Barnadas C, Bouchier C, Henry-Halldin C, Gray LR, Ratsimbasoa A, Thonier V, Carod JF, Domarle O, Colin Y et al. (2010): Plasmodium vivax clinical malaria is commonly observed in Duffy-negative Malagasy people. Proc Natl Acad Sci USA 107, 5967-5971

Messeguer X, Escudero R, Farre D, Nunez O, Martinez J, Alba MM (2002): PROMO: detection of known transcription regulatory elements using species-tailored searches. Bioinformatics $\underline{18}, 333-334$ 
Miller LH, Mason SJ, Dvorak JA, McGinniss MH, Rothman IK (1975): Erythrocyte receptors for (plasmodium knowlesi) malaria: Duffy blood group determinants. Science $\underline{189}, 561-563$

Minty A, Chalon P, Derocq JM, Dumont X, Guillemot JC, Kaghad M, Labit C, Leplatois P, Liauzun P, Miloux B (1993): Interleukin-13 is a new human lymphokine regulating inflammatory and immune responses. Nature 362, 248-250

Modiano D, Petrarca V, Sirima BS, Nebie I, Diallo D, Esposito F, Coluzzi M (1996): Different response to plasmodium falciparum malaria in west african sympatric ethnic groups. Proc Natl Acad Sci U S A 93, 13206-13211

Murphy SC, Harrison T, Hamm HE, Lomasney JW, Mohandas N, Haldar K (2006): Erythrocyte $\mathrm{g}$ protein as a novel target for malarial chemotherapy. PLoS Med $\underline{3}$, e528

MWG Biotech AG (2010): MWG Thermocycler. Verfügbar unter http://www .mwg-biotech. com Abrufdatum: 28.6.2010

Nothnagel M, Ellinghaus D, Schreiber S, Krawczak M, Franke A (2009): A comprehensive evaluation of SNP genotype imputation. Hum Genet 125, 163-171

Ohashi J, Naka I, Patarapotikul J, Hananantachai H, Looareesuwan S, Tokunaga K (2003): A single-nucleotide substitution from $\mathrm{c}$ to $\mathrm{t}$ at position -1055 in the il-13 promoter is associated with protection from severe malaria in thailand. Genes Immun $\underline{4}, 528-531$

Palmer-Crocker RL, Hughes CC, Pober JS (1996): Il-4 and il-13 activate the jak2 tyrosine kinase and stat6 in cultured human vascular endothelial cells through a common pathway that does not involve the gamma c chain. J Clin Invest $\underline{98}, 604-609$

Perlmann P, Perlmann H, Berzins K, Troye-Blomberg M (1998): Selected problems of malaria blood stage immunity. Tokai J Exp Clin Med 23, 55-62

Philipson LH (2002): beta-Agonists and metabolism. J Allergy Clin Immunol 110, S313317

Phillips RS (2001): Current status of malaria and potential for control. Clin Microbiol Rev 14, 208-226 
Plebanski M, Proudfoot O, Pouniotis D, Coppel RL, Apostolopoulos V, Flannery G (2002): Immunogenetics and the design of plasmodium falciparum vaccines for use in malaria-endemic populations. J Clin Invest 110, 295-301

van der Pouw Kraan TC, van Veen A, Boeije LC, van Tuyl SA, de Groot ER, Stapel SO, Bakker A, Verweij CL, Aarden LA, van der Zee JS (1999): An il-13 promoter polymorphism associated with increased risk of allergic asthma. Genes Immun 1, 61-65

Purcell S, Neale B, Todd-Brown K, Thomas L, Ferreira MA, Bender D, Maller J, Sklar P, de Bakker PI, Daly MJ et al. (2007): Plink: a tool set for whole-genome association and population-based linkage analyses. Am J Hum Genet 81, 559-575

Rathi S, Kazerounian S, Banwait K, Schulz S, Waldman SA, Rattan S (2003): Functional and molecular characterization of beta-adrenoceptors in the internal anal sphincter. $\mathrm{J}$ Pharmacol Exp Ther $\underline{305}$, 615-624

Rice TK, Schork NJ, Rao DC (2008): Methods for handling multiple testing. Adv Genet $\underline{60}$, 293-308

Rihet P, Traore Y, Abel L, Aucan C, Traore-Leroux T, Fumoux F (1998): Malaria in humans: Plasmodium falciparum blood infection levels are linked to chromosome 5q31-q33. Am J Hum Genet 63, 498-505

del Rio-Navarro BE, Corona-Hernandez L, Fragoso-Rios R, Berber A, Torres-Alcantara S, Cuairan-Ruidiaz V, Sienra-Monge JJ (2001): Effect of salmeterol and salmeterol plus beclomethasone on saliva flow and IgA in patients with moderate-persistent chronic asthma. Ann Allergy Asthma Immunol 87, 420-423

Roche Applied Science (2010): Roche LightTyper SNP Instrument. Verfügbar unter https://www.roche-applied-science.com/ProdInfo/html/3_8_5_2_1_1.html Abrufdatum: 28.6.2010

Rogan DF, Cousins DJ, Santangelo S, Ioannou PA, Antoniou M, Lee TH, Staynov DZ (2004): Analysis of intergenic transcription in the human il-4/il-13 gene cluster. Proc Natl Acad Sci U S A 101, 2446-2451 
Rowe AK, Rowe SY, Snow RW, Korenromp EL, Schellenberg JR, Stein C, Nahlen BL, Bryce J, Black RE, Steketee RW (2006): The burden of malaria mortality among african children in the year 2000. Int J Epidemiol $\underline{35}, 691-704$

Rozen S, Skaletsky H (2000): Primer3 on the www for general users and for biologist programmers. Methods Mol Biol 132, 365-386

Sag C, Ozden FO, Acikgoz G, Anlar FY (2007): The effects of combination treatment with a long-acting beta2-agonist and a corticosteroid on salivary flow rate, secretory immunoglobulin A, and oral health in children and adolescents with moderate asthma: a 1-month, single-blind clinical study. Clin Ther 29, 2236-2242

Sanger F, Nicklen S, Coulson AR (1977): Dna sequencing with chain-terminating inhibitors. Proc Natl Acad Sci U S A $\underline{74}, 5463-5467$

Schellenberg D, Menendez C, Kahigwa E, Aponte J, Vidal J, Tanner M, Mshinda H, Alonso P (2001): Intermittent treatment for malaria and anaemia control at time of routine vaccinations in tanzanian infants: a randomised, placebo-controlled trial. Lancet $\underline{357}$, $1471-1477$

Schorderet DF (1991): Using OMIM (On-line Mendelian Inheritance in Man) as an expert system in medical genetics. Am J Med Genet 39, 278-284

Shephard N (2005): Genass: Stata module to perform genetic case-control association tests. Statistical Software Components, Boston College Department of Economics. URL http://ideas.repec.org/c/boc/bocode/s456415.html

Sheppard JR, Wehner JM, McSwigan JD, Shows TB (1983): Chromosomal assignment of the gene for the human beta 2-adrenergic receptor. Proc Natl Acad Sci U S A $\underline{80}, 233-$ 236

Sherry ST, Ward MH, Kholodov M, Baker J, Phan L, Smigielski EM, Sirotkin K (2001): dbSNP: the NCBI database of genetic variation. Nucleic Acids Res 29, 308-311

StataCorp LP (2010): Stata Data Analysis and Statistical Software . Verfügbar unter http://www. stata.com/statamp/ Abrufdatum: 28.6.2010 
Suppiah V, Rooney M, Vandenbroeck K (2006): Polymorphisms in the interleukin-4 and il-4 receptor genes modify risk for chronic inflammatory arthropathies in women. Exp Mol Pathol 81, 239-244

Taira CA, Carranza A, Mayer M, Di Verniero C, Opezzo JA, Hocht C (2008): Therapeutic implications of beta-adrenergic receptor pharmacodynamic properties. Curr Clin Pharmacol $\underline{3}, 174-184$

Tecan (2010): Tecan Genesis Workstation. Verfügbar unter http://www.tecan.com/1.93/gemini Abrufdatum: 28.6.2010

The International Conference on Harmonisation of Technical Requirements for Registration of Pharmaceuticals for Human Use (2010): Ich guidelines. Verfügbar unter http://www.ich.org/cache/html/250-272-1.html Abrufdatum: 28.6.2010

Trigg P, Kondrachine AV: The current global malaria situation; in: Malaria - parasite biology, pathogenesis, and protection; hrsg. v. Sherman IW; ASM Press, Washington $1998,11-24$

Vasakova M, Striz I, Slavcev A, Jandova S, Dutka J, Terl M, Kolesar L, Sulc J (2007): Correlation of il-1alpha and il-4 gene polymorphisms and clinical parameters in idiopathic pulmonary fibrosis. Scand J Immunol 65 , 265-270

Verra F, Luoni G, Calissano C, Troye-Blomberg M, Perlmann P, Perlmann H, Arca B, Sirima BS, Konate A, Coluzzi M et al. (2004): Il4-589c/t polymorphism and ige levels in severe malaria. Acta Trop 90, 205-209

Wang N, Akey JM, Zhang K, Chakraborty R, Jin L (2002): Distribution of recombination crossovers and the origin of haplotype blocks: the interplay of population history, recombination, and mutation Am J Hum Genet 71, 1227-1234

Wang XS, Lau HY (2006): Beta-adrenoceptor-mediated inhibition of mediator release from human peripheral blood-derived mast cells. Clin Exp Pharmacol Physiol 33, 746-750

WHO (1997a): The world health report 1996-fighting disease, fostering development. World Health Forum $\underline{18}$, 1-8 
WHO (1997b): World malaria situation in 1994. part i. population at risk. Wkly Epidemiol $\operatorname{Rec} \underline{72}, 269-274$

WHO (2010): World malaria report 2008. Verfügbar unter www. who.int/malaria/wmr2008/ Abrufdatum: 28.6.2010

Williams TN, Maitland K, Bennett S, Ganczakowski M, Peto TE, Newbold CI, Bowden DK, Weatherall DJ, Clegg JB (1996): High incidence of malaria in alpha-thalassaemic children. Nature 383, 522-525

Yanez DM, Manning DD, Cooley AJ, Weidanz WP, van der Heyde HC (1996): Participation of lymphocyte subpopulations in the pathogenesis of experimental murine cerebral malaria. J Immunol 157, 1620-1624

Zurawski G, de Vries JE (1994): Interleukin 13 elicits a subset of the activities of its close relative interleukin 4 . Stem Cells $\underline{12}, 169-174$ 


\section{Abbildungsverzeichnis}

1.1 Geschätzte weltweite Inzidenz der Malaria auf 1000 Personen . . . . . . . . 4

1.2 Geschätzte weltweite Mortalität der Malaria auf 1000 Personen . . . . . . . 5

1.3 Geschätzter Prozentsatz der durch Plasmodium falciparum verursachten weltweiten Malaria-Fälle . . . . . . . . . . . . . . . . . . . 6

1.5 5q31-33-Region: Übersicht der Satellitenmarker . . . . . . . . . . . . . . . . . 10

1.4 Lebenszyklus der Malaria . . . . . . . . . . . . . . . . . . . . . 16

2.1 ADRB2: Übersicht der sequenzierten Abschnitte . . . . . . . . . . . . . . . . 21

2.2 ADRB2: Übersicht der sequenzierten Abschnitte, Teil $2 \ldots \ldots . \ldots . . \ldots 22$

2.3 Optimierung der PCR: Auftragen der Produkte aus verschiedenen Protokollen auf das Agarosegel . . . . . . . . . . . . . . . . . . . . . 24

3.1 Linkage der Varianten aus der IL4/IL13-Region . . . . . . . . . . . . . . . . . 30

3.2 Kaplan-Meier-Kurve, Variante IL13 -1112 (rs1800925) ～. . . . . . . . . . . . 34

3.3 Linkage der Varianten aus der ADRB2-Region . . . . . . . . . . . . . . . . . . 38

3.4 Übersicht der Kaplan-Meier-Kurven für verschiedene Varianten aus der

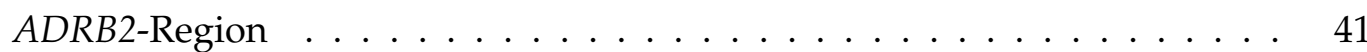




\section{Tabellenverzeichnis}

2.1 Übersicht über die Studienpopulation . . . . . . . . . . . . . . . . . . . . . . 19

2.2 LightTyper: Übersicht der verwendeten Primer . . . . . . . . . . . . . . . . 28

3.1 IL4/IL13-Varianten: Hardy-Weinberg-Test . . . . . . . . . . . . . . . . . . . . 29

3.2 IL4/IL13-Region: Übersicht der häufigsten Haplotypen . . . . . . . . . . . . 31

3.3 IL4/IL13-Varianten: Zeiten bis zum ersten Ereignis, gegliedert nach Phäno-

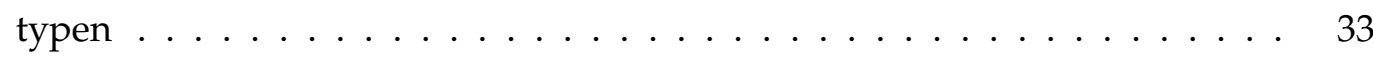

3.4 Inzidenzen von IL4/IL13-Varianten, gegliedert nach Phänotypen . . . . . . 35

3.5 IL4: Assoziationen des Haplotyp-Blockes BLOCK1 mit dem Phänotyp „klinische Malaria" . . . . . . . . . . . . . . . . . . . . . 36

3.6 ADRB2-Varianten: Hardy-Weinberg-Test . . . . . . . . . . . . . . . . 37

3.7 ADRB2-Region: Übersicht der häufigsten Haplotypen . . . . . . . . . . . . . 39

3.8 ADRB2-Varianten: Zeiten bis zum ersten Ereignis, gegliedert nach Phäno-

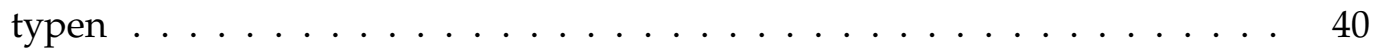

3.9 Inzidenzen von ADRB2-Varianten, gegliedert nach Phänotypen . . . . . . . 42

3.10 ADRB2-Region: Assoziationen der einzelnen Haplotypblöcke, Phänotyp „Klinische Malaria" . . . . . . . . . . . . . . . . . . . . . . . . . . 43

6.1 Sequenzierung: Mastermix Abschnitt 1 . . . . . . . . . . . . . . . . 59

6.2 Sequenzierung: Mastermix Abschnitt 2 . . . . . . . . . . . . . . . . . 59

6.3 Sequenzierung: Mastermix Abschnitt 3 . . . . . . . . . . . . . . . . 60

6.4 Sequenzierung: Mastermix Abschnitt 4 . . . . . . . . . . . . . . . . 60

6.5 Sequenzierung: Mastermix Abschnitt 5 . . . . . . . . . . . . . . . 61

6.6 Sequenzierung: Mastermix Big-Dye-Reaktion . . . . . . . . . . . . . . . 61

6.7 Sequenzierung: Thermozykler-Protokolle . . . . . . . . . . . . . . . 61 
6.8 Big-Dye-Reaktion: Thermozykler-Protokoll . . . . . . . . . . . . . . 62

6.9 LightTyper Assay: IL13 $-1112 \ldots \ldots$. . . . . . . . . . . . . . . . 62

6.10 LightTyper Assay: IL13 R110Q . . . . . . . . . . . . . . . . . . . . . . 63

6.11 LightTyper Assay: IL4 -1098 . . . . . . . . . . . . . . . . . . . . . . 63

6.12 LightTyper Assay: IL4 $-33 \ldots \ldots \ldots$. . . . . . . . . . . . . . 64

6.13 LightTyper Assay: IL4 $-589 \ldots \ldots$. . . . . . . . . . . . . . . . . . 64

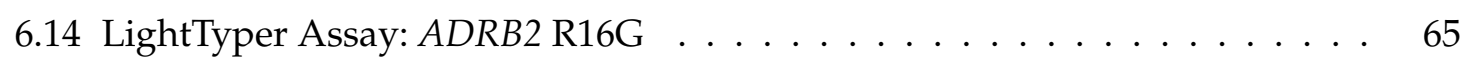

6.15 LightTyper Assay: ADRB2 Q27E . . . . . . . . . . . . . . . . . . 65

6.16 LightTyper: Thermozykler-Protokoll . . . . . . . . . . . . . . 66 


\section{Dank sage ich von Herzen allen, die zur Verwirklichung dieser Dissertation beigetra-}

gen haben. Mein besonderer Dank gilt Herrn Professor Dr. med. Jürgen May für die Initiierung, intensive Betreuung und Förderung meiner Arbeit. Ebenso danke ich Herrn Professor Dr. med. Christian G. Meyer für die permanente Unterstützung. Mein Dank gilt gleichermaßen dem Direktor der Abteilung Medizinische Mikrobiologie der Universitätsmedizin Göttingen Herrn Professor Dr. med. Uwe Groß für die Betreuung meiner Dissertation in Göttingen.

Ebenso danke ich Frau Dr. med. Christina Kreuzberg und Herrn Dr. med. Robin Kobbe für die gute Zusammenarbeit während meiner Zeit in Ghana. Mein Dank gilt auch allen Mitarbeitern des Kumasi Centre for Collaborative Research in Tropical Medicine, insbesondere Lincoln und Baindu Grankpala. Für die gute Zusammenarbeit danke ich weiterhin den Mitarbeitern der Arbeitsgruppe Tropenmedizinische Grundlagenforschung (TMGF) am Bernhard-Nocht-Institut in Hamburg. Insbesondere gilt mein Dank

Herrn Dr. med. Thorsten Thye und Herrn Dr. med. Norbert Schwarz für die stetige Hilfsbereitschaft sowie Christa Ehmen und Jürgen Sievertsen für die Einarbeitung und Unterstützung bei meinen Arbeiten im Labor.

Mein ganz besonderer Dank gilt den Familien, die sich zur Teilnahme an den Untersuchungen bereit erklärt haben. 